\title{
Standardized Gasoline Compression Ignition Fuels Matrix
}

\author{
Author, co-author (Do NOT enter this information. It will be pulled from participant tab in \\ MyTechZone) \\ Affiliation (Do NOT enter this information. It will be pulled from participant tab in MyTechZone)
}

\begin{abstract}
Direct injection compression ignition engines running on gasolinelike fuels have been considered an attractive alternative to traditional spark ignition and diesel engines. The compression and lean combustion mode direct injection of fuel eliminates throttle losses yielding higher thermodynamic efficiencies and the better mixing of fuel/air due to the longer ignition delay times of the gasoline-like fuels allows better emission performance such as nitric oxides (NOx) and particulate matter (PM). These gasoline-like fuels which usually have lower octane compared to market gasoline have has been identified as a viable option for the gasoline compression ignition (GCI) engine applications due to its lower reactivity and lighter evaporation longer ignition delay characteristies compared to diesel and lighter evaporation compared to gasoline fuel. The properties, specifications and sources of these GCI fuels are not fully understood yet because this technology is relatively new. In this work, a GCI fuel matrix is being developed based on the significance of certain physical and chemical properties in GCI engine operation. Those properties were chosen to be density, temperature at 90 volume $\%$ evaporation (T90) or final boiling point (FBP) and research octane number (RON) and the ranges of these properties were determined from the data reported in literature. These proposed fuels were theoretically formulated, while applying realistic constraints, using species present in real refinery streams gasoline-like fuels. Finally, three-dimensional (3D) engine computational fluid dynamics (CFD) simulations were performed for using the proposed GCI fuels and the similarities and differences were highlighted.
\end{abstract}

\section{Introduction}

The rapid increases in population and living standards in developing countries are expected to increase global demand for transportation energy at an annual rate of $1-1.5 \%$ by 2050 [1-4]. Despite strong growth in alternative energy and competing technologies (e.g. electric cars), traditional petroleum-based fuels are expected to be the major source of the transportation energy demand in the interim future, both for passenger and commercial transportation sectors [2-4]. Whilst, both proven and unproven crude reserves can meet this increased demand $[4,5]$. A major concern of the utilization of fossil fuels is the emission of greenhouse gases (GHG) which impose significant burden on the environment. Therefore, regulatory authorities are enforcing stringent $\mathrm{CO}_{2}$ and tailpipe emissions regulations on the transportation sector. Thus, technology that accommodates overall lean burn combustion with extremely low emissions can help reducing the global energy demand and minimizing GHG emissions.
Various advanced compression ignition engines have been investigated as technologies that combine the best of gasoline and diesel engines. Combustion strategies such as homogeneous charge compression ignition (HCCI) [6], reactivity-controlled compression ignition (RCCI) [7-9], and partially-premixed compression ignition (PPCI) [4, 10-12] have sought to combine the benefits of the relatively lower complexity simple design of gasoline engines and their after treatment systems and the higher efficiencies of diesel engines. These engine technologies share some high-level characteristics even though the engine operating parameters such as timing and number of injections, fuel type, and air system requirements may differ. Compression ignition operation eliminates traditional engine knock observed in spark-ignition (SI) engines, and globally lean operation through direct injection (DI) eliminates throttling losses. At the same time, better greater mixing of fuel and air prior to combustion reduces soot production relative to the conventional mixing-controlled (diesel) combustion.

The enabling fuels for such GCI, partially premixed compression ignition (PPCI) and multiple premixed compression ignition (MPCI) combustion modes are generally in the gasoline boiling range. However, the specifications of the enabling fuel for this engine technology are not well defined. Many fuels with varying physical and chemical properties, such as ignition quality, distillation curve and chemical compositions, have been considered in previous works. These include conventional gasoline [3, 13-17], conventional diesel [10, 13, 16-21], gasoline-diesel blends ("dieseline") [3, 20, 22-25], low-octane gasolines ("naphthas") $[3,4,11,13-15,26-30]$ and reference fuel blends (composed of iso-octane, $n$-heptane, toluene) $[3,13,15,31,32]$. Compared to commercial gasoline and diesel fuels, blends of various refinery streams with low octane numbers (RON) in the 50-80 range have recently been considered attractive alternatives to provide suitable chemical characteristics (longer ignition delay than diesel) in GCI engines at lower production cost and well-to-tank $\mathrm{CO}_{2}$ emissions. Hao et al. [33] found that compared with the conventional pathway, the low-octane gasoline-GCI pathway leads to a $24.6 \%$ reduction in energy consumption and a $22.8 \%$ reduction in GHG emissions. Our research group in Saudi Aramco extensively investigated the combustion of various fuels in GCI engines [4, 11, 12, 26, 34-38].

It is clear from literature that the properties (RON, MON, density, boiling range, etc. and ...) of the fuel that is suitable for GCI or MPCI are not fully determined yet. Certain fuel properties could affect the performance of the engine because since GCI combustion greatly depends is dependent on mixture stratification and as well as chemical kinetics [11, 12, 34, 39-42]. For example, some studies indicate that there are direct impacts of fuel distillation and aromatic 
content on the soot emissions of PPCI engines [20,43], while others report a minimal effect $[34,44]$. The Aramco research group extensively investigated the effect of the fuel physical and chemical properties on GCI combustion and emissions [11, 12, 34, 39-41]. They have reported that the distillation characteristics and RON of the fuel are critical in GCI combustion. Kim et al. [45] studied the effects of some physical properties (density, vapor pressure, viscosity, surface tension, heat of vaporization and specific heat capacity) in a reaction fuel sprays. They found that density, viscosity, heat of vaporization and specific heat had significant impact on liquid penetration length. They also reported that specific heat and density significantly affected the ignition delay of the system. Lacey et al. [46] also studied the effects of the properties of gasoline refinery streams on the auto-ignition quality of a fuel and the HCCI combustion. They have observed that the fuel composition significantly affects the combustion phasings of gasoline fuels with the same RON and MON. They have proposed a new octane index (OI) correlation that accounts for the aromatics, olefins, saturates and ethanol contents in the gasoline. Nonetheless, most of the studies have shown that fuel reactivity, or homogeneous ignition delay, is an important parameter in optimizing the performance of PPCI engines over wide range of operating conditions.

The purpose of the current study is to propose a standardized GCI fuel matrix for research purposes. A similar methodology to what has already been done for Fuels for Advanced Combustion Engines (FACE) gasolines [47] was followed here. Eleven GCI fuels were proposed based on chosen targeted physical and chemical properties such as density, T90 and RON. Density was chosen as one of the important properties because it is proportional to the fuel consumption. T90 was considered because of its direct effect on the evaporation of the fuel which dictates its mixing with the in-cylinder air and hence combustion in the GCI mode. RON was chosen as a representative of the autoignition quality of the fuel. The proposed fuels were theoretically formulated and their properties were calculated. Finally, three-dimensional engine CFD simulations were performed to investigate the similarities and differences between the combustion and emissions of the proposed fuels in part-load GCI engine operation.

\section{GCI Fuel Matrix}

\section{Proposed Matrix}

Many previous studies have investigated the GCI combustion mode operating on fuels that are more reactive than commercial gasolines and have less reactivity compared to diesel fuels. These fuels are usually blended from various straight-run gasoline refinery streams. The research group at Saudi Aramco and its collaborators have extensively studied the combustion of many of these fuels in GCI engine operation at a wide range of operating conditions $[4,11,12$, $24,26,34,35,37,38,40,48-50]$. The specifications of these fuels are not regulated like the gasoline and diesel fuels. Therefore, the fuels used in the experiments are usually specific to the region, refinery or the load range of the studied engine.

\footnotetext{
The determination of the design parameters depends on the engine combustion mode and operating conditions. In spark ignition mode, it was previously shown that RON, sensitivity, aromatics and nparaffinic contents were chosen to be the design parameters because of their primary importance to the performance of advanced gasolinefueled spark ignited engines. This was used to propose and formulate the Fuels for Advanced Combustion Engines (FACE) gasolines [47].
}

In HCCI mode, T90 is not critical because of the very early injections where the fuel completely evaporates and premixes with air long before combustion occurs. However, the charge cooling due to the latent heat of vaporization is important because the in-cylinder temperature and equivalence ratio distribution is the main controlling parameter in compression ignition mode. In high-load diffusion combustion mode, T90 and latent heat of vaporization are not essential because of the late injections which occur at high incylinder pressures and temperatures. These high pressures and temperatures cause instantaneous vaporization and ignition of the fuel. Perhaps, the viscosity of the fuel is an important design parameter at these engine conditions because it affects the spray exit velocities and hence the breakup, mixing and combustion. In this work, the partially premixed compression ignition (PPCI) where injections occur between -50 to -20 CAD aTDC is the targeted combustion mode. Previous PPCI engines studies revealed that the density [39], T90 (or final boiling point (FBP)) [34, 39, 41] and the $\operatorname{RON}[10,13,34,48-51]$ of the GCI fuel are more influential than other physical and chemical properties when it comes to in PPCI GCI engine operation. Other properties such as the heat of vaporization, lower heating value, hydrogen to carbon ratio, sensitivity, etc. might differently affect the PPCI combustion however, the density, T90 and RON were chosen to be the design parameters in this study. Therefore, the abovementioned properties are shown and discussed more than others in this work.

Subsequently, a three-dimensional matrix of the fuels that have been examined in GCI engines by the Saudi Aramco research group and its collaborators is shown in Figure 1. As can be seen from Figure 1, the physical and chemical properties of the tested fuels are scattered over acress a wide range. This large scatter is mainly due to the unavailability of standard specifications for GCI engine fuels. Densities between $650 \mathrm{~kg} / \mathrm{m} 3$ and $770 \mathrm{~kg} / \mathrm{m} 3$, RON between 20 and 80 and $\mathrm{T} 90$ between $70^{\circ} \mathrm{C}$ and $338^{\circ} \mathrm{C}$ are observed from Figure 1. Aramco fuels (AF) 16, 17 and 18 have octane numbers and boiling properties that are similar to diesel fuels and hence they are not included in the range covered in this study. The values of their properties (density, T90 and RON) are provided in Figure 1.

Based on the relevant range observed in Figure 1, eleven different GCI fuels were proposed and these along with the Aramco fuels are shown in Figure 2. As can be seen from Figure 2, the proposed GCI fuels enclose the Aramco fuels that are within the gasoline boiling and density ranges. The GCI fuels matrix is presented in Figure 3. These GCI fuels were chosen in a systematic way where the effects of the individual targeted properties were isolated. The densities, T90s and RONs of the eleven proposed fuels are listed in Table 1. Regarding RON, G1, G2 and G3 have the same T90 and density however they have RON values of 85, 60 and 40, respectively. The RON effect was examined at different densities and T90s. G8 and G9 also explore the RON effect but at lower densities compared to G1, G2 and G3. G7 and G10 also study the effect of RON but at lower densities and T90s compared to G1, G2 and G3.

Regarding the effects of density and T90, G1 and G9 paired up to isolate the density effect by having the same RON and T90. G9 and G10 paired up to isolate T90 by having the same RON and density. Five proposed fuels have RON of 60 but different physical characteristics for the same purpose of isolating the effects of the individual properties. The T90 effect was isolated through the combinations of G7/G8 and G2/G5. The density effect was isolated through the combinations of G2/G8 and G6/G7. G4 was proposed so that it has similar T90 to G5 and similar density to G6. In addition, G3 and G4 enclose one of the studied fuels (Aramco fuel \#11) at 
RON of 40. Finally, G11 is standalone fuel which was chosen to be a representative of few of the Aramco fuels that had properties close to G11.

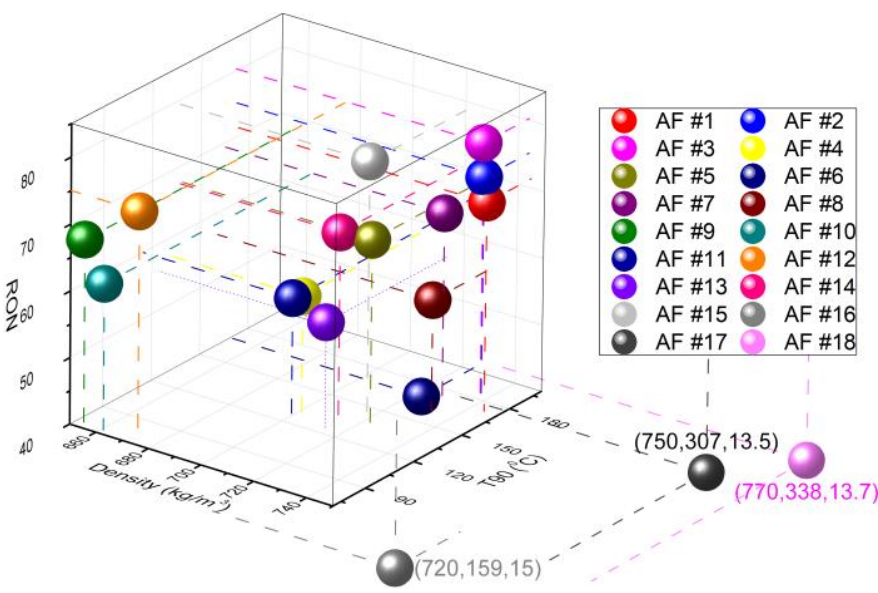

Figure 1. Matrix of various Aramco fuels that were evaluated in different GCI engine applications.

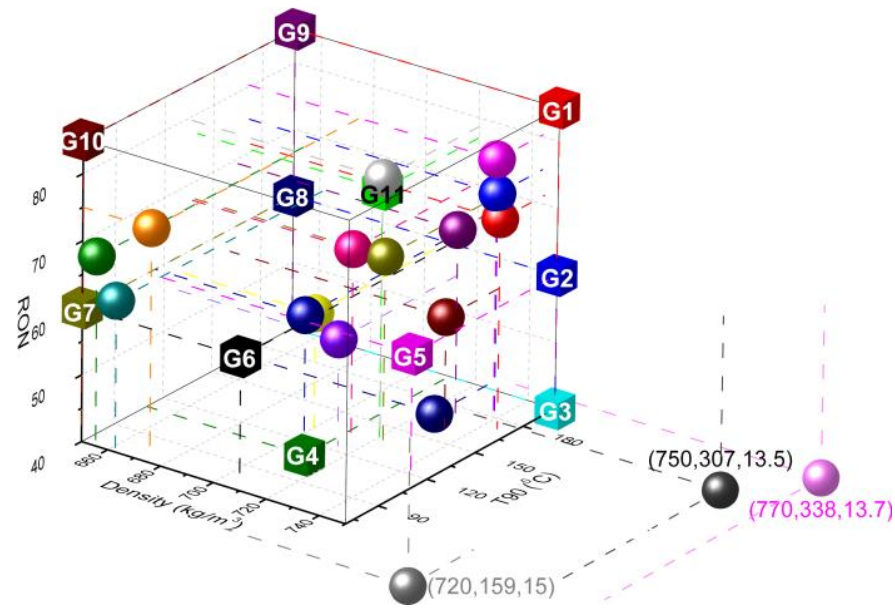

Figure 2. Matrix of GCI and Aramco fuels.

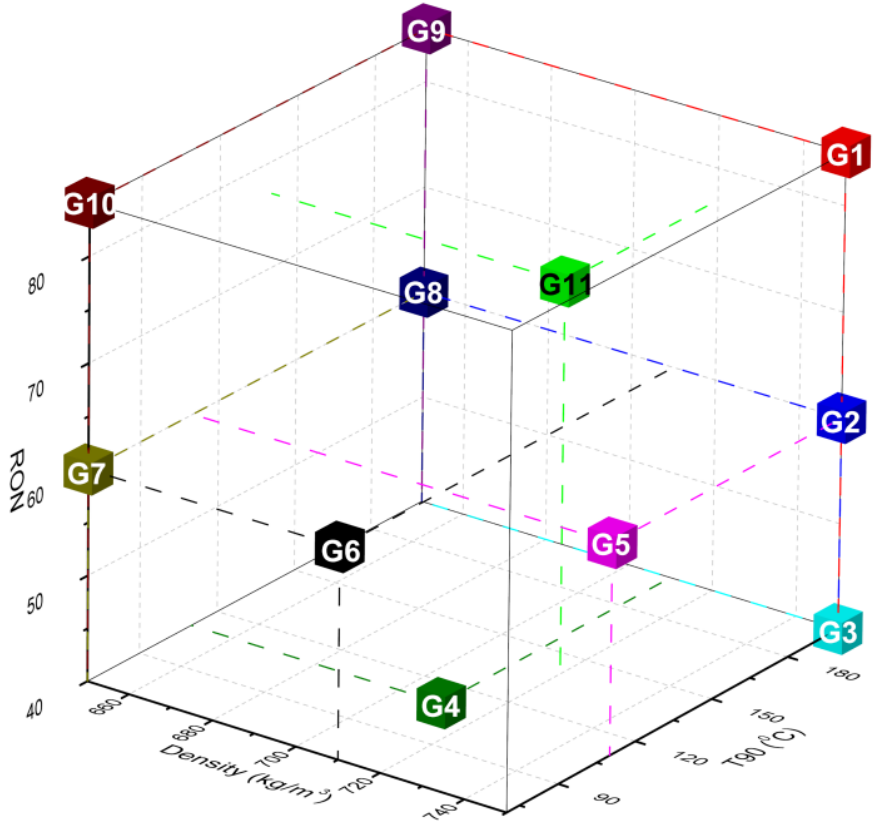

Figure 3. GCI fuels matrix.

Table 1. Densities, RON and T90s of the eleven proposed GCI fuels.

\begin{tabular}{|l|l|l|l|}
\hline Fuel & RON & Density at $15^{\circ} \mathrm{C}\left(\mathrm{kg} / \mathrm{m}^{3}\right)$ & T90 $\left({ }^{\circ} \mathrm{C}\right)$ \\
\hline G1 & 85 & 750 & 200 \\
\hline G2 & 605 & 750 & 200 \\
\hline G3 & 40 & 750 & 200 \\
\hline G4 & 40 & 710 & 110 \\
\hline G5 & 60 & 750 & 110 \\
\hline G6 & 60 & 710 & 70 \\
\hline G7 & 60 & 650 & 70 \\
\hline G8 & 60 & 650 & 200 \\
\hline G9 & 85 & 650 & 200 \\
\hline G10 & 85 & 650 & 70 \\
\hline G11 & 77 & 720 & 140 \\
\hline
\end{tabular}

\section{Theoretical Fuel Matrix}

The formulation of the eleven proposed GCI fuels with the properties listed in Table 1 was theoretically attempted. The following steps were followed:

1. Step 1: a database of species that are relevant to in the gasoline boiling range and are found in the detailed hydrocarbon analyses of conventional gasoline and gasoline-like (naphtha) fuels was generated. The detailed hydrocarbon analyses of few fuels in the gasoline boiling range and are contributors relevant to the gasoline blending process were considered for this database. Subsequently, a database of 134 different species were identified and their properties such as the density, T90 (and FBP) and RON were obtained from the gas chromatography (GC) database available at the research and development center in Saudi Aramco. Additional properties such as the molecular 
weight and MON were also included in the database for further analysis. This database was compiled in Excel.

2. Step 2: the properties of the multi-component mixtures were calculated as follows,

$$
\begin{aligned}
\rho_{\text {mix }} & =\sum_{i=0}^{N} x_{i} \rho_{i} \\
\operatorname{RON}_{\text {mix }} & =\sum_{i=0}^{N} x_{i} R O N_{i}
\end{aligned}
$$

where $\rho_{\text {mix }}$ and $R O N_{\text {mix }}$ are the density and RON of the multicomponents mixture, $i$ represents the individual species is the species, $N$ is the total number of species in the mixture and $x_{i}$ is the mole fraction of species $i$ in the mixture.

The linear-by-mole blending rule was used here to calculate the RON of the formulated mixtures. The linear-by-mole is a better representative than linear-by-volume to predict the octane numbers of multi-component mixtures. This was proven for toluene primary reference fuels (TPRF) [52], TPRF with ethanol $[53,54]$ and multi-component with ethanol [55] mixtures. More complicated blending rules exist in literature. Ghosh et al. [56] developed a multi-variable detailed gasoline composition-base octane model. However, the linear-by-mole was chosen here because it was easier to be handled by the optimization solver. Also, the accuracy of the octane number prediction is not the main objective of this work.

3. Step 3: the solver package in Microsoft Excel was used to calculate the volume fractions of species to match the target properties (density, T90 and RON) of the eleven GCI fuels. Constraints were applied when formulating the fuels. The aromatics and olefinic contents were forced to be less than 30 vol. $\%$ and 20 vol. $\%$, respectively. The objective function of the solver was to minimize the cumulative error between the calculated and targeted properties listed in Table 1.

Based on that, eleven theoretical fuels were formulated with properties that are close to the targeted ones. The compositional distributions of the formulated fuels in terms of n-paraffinic, isoparaffinic, aromatic, naphthenic and olefinic (PIONA) contents are is presented in Table 2 and Figure 4. As can be seen from Figure 4, most of the fuels are highly paraffinic (n-paraffins and iso-paraffins) except GEF 5 and eleven G11 where high concentrations of naphthenes are observed.

Table 2. PIONA contents of the eleven formulated theoretical GCI fuels.

\begin{tabular}{|l|l|l|l|l|l|}
\hline Fuel & n-Paraffins & i-Paraffins & Aromatics & Olefins & Naphthenes \\
\hline G1 & 10.4 & 52.9 & 29.9 & 3.9 & 2.9 \\
\hline G2 & 35.7 & 6.2 & 21.9 & 17.8 & 18.4 \\
\hline G3 & 64.9 & 7.0 & 22.9 & 1.2 & 4.0 \\
\hline G4 & 41.0 & 24.9 & 0.0 & 0.0 & 34.1 \\
\hline G5 & 1.2 & 41.2 & 10.7 & 0.0 & 46.9 \\
\hline G6 & 60.3 & 5.1 & 15.5 & 4.0 & 15.0 \\
\hline G7 & 82.7 & 3.5 & 2.0 & 11.8 & 0.0 \\
\hline G8 & 51.3 & 47.3 & 1.4 & 0.0 & 0.0 \\
\hline G9 & 6.7 & 88.8 & 4.4 & 0.0 & 0.0 \\
\hline G10 & 21.7 & 51.6 & 0.0 & 19.9 & 6.7 \\
\hline G11 & 28.6 & 18.7 & 3.8 & 0.0 & 48.8 \\
\hline
\end{tabular}

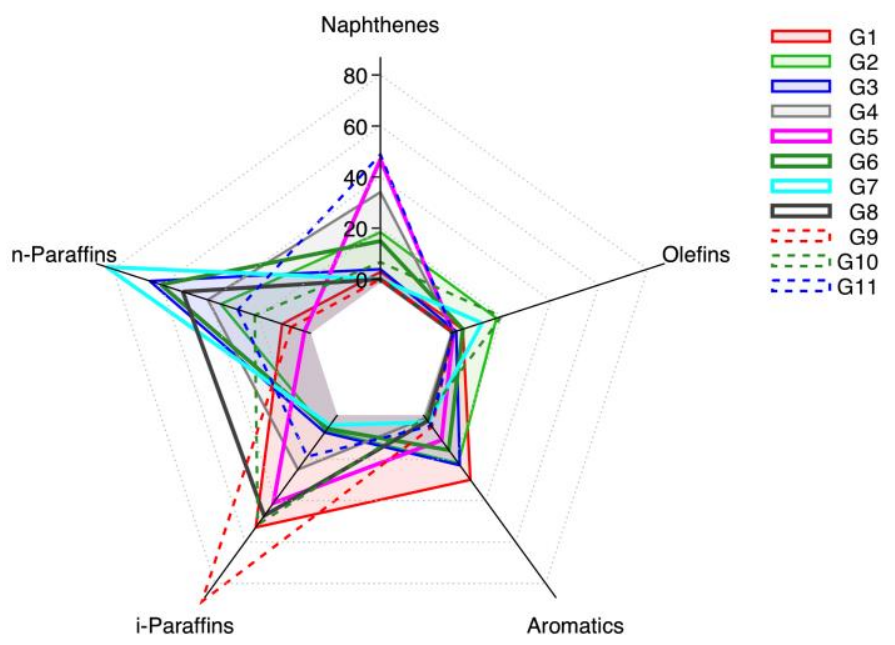

Figure 4. PIONA distribution of the eleven formulated theoretical GCI fuels.

The carbon number distribution of the eleven formulated fuels are also presented here. The composition of the formulated theoretical GCI fuels in terms of carbon numbers are listed Table 3 and presented in Figure 5. It is clear that the fuels with lower densities such as G5, G6, G7, G8, G9, G10 and G11 contain high fractions of the low carbon numbers (C3, C4, C5 and C6). The rest of the fuels have a wide distribution of the carbon numbers $\mathrm{C} 7$ to C12. The detailed hydrocarbon analyses (DHA) of the eleven GCI fuels are provided in the Appendix.

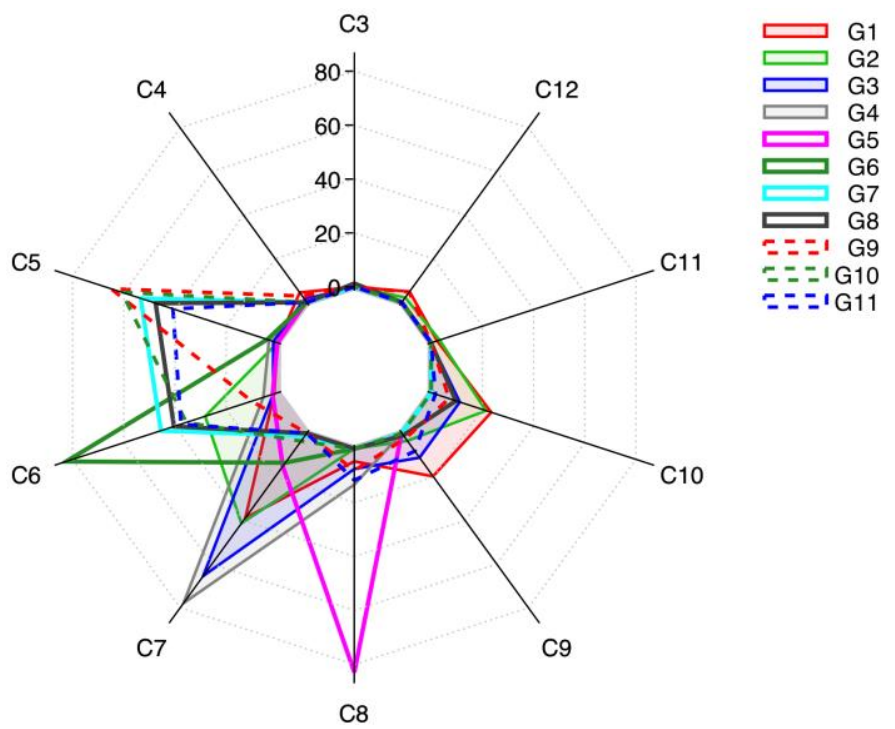

Figure 5. Carbon number distribution of the eleven formulated theoretical GCI fuels. 


\begin{tabular}{|l|l|l|l|l|l|l|l|l|l|l|}
\hline Fuel & C3 & C4 & C5 & C6 & C7 & C8 & C9 & C10 & C11 & C12 \\
\hline G1 & 0.0 & 4.5 & 0.0 & 1.3 & 38.8 & 4.7 & 19.8 & 23.5 & 2.3 & 4.9 \\
\hline G2 & 0.0 & 0.0 & 0.0 & 28.2 & 41.3 & 0.0 & 3.5 & 21.4 & 3.3 & 2.2 \\
\hline G3 & 0.0 & 1.4 & 1.6 & 1.7 & 65.4 & 7.5 & 11.2 & 11.2 & 0.0 & 0.0 \\
\hline G4 & 0.0 & 0.0 & 3.3 & 5.5 & 77.9 & 13.3 & 0.0 & 0.0 & 0.0 & 0.0 \\
\hline G5 & 0.0 & 0.0 & 0.0 & 1.9 & 15.2 & 82.9 & 0.0 & 0.0 & 0.0 & 0.0 \\
\hline G6 & 0.0 & 0.0 & 4.0 & 82.5 & 13.5 & 0.0 & 0.0 & 0.0 & 0.0 & 0.0 \\
\hline G7 & 0.0 & 0.0 & 53.4 & 45.5 & 1.2 & 0.0 & 0.0 & 0.0 & 0.0 & 0.0 \\
\hline G8 & 1.3 & 0.0 & 47.6 & 40.4 & 0.0 & 0.0 & 1.0 & 9.7 & 0.0 & 0.0 \\
\hline G9 & 0.0 & 2.9 & 64.9 & 10.1 & 0.0 & 8.1 & 2.3 & 7.0 & 0.0 & 4.7 \\
\hline G10 & 0.0 & 0.0 & 60.8 & 35.6 & 3.6 & 0.0 & 0.0 & 0.0 & 0.0 & 0.0 \\
\hline G11 & 0.0 & 0.0 & 40.8 & 37.7 & 0.0 & 11.7 & 8.2 & 1.7 & 0.0 & 0.0 \\
\hline
\end{tabular}

\section{Properties of the GCI Fuels}

The physical and chemical properties of the eleven formulated fuels were calculated using Aspen HYSYS. The fluid package used for the liquid properties estimate was Peng Robinson. The vapor fraction of the mixture was fixed to $0 \%$. The liquid properties extracted from Aspen HYSYS were viscosity, surface tension, heat of vaporization, vapor pressure, thermal conductivity, mass density, and mass heat capacity. The calculated RON, MON and sensitivity ( $=$ RON-MON) of the eleven fuels are presented in Figure 6. The targeted RON are also shown in Figure 6. As expected, the calculated RON values of the eleven GCI fuels are similar to the proposed ones (Table 1). Moreover, the GCI fuels have different sensitivities with G4, G5 and G7 are almost non-sensitive $(\mathrm{S} \approx 0)$, G11 is highly sensitive and the rest have moderate sensitivities. This variance in sensitivity can be used as a secondary design parameter in the presented GCI fuels because of the realistic range ( $\mathrm{S}=0$ to 9 ). The calculated and targeted densities and T90s of the GCI fuels are shown in Figure 7. The densities are matching the targeted ones as can be seen from Figure 7. However, there are some differences between the targeted and calculated T90s (Figure 7b). The calculated molecular weight (MW), Reid vapor pressure (RVP), lower heating value (LHV), hydrogen to carbon $(\mathrm{H} / \mathrm{C})$ ratio and the critical temperature $\left(\mathrm{T}_{\mathrm{CR}}\right)$ of the GCI fuels are presented in Figure 8. Note that the RVP is plotted on a logarithmic scale. Among the properties shown in Figure 8, only RVP is regulated for commercial gasoline fuels. In the united states (US) Satudi Arabia, RVP is recommended to be less than $10370 \mathrm{kPa}$ as per the specifications. It is noted that most of the all GCI fuels are under this threshold except G9 which has a marginally higher RVP $(120 \mathrm{kPa})$. However, the low density GCI fuels (G7, G8, G9 and G10) have RVP that are marginally higher than the regulated value. The rest of the properties are within the gasoline fuels range. As expected, LHV (Figure 8c) is directly proportional to the $\mathrm{H} / \mathrm{C}$ ratio (Figure 8d). Finally, the D86 distillation curves (evaporation rate versus temperature) of the GCI fuels are presented in Figure 9. All the fuels are within the gasoline boiling range. The calculated properties of the GCI fuels are presented in Table 4.
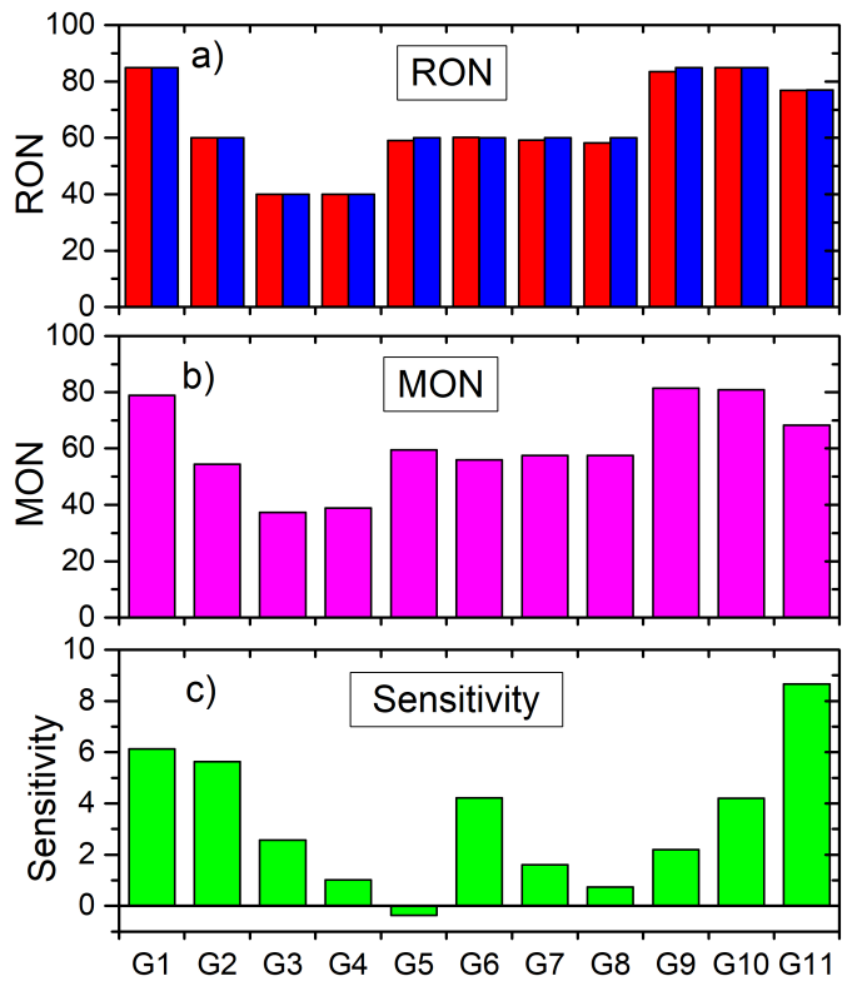

Figure 6. Calculated a) RON (red is target and blue is calculated), b) MON and c) sensitivity of the GCI fuels. 


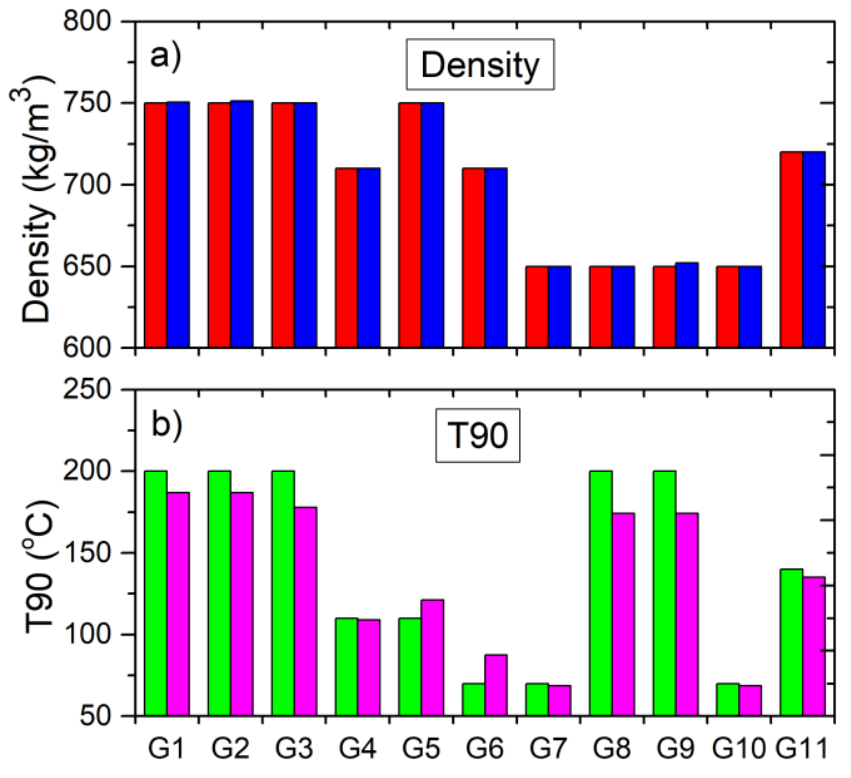

Figure 7. Calculated a) density (red is target and blue is calculated) and b) T90 (green is target and magenta is calculated) of the GCI fuels.

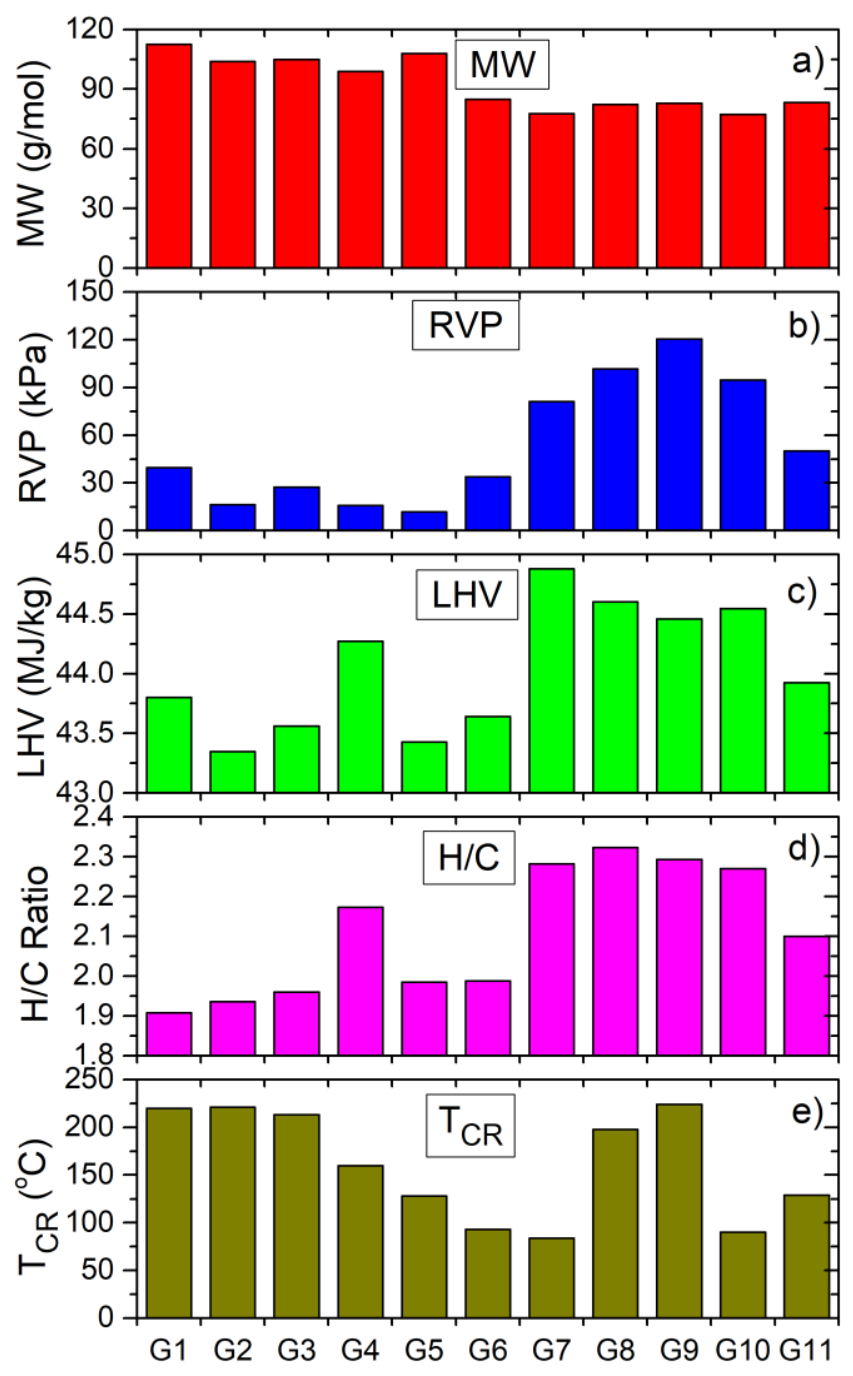

Page 6 of 27

$10 / 19 / 2016$
Figure 8. Calculated a) molecular weight (MW), b) Reid vapor pressure (RVP), c) lower heating value (LHV), d) hydrogen to carbon (H/C) ratio and critical temperature $\left(\mathrm{T}_{\mathrm{CR}}\right)$ of the GCI fuels.

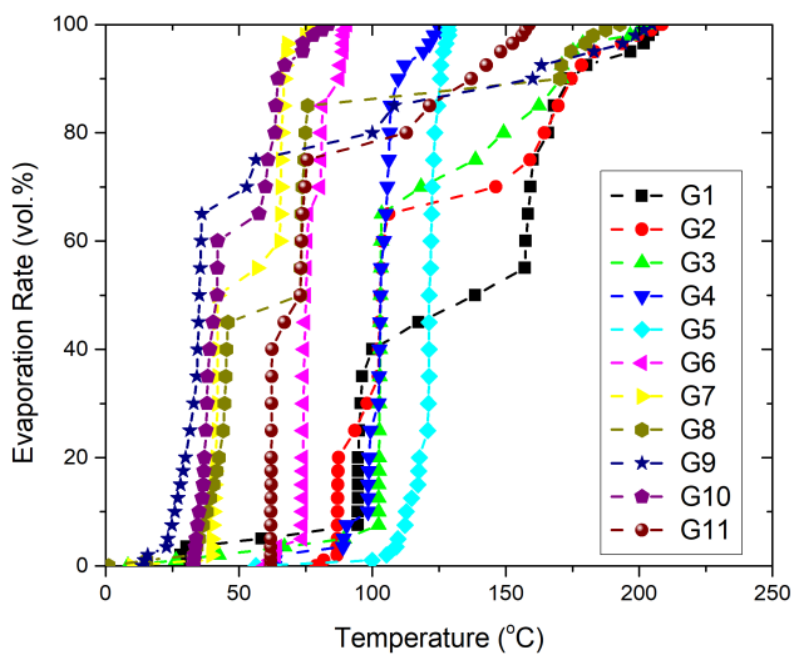

Figure 9. D86 distillation curves of the GCI fuels. 


\begin{tabular}{|l|l|l|l|l|l|l|l|l|l|l|}
\hline Fuel & RON & MON & $\mathrm{S}$ & $\mathrm{T} 90\left({ }^{\circ} \mathrm{C}\right)$ & Den. $\left(\mathrm{kg} / \mathrm{m}^{3}\right)$ & $\mathrm{MW}(\mathrm{g} / \mathrm{mol})$ & $\mathrm{RVP}(\mathrm{Pa})$ & $\mathrm{LHV}(\mathrm{MJ} / \mathrm{kg})$ & $\mathrm{H} / \mathrm{C}$ & $\mathrm{T}_{\mathrm{CR}}\left({ }^{\circ} \mathrm{C}\right)$ \\
\hline G1 & 85.0 & 78.9 & 6.1 & 186.9 & 750.5 & 112.6 & 39.6 & 43.8 & 1.91 & 220 \\
\hline G2 & 60.0 & 54.4 & 5.6 & 186.9 & 751.2 & 103.9 & 16.4 & 43.3 & 1.94 & 221 \\
\hline G3 & 40.0 & 37.4 & 2.6 & 177.9 & 750.0 & 104.8 & 27.3 & 43.6 & 1.96 & 213 \\
\hline G4 & 40.0 & 39.0 & 1.0 & 109.1 & 710.0 & 98.9 & 15.9 & 44.3 & 2.17 & 160 \\
\hline G5 & 59.1 & 59.5 & -0.4 & 121.2 & 750.0 & 107.9 & 11.9 & 43.4 & 1.98 & 128 \\
\hline G6 & 60.2 & 56.0 & 4.2 & 87.5 & 710.0 & 84.8 & 33.9 & 43.6 & 1.99 & 93 \\
\hline G7 & 59.1 & 57.5 & 1.6 & 68.7 & 650.0 & 77.7 & 81.2 & 44.9 & 2.28 & 84 \\
\hline G8 & 58.2 & 57.5 & 0.7 & 174.2 & 650.0 & 82.4 & 101.7 & 44.6 & 2.32 & 198 \\
\hline G9 & 83.6 & 81.4 & 2.2 & 174.2 & 652.0 & 82.8 & 120.5 & 44.5 & 2.29 & 224 \\
\hline G10 & 85.0 & 80.8 & 4.2 & 68.7 & 650.0 & 77.2 & 94.7 & 44.5 & 2.27 & 90 \\
\hline G11 & 76.9 & 68.2 & 8.7 & 135.0 & 720.0 & 83.3 & 50.1 & 43.9 & 2.10 & 129 \\
\hline
\end{tabular}

\section{Engine CFD Modelling}

\section{Numerical Setup}

\section{Engine Combustion Chamber Configuration}

A single cylinder 4 valve engine with a 14.5:1 geometric compression ratio (CR) is used in this investigation. Table 5 shows the details of the engine specifications. The combustion chamber is originally designed to accommodate stratified charge spark ignition combustion. A multi-hole GDI injector is centrally mounted adjacent to the spark plug (Figure 10). In GCI combustion tests, the spark is disabled as is the case in the subsequent simulations. The operating fuel injection pressure range is $50-250$ bars, which is about 10 times lower than a conventional diesel injector. As such, spray atomization and penetration characteristics are expected to be significantly different. For the purpose of this study, a new set of pistons was designed to accommodate the PPC combustion strategy and the pentroof cylinder head design of the base engine. To improve fuel containment, a diesel bowl-like feature was added. It also has a reentry feature to ensure that spray interaction occurs inside the bowl. Figure 11 shows the geometric features of the piston bowl and cylinder head.

Table 5. Single cylinder engine specifications.

\begin{tabular}{|l|l|}
\hline Cylinders & 1 \\
\hline Number of Valves & 4 \\
\hline Displacement (L) & 0.552 .2 \\
\hline Bore $(\mathrm{mm})$ & 86 \\
\hline Stroke $(\mathrm{mm})$ & 94.6 \\
\hline Connecting Rod $(\mathrm{mm})$ & 148 \\
\hline CR & $14.5: 1$ \\
\hline Fuel Injector & Centrally mounted, multi-hole GDI \\
\hline Injection pressure (bar) & 150 \\
\hline Spray angle $\left({ }^{\circ}\right)$ & 100 \\
\hline Number of nozzles & 10 \\
\hline Nozzle diameter $(\mathrm{mm})$ & 0.124 \\
\hline Peak load (BMEP, bar) & 22 \\
\hline
\end{tabular}

Page 7 of 27

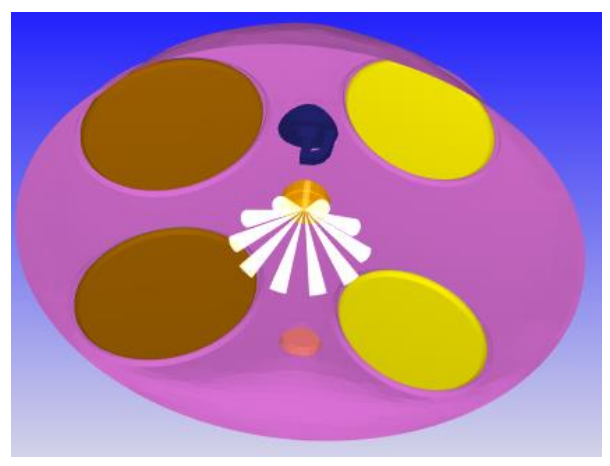

Figure 10. Base engine combustion chamber shape: Pentroof style 4 valve head. Exhaust valves (yellow) and intake valves (brown).

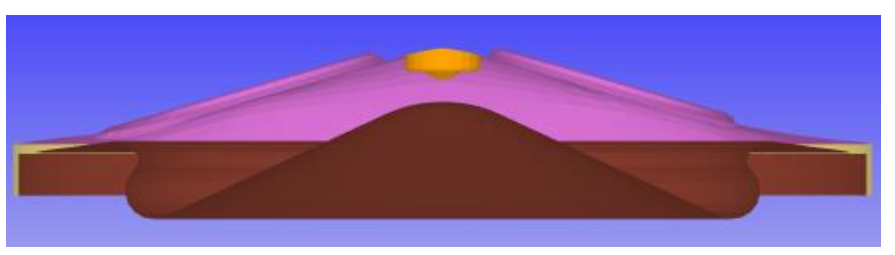

Figure 11. Side view picture of the piston and cylinder head.

\section{Engine Modelling}

CONVERGE v2.4 [57] was used to perform the CFD simulations in this work. CONVERGE [57] is a general purpose CFD code to solve multi-dimensional reacting flows with stationary and moving boundaries. More detailed descriptions of the models can be found in [57]. The RANS-based turbulent renormalization group (RNG) k- $\varepsilon$ model was utilized the used throughout the simulions. A Lagrangian spray model based on the blob injection model of Reitz and Diwakar [58] was used, wherein computational parcels of liquid with a characteristic size equal to the effective nozzle diameter were introduced into the computational domain. The spray breakup models were awee implemented based on the recommendations from the constant volume chamber simulations [40]. 
Prior to performing 3D engine simulations, the spray models need to be calibrated against a spray that is similar to what is used in the current work. Engine combustion network (ECN4) spray G [59] was found to be the closest to the injection considered here in terms of the spray angle $\left(80^{\circ}\right)$, injection pressure (200 bar) and the utilized fuel (iso-octane). A Lagrangian discrete parcel method was used for spray modeling by introducing parcels (groups of droplets) of liquid into the gas phase computational domain with Rosin-Rammler distributions. As a breakup algorithm of liquid spray, the modified Kelvin-Helmholtz and Rayleigh-Taylor (KH-RT) model was used without an ad hoc breakup length [60]. The spray and turbulence models used in this work were successfully validated against Spray G and more details about the spray model validation can be found in [40]. Models for the dynamic drop drag [61] and droplet turbulent dispersion [62] were also used here. Frossling's [62] droplet evaporation model was implanted in this work with all base parcel species are considered as evaporation source. The SAGE detailed chemistry solver [63] along with multi-zone approach was used as a combustion sub-model. Grid generation was done during run-time by utilizing both fixed embedding of cells and adaptive mesh refinement (AMR) based on key parameters gradients.

The in-cylinder region geometry was meshed and used in the subsequent engine CFD simulations. The engine specifications are presented in Table 5. The base mesh size used in this work was 4 $\mathrm{mm}$. The mesh was refined to $2 \mathrm{~mm}$ in a geometrical cylinder that contains the cylinder region. The cylinder region had additional embedding levels with the base grid size of $1 \mathrm{~mm}$. The mesh near the nozzle exit was further refined to $0.25 \mathrm{~mm}$ when during the injection process. In addition to these fixed embedding refinements, temperature and velocity AMR with an embedding level of 3 for each were implemented, resulting in the smallest grid size of $0.25 \mathrm{~mm}$ in the domain. This proved to produce grid independent solution for the simulated motored runs and hence the same mesh is utilized for the subsequent GCI cases. Similar grid was utilized by our group in recent works [11, 12, 34, 40]. Kodavasal et al. [42] showed that a finer grid might be needed to reach grid independent solution for reacting cases; however, the current grid was considered sufficient for the objectives of this study which was mainly examining the effect of fuels' properties on the engine performance. The reduced PRF chemical kinetic models developed by KAUST (64 species and 376 reactions) was used in this work [64]. The prediction of NOx emissions was performed using the extended Zedovich thermal NOx model. The soot formation and oxidation were simulated through the two-step Hiroyasu-NSC (Nagle and Strickland-Constable) approach. Acetylene was considered as the inception species in the soot model.

The eleven GCI fuels were used in the engine simulations are the eleven GCI fuels presented earlier. The RON of these fuels range from 40 to 85 and hence require different intake conditions to obtain combustion near top dead center (TDC). The intake pressures and temperatures were set to $1.25 \mathrm{bar}$ and $385 \mathrm{~K}$ for RON85 (G1, G9 and G10), 1.1bar and 333K for RON60 (G2, G5, G6, G7 and G8) and 1.1 bar and $298 \mathrm{~K}$ for RON40 (G3 and G4), respectively. The engine details presented in Table 5 were utilized here. The injection pressure was $150 \mathrm{bar}$, the fuel temperature was $363 \mathrm{~K}$ and the injected fuel was $14.5 \mathrm{mg} /$ cycle corresponding to an equivalence ratio of 0.3 to 0.33 depending on the intake conditions. 6bar net mean effective pressure (NMEP) is the targeted load point in this work. The start of injection (SOI) was set to -20 to CAD aTDC and the engine speed was 1500 RPM. The presented simulations were performed without exhaust gas recirculation (EGR) and 0.5 swirl ratio was utilized in the subsequent simulations. Closed cycle engine simulations were performed here where only the compression and expansion strokes were modelled.
Table 6 below lists the important engine simulation parameters used in the subsequent simulations. The utilized spray rate shape is shown in Figure 12. This rate shape was derived from a common rail diesel injector. The rate shape of the injector modeled here was not available at the time of the simulations we performed. The rate shape does not change the comparisons and conclusions made in this work and hence the rate shape is provided here for results reproduction. The boundary conditions were obtained from [65] where GT-Power was used to calculate parameters that are relevant to the engine simulations.

PRF surrogates (mixtures of $n$-heptane and iso-octane) were used in this work. The PRF numbers were set to match RON of the GCI fuels presented in Table 4. PRF85 (85 vol.\% iso-octane and 15 vol.\% nheptane) was used as a chemical surrogate for G1, G9 and G10. PRF 83.6 was utilized for G9. PRF60, PRF59.1 and PRF58.3 were used to mimic the autoignition characteristics of G2, G5, G6, G7 and G8 and PRF40 was used to simulate the chemistry G3 and G4. The physical properties of the GCI fuels were calculated from the detailed hydrocarbon analysis (DHA) using Aspen HYSYS and formatted as per CONVERGE requirements. These physical properties were enforced on the PRF surrogates. In other words, the surrogate used in the subsequent simulations burn like a PRF but breakup, evaporate and mix like the actual GCI fuel. This approach has been previously demonstrated to work well $[11,12,34,40]$. To help facilitating performing CFD simulations using the proposed fuels, the liquid properties of the eleven GCI fuels in CONVERGE format are provided in the Appendix. These liquid data along with the information provided in Table 4 are sufficient to perform various kinds of simulations ( 0 to $3 \mathrm{D}$ ) using any of the proposed fuels. In addition, the energy input, that is the injected fuel mass multiplied by the LHV of the GCI fuel, was conserved in the simulations because CONVERGE allows the user to set the LHV of the utilized fuel surrogate mixture used.

Table 6. GCI operating conditions for simulations.

\begin{tabular}{|l|l|}
\hline Engine speed (RPM) & 1500 \\
\hline Intake pressure (bar) & 1.25 for G1, G9 and G10 \\
& 1.1 for G2, G3, G4, G5, G6, G7 and G8 \\
\hline & 385 for G1, G9 and G10 \\
& 333 for G2, G5, G6, G7 and G8 \\
Intake temperature (K) & Multi-hole \\
\hline Injector & 10 \\
\hline Number of nozzles & 0.124 \\
\hline Nozzle diameter (mm) & 100 \\
\hline Spray angle $\left({ }^{\circ}\right)$ & -20 \\
\hline SOI $($ aTDC) & 14.5 \\
\hline Injected mass (mg/cycle) & 150 \\
\hline Injection pressure (bar) & 363 \\
\hline Fuel temperature $(\mathrm{K})$ & 0 \\
\hline EGR level $(\%)$ & 0.5 \\
\hline Swirl ratio & -180 \\
\hline Start of simulations $\left({ }^{\circ} \mathrm{CA}\right)$ & 180 \\
\hline End of simulations $\left({ }^{\circ} \mathrm{CA}\right)$ & 403 \\
\hline $\mathrm{T}_{\text {liner }}(\mathrm{K})$ & 403 \\
\hline $\mathrm{T}_{\text {head }}(\mathrm{K})$ & 423 \\
\hline $\mathrm{T}_{\text {piston }}(\mathrm{K})$ & \\
& \\
\hline
\end{tabular}




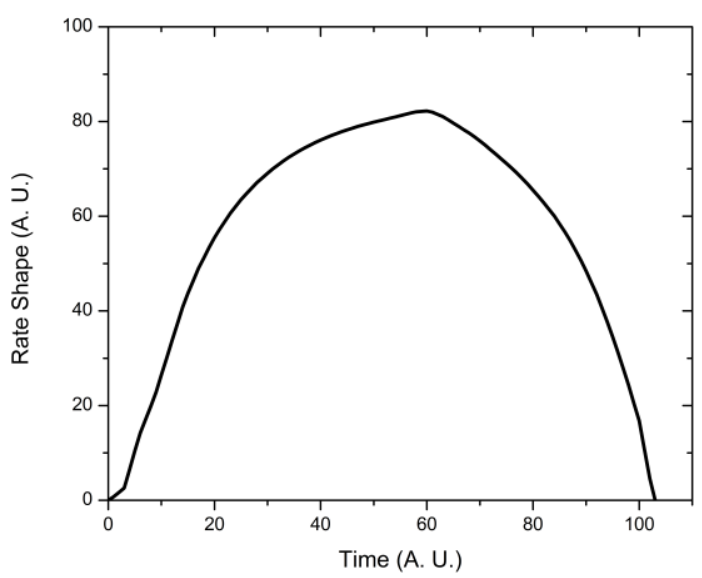

Figure 12. Spray rate shape.

\section{Results and Discussions}

Closed cycle engine simulations were performed for G1, G9 and G10 using PRF85 surrogates and the parameters listed in Table 6. Any differences in the results are associated with the physical properties, the minor differences in RON values and the lower heating values of the fuels. The calculated in-cylinder pressures for RON85 simulations with G1, G9 and G10 physical properties are presented in Figure 13. As can be seen from Figure 13, the physical properties of the fuel affect the combustion in CI mode. The combustion is affected by the fuel/air mixing which is dependent on the physical properties of the fuel. In addition, the heat release associated with the heating value of the fuel affect the combustion behavior. It is clear that the combustion phasing is proportional to the density (G1 and G9) and T90 (G9 and G10). The effect of T90 on the combustion phasing is more pronounced compared to the density effect. Further analysis has been performed and the indicated specific fuel consumption (ISFC), the thermal efficiency (TE) maximum pressure rise rate (MPRR), crank angle for 50 and 90\% burn (CA50 and CA90), specific soot (sSoot), specific NOx (sNOx) and specific hydrocarbons ( $\mathrm{sHC}$ ) emissions were calculated for the three fuels. The thermal efficiency was presented here to eliminate the effect of the LHVs on the performance of the GCI engine. The results are presented in Figure 14. Note that the y-axis is logarithmic scale. There are not much differences in ISFC, MPRR and sSoot between the three fuels. The ISFC and TE of G9 are better than G1 and G10. The combustion duration (not shown here) of G10 is longer than G1 and G9 while the $\mathrm{HC}$ emissions are signifieantly lower because of the more complete combustion. NOx from G10 is also slightly lower than G1 and G9. Overall, G9 and G10 yield better GCI engine performance and emissions when compared to G1.

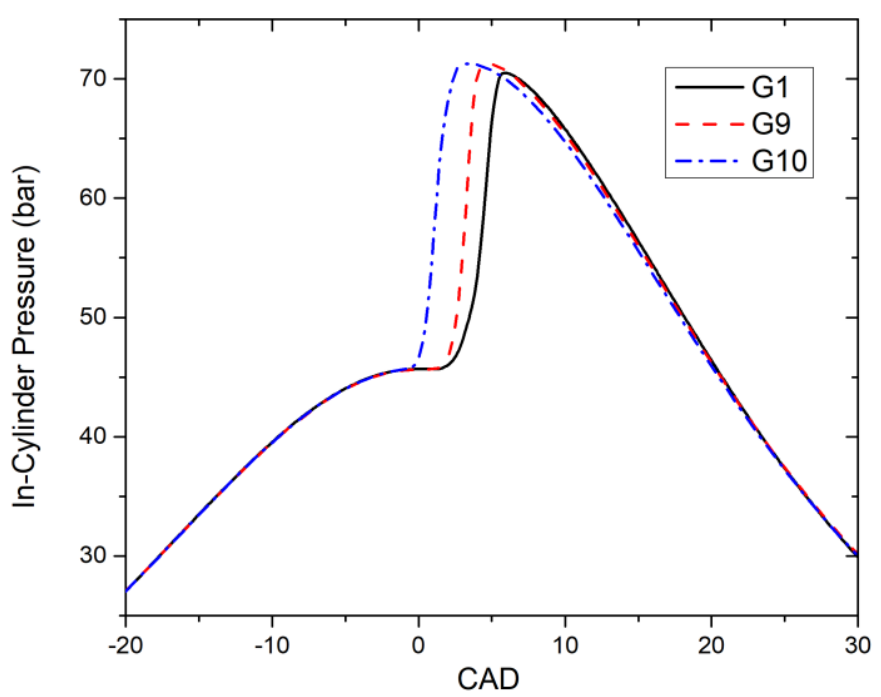

Figure 13. In-cylinder pressures for G1, G9 and G10 engine simulations.

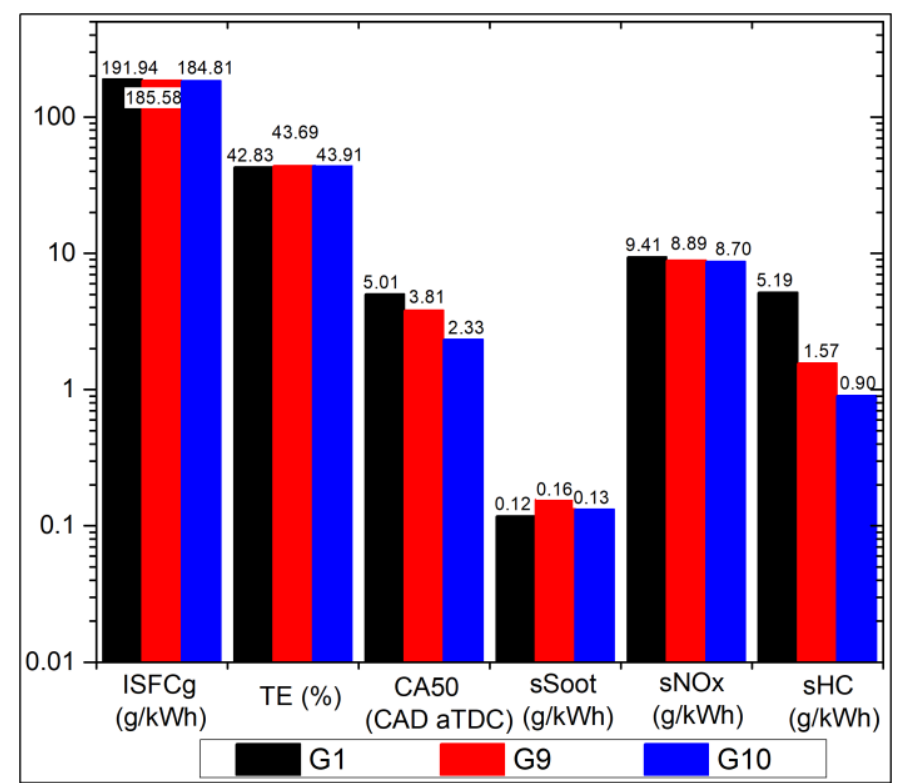

Figure 14. ISFC, TE, MPRR, CA50, CA90, sSoot, sNOx, sHC for G1, G9 and G10.

The same procedure has been followed for RON60 fuels (G2, G5, G6, G7 and G87. Figure 15 shows the in-cylinder pressures and Figure 16 presents the rest of combustion parameters and emissions for the RON60 fuels. Similar trends to the RON85 fuels are observed here for RON60 fuels. In summary, fuels with lower density and/or T90 (G5, G7 and G8) result in earlier combustion phasings and lower overall emissions. Compared to G2, G7 and G8 yielded around 8\% and $5.7 \%$ improvements in mass-based ISFC and TE, respectively. An improvement of $8.8 \%$ in TE was observed with G5 compared to G2. However, NOx emissions are higher for G5, G7 and G8 compared to $\mathrm{G} 2$ because of the earlier combustion phasing. Calculating the volume-based ISFC would be useful because consumers pay for fuels on volume basis and hence fuels with higher densities are favorable. Comparing G2 and G8, the volume based ISFC are $254.46 \mathrm{~mL} / \mathrm{kWh}$ and $269.76 \mathrm{~mL} / \mathrm{kWh}$, respectively. It is clear that the trends have reversed where $\mathrm{G} 2$ result in lower volume based fuel consumption. The fuel consumption comparison between 
G2 and G5 does not change when converting it to volume-based because they have the same densities and hence G5 (234.13 $\mathrm{mL} / \mathrm{kWh}$ ) is still more favorable than $\mathrm{G} 2$ and yield better fuel consumption.

The RON40 fuels (G3 and G4) were also simulated in the same engine configuration and the in-cylinder pressures and the combustion parameters and emissions of the RON40 fuels are presented in Figure 17 and Figure 18, respectively. The same observations are made here except that the higher LHV value of G4 resulted in a maximum in-cylinder pressure that is higher than that of G3 yielding a significantly lower ISFC and HC emissions. Also, the TE of G4 is significantly improved compared to G3 which means that optimum combustion phasing and minimum heat loss are obtained when using G4 instead of G3. In fact, the lowest mass-based ISFC and highest TE among the 10 simulated fuels is from G4 (169.68 $\mathrm{g} / \mathrm{kWh}$ and $47.98 \%)$. G4 (238.98 mL/kWh) has lower volume-based fuel consumption compared to G3 (254.44 mL/kWh). Similar to RON85 and RON60 fuels, the lower T90 of G4 resulted in better incylinder mixing and hence significantly lower sSoot emissions.

The presented engine CFD simulations are just an illustrative example of how the physical and chemical properties of the fuels affect the combustion and emissions at GCI engine operation. Sensitivity was not accounted for in these simulations which were performed at only one engine condition (no-EGR low-load case). Accounting for sensitivity by using different surrogates such as toluene primary reference fuels (TPRF) can be a way to improve the predictions and highlight the effect of sensitivity on GCI combustion. Furthermore, simulating other engine conditions such as high-EGR and high-load can be very useful to examine the effect of engine operating range on the differences caused by the fuels' properties.

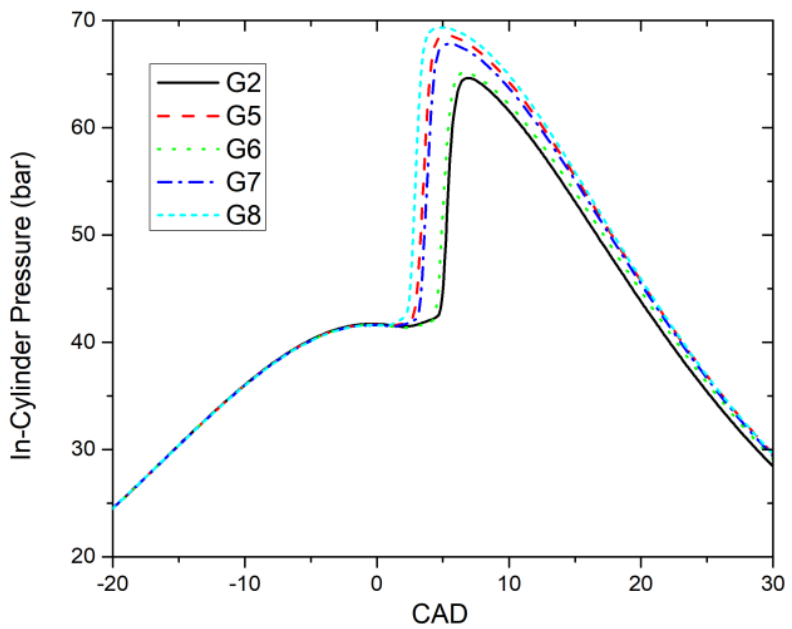

Figure 15. In-cylinder pressures from G2, G5, G6, G7 and G8 engine simulations.

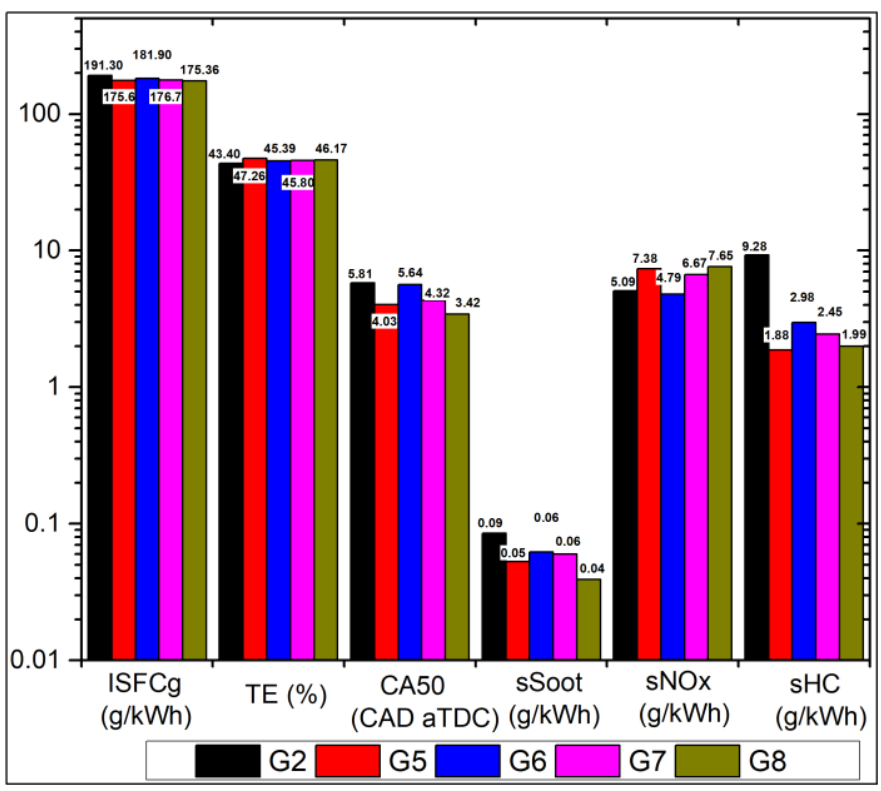

Figure 16. ISFC, TE, MPRR, CA50, CA90, sSoot, sNOx, sHC from G2, G5, G6, G7 and G8.

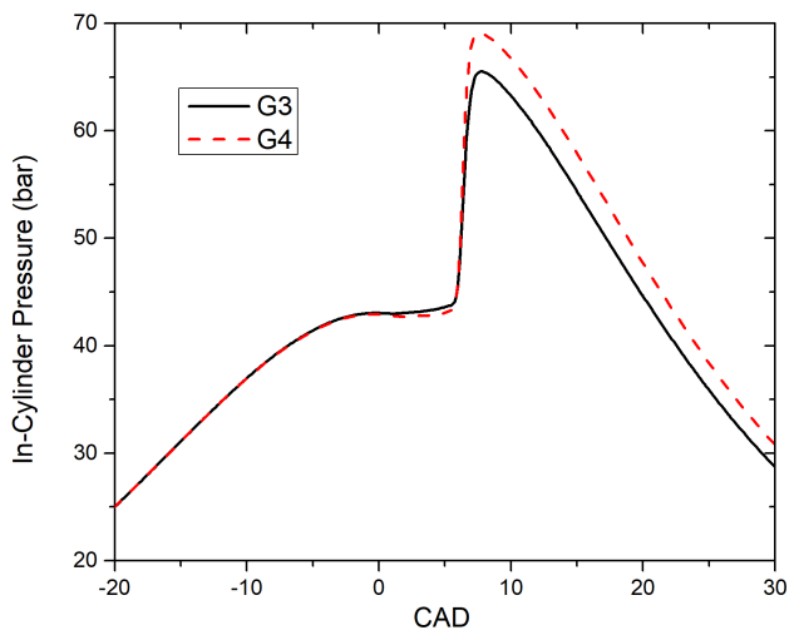

Figure 17. In-cylinder pressures from G3 and G4 engine simulations. 


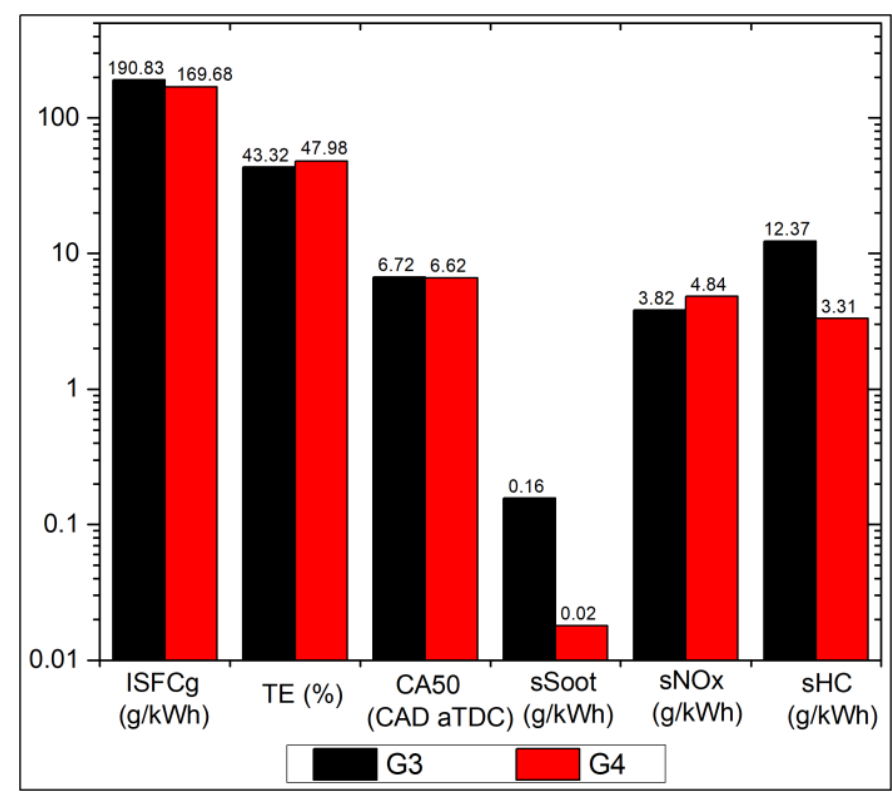

Figure 18. ISFC, TE, MPRR, CA50, CA90, sSoot, sNOx, sHC from G3 and G4.

\section{Summary/Conclusions}

A GCI fuel matrix containing eleven standardized fuels was proposed here based on physical and chemical properties that are relevant to GCI combustion. The properties used to design the matrix were determined to be density, RON and T90. The proposed fuels were theoretically formulated using equations of state and their compositions and properties were calculated and discussed. 3D CFD GCI engine simulations were performed to investigate the similarities and differences in the combustion parameters and engine-out emissions between the proposed GCI fuels at part load conditions. It is noted that fuels with lower densities and T90 yield better massbased fuel consumptions and engine-out emissions. The content of this work might be very useful to the GCI engine research community because of the standardized nature of the proposed fuels and the ranges of the considered parameters. In addition, the engine simulations present the research community with information about the directions the GCI engine take with these fuels.

\section{References}

1. U.S. Energy Information Administration (EIA), "International Energy Outlook 2014: World Petroleum and Other Liquid Fuels," Washington, DC 20585, DOE/EIA0484(2014), 2014.

2. ExxonMobil Explore the Outlook for Energy: A View to 2040. 2016.

3. Li, T., Moriwaki, R., Ogawa, H., Kakizaki, R., et al., "Dependence of premixed low-temperature diesel combustion on fuel ignitability and volatility, "SAE Int. J. Engines, 13(1):14-27, 2011, doi: $10.1177 / 1468087411422852$.

4. Viollet, Y., Chang, J., and Kalghatgi, G., "Compression Ratio and Derived Cetane Number Effects on Gasoline Compression Ignition Engine Running with Naphtha Fuels, " SAE Int. J. Fuels Lubr., 7(2):412-426, 2014, doi: doi:10.4271/2014-01-1301.
5. Xu, C.L. and Bell, L., "Global reserves, oil production show increases for 2014," Oil Gas J., 112(12):30-31, 2014.

6. Zhao, H., "HCCI and CAI engines for the automotive industry," Elsevier, 2007.

7. Hanson, R.M., Kokjohn, S.L., Splitter, D.A., and Reitz, R.D., "An Experimental Investigation of Fuel Reactivity Controlled PCCI Combustion in a Heavy-Duty Engine,"

SAE Int. J. Engines, 3(1):700-716, 2010, doi: 10.4271/2010-01-0864.

8. Reitz, R.D. and Duraisamy, G., "Review of high efficiency and clean reactivity controlled compression ignition (RCCI) combustion in internal combustion engines, "Prog. Energy Combust. Sci., 46:12-71, 2015, doi: https://doi.org/10.1016/j.pecs.2014.05.003.

9. Ickes, A., Wallner, T., Zhang, Y., and De Ojeda, W., "Impact of Cetane Number on Combustion of a GasolineDiesel Dual-Fuel Heavy-Duty Multi-Cylinder Engine," SAE Int. J. Engines, 7(2):860-872, 2014, doi: 10.4271/2014-01-1309.

10. Kalghatgi, G., Risberg, P., and Ångström, H., "Advantages of fuels with high resistance to autoignition in lateinjection, low-temperature, compression ignition combustion, " SAE Technical Paper 2006-01-3385, 2006, doi: 10.4271/2006-01-3385.

11. Badra, J., Elwardany, A., Sim, J., Viollet, Y., et al., "Effects of In-Cylinder Mixing on Low Octane Gasoline Compression Ignition Combustion," SAE Technical Paper 2016-01-0762, 2016, doi: 10.4271/2016-01-0762.

12. Badra, J.A., Sim, J., Elwardany, A., Jaasim, M., et al., "Numerical Simulations of Hollow-Cone Injection and Gasoline Compression Ignition Combustion With Naphtha Fuels," J. Energy Resour. Technol., 138(5):052202-052202, 2016, doi: 10.1115/1.4032622.

13. Manente, V., Zander, C.-G., Johansson, B., Tunestal, P., et al., "An Advanced Internal Combustion Engine Concept for Low Emissions and High Efficiency from Idle to Max Load Using Gasoline Partially Premixed Combustion, " SAE Technical Paper 2010-01-2198, 2010, doi: doi:10.4271/2010-01-2198.

14. Sellnau, M., Foster, M., Hoyer, K., Moore, W., et al., "Development of a Gasoline Direct Injection Compression Ignition (GDCI) Engine, " SAE Int. J. Engines, 7(2):835851, 2014, doi: $10.4271 / 2014-01-1300$.

15. Kalghatgi, G.T., Hildingsson, L., Harrison, A.J., and Johansson, B., "Autoignition quality of gasoline fuels in partially premixed combustion in diesel engines, " Proc. Combust. Inst., 33(2):3015-3021, 2011, doi: http://dx.doi.org/10.1016/j.proci.2010.07.007.

16. Kalghatgi, G.T., Risberg, P., and Ångström, H.-E., "Partially Pre-Mixed Auto-Ignition of Gasoline to Attain Low Smoke and Low NOx at High Load in a Compression Ignition Engine and Comparison with a Diesel Fuel, "SAE Technical Paper 2007-01-0006, 2007, doi: 10.4271/200701-0006.

17. Ciatti, S. and Subramanian, S.N., "An Experimental Investigation of Low-Octane Gasoline in Diesel Engines," J. Eng. Gas Turbines Power, 133(9):092802-092802, 2011, doi: $10.1115 / 1.4002915$.

18. Kalghatgi, G., Hildingsson, L., and Johansson, B., "Low NOx and Low Smoke Operation of a Diesel Engine Using Gasolinelike Fuels, " J. Eng. Gas Turbines Power, 132(9):092803-092803, 2010, doi: 10.1115/1.4000602.

19. Ickes, A.M., Bohac, S.V., and Assanis, D.N., "Effect of fuel cetane number on a premixed diesel combustion

Page 11 of 27 
mode," SAE Int. J. Engines, 10(4):251-263, 2009, doi: 10.1243/14680874JER03809. al., "Advanced Combustion for Low Emissions and High Efficiency Part 2: Impact of Fuel Properties on HCCI Combustion," SAE Technical Paper 2008-01-2404, 2008, doi: 10.4271/2008-01-2404.

21. Akihama, K., Kosaka, H., Hotta, Y., Nishikawa, K., et al., "An Investigation of High Load (Compression Ignition) Operation of the "Naphtha Engine" - a Combustion Strategy for Low Well-to-Wheel CO2 Emissions, " SAE Int. J. Fuels Lubr., 1(1):920-932, 2008, doi: 10.4271/2008-011599.

22. Weall, A. and Collings, N., "Investigation into Partially Premixed Combustion in a Light-Duty Multi-Cylinder Diesel Engine Fuelled Gasoline and Diesel with a Mixture of, " SAE Technical Paper 2007-01-4058, 2007, doi: 10.4271/2007-01-4058

23. Zhang, F., Xu, H., Zeraati Rezaei, S., Kalghatgi, G., et al., "Combustion and Emission Characteristics of a PPCI Engine Fuelled with Dieseline, " SAE technical Paper 201201-1138, 2012, doi: 10.4271/2012-01-1138.

24. Chang, J., Kalghatgi, G., Amer, A., Adomeit, P., et al., "Vehicle Demonstration of Naphtha Fuel Achieving Both High Efficiency and Drivability with EURO6 Engine-Out NOx Emission," SAE Int. J. Engines, 6(1):101-119, 2013, doi: $10.4271 / 2013-01-0267$.

25. Han, D., Ickes, A.M., Bohac, S.V., Huang, Z., et al., "Premixed low-temperature combustion of blends of diesel and gasoline in a high speed compression ignition engine," Proc. Combust. Inst., 33(2):3039-3046, 2011, doi: http://dx.doi.org/10.1016/j.proci.2010.07.045.

26. Zhang, Y., Voice, A., Tzanetakis, T., Traver, M., et al., "An Evaluation of Combustion and Emissions Performance With Low Cetane Naphtha Fuels in a Multicylinder HeavyDuty Diesel Engine, " J. Eng. Gas Turbines Power, 138(10):102805-102805, 2016, doi: 10.1115/1.4032879.

27. Kim, K., Wang, Z., Wang, B., Shuai, S., et al., "Load expansion of naphtha multiple premixed compression ignition (MPCI) and comparison with partially premixed compression ignition (PPCI) and conventional diesel combustion (CDC), " Fuel, 136:1-9, 2014, doi: http://dx.doi.org/10.1016/i.fuel.2014.07.030

28. Wang, B., Wang, Z., Shuai, S., and Xu, H., "Combustion and emission characteristics of Multiple Premixed Compression Ignition (MPCI) mode fuelled with different low octane gasolines, " Appl. Energy, 160:769-776, 2015, doi: http://dx.doi.org/10.1016/j.apenergy.2015.01.115.

29. Wang, B., Wang, Z., Shuai, S., Yang, H., et al., "Combustion and emission characteristics of Multiple Premixed Compression Ignition (MPCI) fuelled with naphtha and gasoline in wide load range," Energy Convers. Manage., 88:79-87, 2014, doi: http://dx.doi.org/10.1016/j.enconman.2014.08.045.

30. Yang, H., Shuai, S., Wang, Z., and Wang, J., "Fuel octane effects on gasoline multiple premixed compression ignition (MPCI) mode, " Fuel, 103:373-379, 2013, doi: http://dx.doi.org/10.1016/j.fuel.2012.05.016.

31. Kalghatgi, G., Hildingsson, L., Harrison, A., and Johansson, B., "Surrogate fuels for premixed combustion in compression ignition engines, " Int. J. Engine Res.:452-465, 2011, doi: https://doi.org/10.1177/1468087411409307.

32. Rose, K.D., Cracknell, R.F., Rickeard, D.J., Ariztegui, J., et al., "Impact of Fuel Properties on Advanced Combustion Performance in a Diesel Bench Engine and Demonstrator
Vehicle," SAE Technical Paper 2010-01-0334, 2010, doi: 10.4271/2010-01-0334.

33. Hao, H., Liu, F., Liu, Z., and Zhao, F., "Compression ignition of low-octane gasoline: Life cycle energy consumption and greenhouse gas emissions, " Appl. Energy, 181:391-398, 2016, doi: http://dx.doi.org/10.1016/j.apenergy.2016.08.100.

34. Badra, J., Viollet, Y., Elwardany, A., Im, H.G., et al., "Physical and chemical effects of low octane gasoline fuels on compression ignition combustion," Appl. Energy, 183:1197-1208, 2016, doi:

http://dx.doi.org/10.1016/j.apenergy.2016.09.060.

35. Chang, J., Kalghatgi, G., Amer, A., and Viollet, Y., "Enabling High Efficiency Direct Injection Engine with Naphtha Fuel through Partially Premixed Charge Compression Ignition Combustion, " SAE Technical Paper 2012-01-0677, 2012, doi: doi:10.4271/2012-01-0677.

36. Chang, J., Viollet, Y., Alzubail, A., Abdul-Manan, A.F.N., et al., "Octane-on-Demand as an Enabler for Highly Efficient Spark Ignition Engines and Greenhouse Gas Emissions Improvement, " SAE Technical Paper 2015-011264, 2015, doi: 10.4271/2015-01-1264.

37. Chang, J., Viollet, Y., Amer, A., and Kalghatgi, G., "Fuel Economy Potential of Partially Premixed Compression Ignition (PPCI) Combustion with Naphtha Fuel," SAE Technical Paper 2013-01-2701, 2013, doi: doi:10.4271/2012-01-0677.

38. Viollet, Y., Abdullah, M., Alhajhouje, A., and Chang, J., "Characterization of High Efficiency Octane-On-Demand Fuels Requirement in a Modern Spark Ignition Engine with Dual Injection System, " SAE Technical Paper 2015-011265, 2015, doi: 10.4271/2015-01-1265.

39. Atef, N., Badra, J., Jaasim, M., Im, H.G., et al., "Numerical investigation of injector geometry effects on fuel stratification in a GCI engine, " Fuel, 214:580-589, 2018, doi: https://doi.org/10.1016/j.fuel.2017.11.036.

40. Badra, J.A., Sim, J., Viollet, Y., Zhang, Y., et al., "CFD Guided Gasoline Compression Ignition Engine Calibration," in Proceedings of the 2017 ASME Internal Combustion Engine Division Fall Technical Conference, 2017, Seattle, Washington, USA, doi: 10.1115/ICEF2017$\underline{3583}$.

41. Naser, N., Jaasim, M., Atef, N., Chung, S.H., et al., "On the effects of fuel properties and injection timing in partially premixed compression ignition of low octane fuels, " Fuel, 207:373-388, 2017, doi:

https://doi.org/10.1016/j.fuel.2017.06.048

42. Kodavasal, J., Kolodziej, C.P., Ciatti, S., and Som, S., "Computational Fluid Dynamics Simulation of Gasoline Compression Ignition," J. Energy Resour. Technol., 137(3):pp. 032212-1-13, 2015.

43. Bakker, P.C., De Abreu Goes, J.E., Somers, L.M.T., and Johansson, B.H., "Characterization of Low Load PPC Operation using RON70 Fuels, " SAE Technical Paper 2014-01-1304, 2014, doi: 10.4271/2014-01-1304.

44. Hildingsson, L., Johansson, B., Kalghatgi, G.T., and Harrison, A.J., "Some Effects of Fuel Autoignition Quality and Volatility in Premixed Compression Ignition Engines," SAE Int. J. Engines, 3(1):440-460, 2010, doi: 10.4271/2010-01-0607.

45. Kim, D., Martz, J., and Violi, A., "Effects of fuel physical properties on direct injection spray and ignition behavior," Fuel, 180:481-496, 2016, doi: http://dx.doi.org/10.1016/j.fuel.2016.03.085.

Page 12 of 27 
46. Lacey, J., Kameshwaran, K., Sathasivam, S., Filipi, Z., et al., "Effects of refinery stream gasoline property variation on the auto-ignition quality of a fuel and homogeneous charge compression ignition combustion, " Int. J. Engine Res., 2016, doi: 10.1177/1468087416647646.

47. Cannella, W., Foster, M., Gunter, G., and Leppard, W., "FACE Gasolines and Blends with Ethanol: Detailed Characterization of Physical and Chemcial Properties," CRC Report No. AVFL-24, 2014

48. Cho, K., Latimer, E., Lorey, M., Cleary, D.J., et al., "Gasoline Fuels Assessment for Delphi's Second Generation Gasoline Direct-Injection Compression Ignition (GDCI) Multi-Cylinder Engine, " SAE Int. J. Engines, 10(4):1430-1442, 2017, doi: 10.4271/2017-01-0743.

49. Kolodziej, C.P., Sellnau, M., Cho, K., and Cleary, D., "Operation of a Gasoline Direct Injection Compression Ignition Engine on Naphtha and E10 Gasoline Fuels, " SAE Int. J. Engines, 9(2):979-1001, 2016, doi: 10.4271/2016-01$\underline{0759}$.

50. Storey, J., Lewis, S., Moses-DeBusk, M., Connatser, R., et al., "Characterization of Hydrocarbon Emissions from Gasoline Direct-Injection Compression Ignition Engine Operating on a Higher Reactivity Gasoline Fuel, " SAE Int. J. Engines, 10(4):1454-1464, 2017, doi: 10.4271/2017-010747.

51. Tuner, M., Johansson, T., Aulin, H., Tunestal, P., et al., Multi Cylinder Partially Premixed Combustion Performance Using Commercial Light-Duty Engine Hardware. 2014, SAE International.

52. Knop, V., Loos, M., Pera, C., and Jeuland, N., "A linearby-mole blending rule for octane numbers of $n$-heptane/isooctane/toluene mixtures, " Fuel, 115(Supplement C):666673, 2014, doi: https://doi.org/10.1016/j.fuel.2013.07.093.

53. AlRamadan, A.S., Sarathy, S.M., Khurshid, M., and Badra, J., "A blending rule for octane numbers of PRFs and TPRFs with ethanol, " Fuel, 180(Supplement C):175-186, 2016, doi: https://doi.org/10.1016/j.fuel.2016.04.032.

54. Foong, T.M., Morganti, K.J., Brear, M.J., da Silva, G., et al., "The octane numbers of ethanol blended with gasoline and its surrogates, " Fuel, 115(Supplement C):727-739, 2014, doi: https://doi.org/10.1016/j.fuel.2013.07.105.

55. Anderson, J.E., Kramer, U., Mueller, S.A., and Wallington, T.J., "Octane Numbers of Ethanol- and

Methanol-Gasoline Blends Estimated from Molar Concentrations, " Energy \& Fuels, 24(12):6576-6585, 2010, doi: $10.1021 /$ ef101125c.

56. Ghosh, P., Hickey, K.J., and Jaffe, S.B., "Development of a Detailed Gasoline Composition-Based Octane Model," Industrial \& Engineering Chemistry Research, 45(1):337345, 2006, doi: 10.1021/ie050811h.

57. Senecal, P., Richards, K., and Pomraning, E., "CONVERGE (Version 2.2.0) Manual," Convergent Science Inc., Madison, WI (2014) 2014.

58. Reitz, R.D. and Diwakar, R., "Structure of high-pressure fuel sprays," SAE Technical Paper 870598, 1987, doi: doi: $10.4271 / 870598$.

59. Parrish, S., Duke, D., Grover, R., Lacey, J., et al. ECN4: Spray G Gasoline Direct-Injection. 2016 [cited 2016 3004-2016]; Available from: http://www.ca.sandia.gov/ecn/workshop/ECN4/ECN4.php.

60. Senecal, P.K., Richards, K.J., Pomraning, E., Yang, T., et al., "A New Parallel Cut-Cell Cartesian CFD Code for Rapid Grid Generation Applied to In-Cylinder Diesel Engine Simulations, " SAE Technical Paper 2007-01-0159, 2007, doi: doi:10.4271/2007-01-0159.

Page 13 of 27

61. Liu, A.B., Mather, D., and Reitz, R.D., "Modeling the effects of drop drag and breakup on fuel sprays, " SAE Technical Paper, 9300721993.

62. Amsden, A.A., O'Rourke, P.J., and Butler, T.D., "Los Alamos National Laboratory," 1989.

63. Senecal, P.K., Pomraning, E., Richards, K.J., Briggs, T.E., et al., "Multi-Dimensional Modeling of Direct-Injection Diesel Spray Liquid Length and Flame Lift-off Length using CFD and Parallel Detailed Chemistry," SAE Technical Paper 2003-01-1043, 2003, doi: doi:10.4271/2003-01-1043.

64. Sarathy, S.M., Atef, N., Alfazazi, A., Badra, J., et al., "Reduced toluene primary reference fuel (TPRF; toluene/nheptane/iso-octane) surrogate chemical kinetic model for compression ignition simulations," SAE Technical Paper 2018-01-0183, 2018.

65. Zhang, Y., Pei, Y., Engineer, N., Cho, K., et al., $C F D$ Guided Combustion Strategy Development for a Higher Reactivity Gasoline in a Light-Duty Gasoline Compression Ignition Engine. 2017, SAE International.

\section{Contact Information}

Jihad Badra, PhD

Fuel Technology Division, Research and Development Center, Saudi Aramco

Building 2293/C9, Dhahran 31311, KSA

E-mail: jihad.badra@aramco.com

Tel.: +966138763056

Mob.: +966544636600

\section{Acknowledgments}

This work was sponsored by the Fuel Technology Division at Saudi Aramco R\&DC.

\section{Definitions/Abbreviations}

$\begin{array}{ll}\boldsymbol{T} & \text { temperature } \\ \boldsymbol{\rho} & \text { density }\end{array}$

\section{Abbreviations}

3D

AMR

aTDC

CAD

CFD

CI

CR

DHA

DI

ECN

EGR

FACE three dimensional

adaptive mesh refinement

after top dead center

crank angle degree

computational fluid dynamics

compression ignition

compression ratio

detailed hydrocarbon analysis

direct injection

engine combustion network

exhaust gas recirculation

fuels for advanced combustion engines 
FBP

GC

GCI

GDI

GHG

HC

HCCI

H/C

ISFC

KR-RT

LHV

MON

MPCI

MPRR

MW

NMEP

NOx

NSC

OI

PIONA final boiling point

gas chromatography

gasoline compression ignition

gasoline direct injection

greenhouse gas

hydrocarbons

homogeneous charge compression

ignition

hydrogen to carbon

indicated specific fuel consumption

Kelvin-Helmholtz and Rayleigh-

Taylor

lower heating value

motor octane number

multiple premixed compression

ignition

maximum pressure rise rate

molecular weight

net mean effective pressure

nitric oxides

Nagle and Strickland-Constable

octane index

n-paraffinic, iso-praffinic, aromatic, naphthenic and olefinic
PM

PPCI

PRF

RANS

RCCI

RNG

RON

RPM

RVP

S

SI

SOI

TDC particulate matter

partially premixed compression

ignition

primary reference fuel

Reynolds-averaged Navier-Stokes

reactivity-controlled compression ignition

Reynolds normalization group

research octane number

revolution per minute

Reid vapor pressure

sensitivity

spark ignition

start of injection

top dead center 


\section{Appendix}

Table A1. Detailed hydrocarbon analyses (DHA) of the elven GCI fuels.

\begin{tabular}{|c|c|c|c|c|c|c|c|c|c|c|c|c|c|c|c|c|c|c|}
\hline & & & & & & & & G1 & G2 & G3 & G4 & G5 & G6 & G7 & G8 & G9 & G10 & G11 \\
\hline Compound & $\begin{array}{l}\text { Carbon } \\
\text { Group } \\
\text { (PIONA) }\end{array}$ & C\# & $\underset{(\mathrm{g} / \mathrm{mol})}{\mathrm{MW}}$ & $\begin{array}{l}\text { Density } \\
(\mathrm{g} / \mathrm{ml})\end{array}$ & $\begin{array}{l}\text { FBP } \\
\left({ }^{\circ} \mathrm{C}\right)\end{array}$ & RON & MON & \multicolumn{11}{|c|}{ Vol.\% } \\
\hline Propane & $\mathrm{P}$ & 3 & 44.10 & 0.50 & -42.00 & 111.9 & 97.1 & 0.00 & 0.00 & 0.66 & 0.00 & 0.15 & 0.03 & 0.37 & 1.25 & 0.07 & 0.08 & 0.00 \\
\hline i-butane & $\mathrm{I}$ & 4 & 58.12 & 0.56 & -11.70 & 103.3 & 97.6 & 4.48 & 0.00 & 0.19 & 0.00 & 0.09 & 0.03 & 0.09 & 0.02 & 2.93 & 0.04 & 0.00 \\
\hline butene-1 & $\mathrm{O}$ & 4 & 56.11 & 0.60 & -6.30 & 97.5 & 80.8 & 0.00 & 0.00 & 0.26 & 0.00 & 0.07 & 0.02 & 0.06 & 0.00 & 0.00 & 0.01 & 0.00 \\
\hline n-butane & $\mathrm{P}$ & 4 & 58.12 & 0.58 & -0.50 & 93.8 & 89.6 & 0.00 & 0.00 & 0.91 & 0.00 & 0.07 & 0.02 & 0.07 & 0.02 & 0.00 & 0.00 & 0.00 \\
\hline c-butene-2 & $\mathrm{O}$ & 4 & 56.11 & 0.62 & 3.70 & 100.0 & 83.5 & 0.00 & 0.00 & 0.00 & 0.00 & 0.07 & 0.02 & 0.48 & 0.00 & 0.00 & 0.05 & 0.00 \\
\hline i-pentane & I & 5 & 72.15 & 0.62 & 27.80 & 92.3 & 90.3 & 0.59 & 0.00 & 0.18 & 0.00 & 0.05 & 0.02 & 0.03 & 46.89 & 64.34 & 39.04 & 0.00 \\
\hline 2-methylbutene-1 & $\mathrm{O}$ & 5 & 70.14 & 0.65 & 31.20 & 102.5 & 81.9 & 0.00 & 0.00 & 0.04 & 0.00 & 0.05 & 0.02 & 0.30 & 0.00 & 0.00 & 0.30 & 0.00 \\
\hline n-pentane & $\mathrm{P}$ & 5 & 72.15 & 0.63 & 36.10 & 61.7 & 62.6 & 0.00 & 0.00 & 0.91 & 3.10 & 0.00 & 0.01 & 51.82 & 0.18 & 0.15 & 20.54 & 0.04 \\
\hline t-pentene- 2 & $\mathrm{O}$ & 5 & 70.14 & 0.65 & 36.30 & 102.5 & 81.9 & 0.00 & 0.00 & 0.04 & 0.00 & 0.05 & 0.02 & 0.31 & 0.00 & 0.00 & 0.28 & 0.00 \\
\hline 2-methylbutene-2 & $\mathrm{O}$ & 5 & 70.14 & 0.66 & 38.60 & 97.3 & 84.7 & 0.00 & 0.00 & 0.06 & 0.00 & 0.04 & 0.01 & 0.18 & 0.00 & 0.00 & 0.33 & 0.00 \\
\hline cyclopentane & $\mathrm{N}$ & 5 & 70.14 & 0.75 & 49.30 & 101.3 & 84.9 & 0.00 & 0.98 & 0.33 & 0.21 & 0.07 & 3.89 & 0.14 & 0.00 & 0.00 & 0.24 & 40.51 \\
\hline 2,2-dimethylbutane & $\mathrm{I}$ & 6 & 86.18 & 0.65 & 49.70 & 91.8 & 93.4 & 0.32 & 0.00 & 0.02 & 0.00 & 0.04 & 0.02 & 0.57 & 0.00 & 0.00 & 1.35 & 0.00 \\
\hline 2,3-dimethylbutane & I & 6 & 86.18 & 0.66 & 58.00 & 103.5 & 94.3 & 0.51 & 0.00 & 0.05 & 0.00 & 0.04 & 0.02 & 1.73 & 0.00 & 9.98 & 4.63 & 8.60 \\
\hline 2-methylpentane & $\mathrm{I}$ & 6 & 86.18 & 0.65 & 60.30 & 73.4 & 73.5 & 0.09 & 0.00 & 0.01 & 0.00 & 0.00 & 0.01 & 0.22 & 0.00 & 0.01 & 1.33 & 0.00 \\
\hline 2-methylpentene-1 & $\mathrm{O}$ & 6 & 84.16 & 0.68 & 62.10 & 94.2 & 81.5 & 0.00 & 0.00 & 0.09 & 0.00 & 0.02 & 0.09 & $\frac{0.22}{1.34}$ & 0.00 & 0.00 & 5.40 & 0.03 \\
\hline 3-methylpentane & I & 6 & 86.18 & 0.66 & 63.30 & 74.5 & 74.3 & 0.08 & 0.00 & 0.03 & 0.00 & 0.00 & 0.00 & 0.28 & 0.00 & 0.00 & 3.07 & 0.03 \\
\hline 2-methylpentene-2 & $\mathrm{O}$ & 6 & 84.16 & 0.69 & 67.30 & 97.8 & 83.0 & 0.00 & 3.49 & 0.11 & 0.00 & 0.03 & 0.66 & 1.95 & 0.00 & 0.00 & 6.70 & 0.03 \\
\hline 3-methyl-c-pentene-2 & $\mathrm{O}$ & 6 & 84.16 & 0.70 & 67.70 & 97.8 & 83.0 & 0.00 & 13.06 & 0.12 & 0.00 & 0.02 & 0.25 & 5.62 & 0.00 & 0.00 & 0.98 & 0.02 \\
\hline t-hexene-2 & $\mathrm{O}$ & 6 & 84.16 & 0.68 & 67.90 & 92.7 & 80.8 & 0.00 & 0.00 & 0.08 & 0.00 & 0.02 & 1.29 & 1.16 & 0.00 & 0.00 & 4.97 & 0.03 \\
\hline n-hexane & $\mathrm{P}$ & 6 & 86.18 & 0.66 & 68.70 & 24.8 & 26.0 & 0.00 & 6.28 & 0.64 & 5.27 & 0.39 & 60.23 & 29.75 & 39.98 & 0.00 & 1.07 & 27.53 \\
\hline methylcyclopentane & $\mathrm{N}$ & 6 & 84.16 & 0.75 & 71.80 & 91.3 & 80.0 & 0.00 & 0.01 & 0.22 & 0.00 & 0.04 & 1.76 & 0.20 & 0.00 & 0.00 & 0.32 & 1.18 \\
\hline benzene & $\mathrm{A}$ & 6 & 78.11 & 0.88 & 80.10 & 126.1 & 112.0 & 0.00 & 0.00 & 0.01 & 0.20 & 0.65 & 15.53 & 2.01 & 0.00 & 0.00 & 1.92 & 0.00 \\
\hline cyclohexane & $\mathrm{N}$ & 6 & 84.16 & 0.78 & 80.70 & 83.0 & 77.2 & 0.34 & 4.94 & 0.26 & 0.00 & 0.64 & 2.54 & 0.16 & 0.00 & 0.00 & 0.31 & 0.00 \\
\hline dimethyl pentadiene & $\mathrm{O}$ & 7 & 96.19 & 0.69 & 70.00 & 94.3 & 78.9 & 3.72 & 0.16 & 0.09 & 0.00 & 0.00 & 0.28 & 0.09 & 0.00 & 0.00 & 0.38 & 0.02 \\
\hline 3,3-dimethylpentene-1 & $\mathrm{O}$ & 7 & 98.19 & 0.70 & 77.50 & 104.4 & 85.4 & 0.00 & 1.09 & 0.12 & 0.00 & 0.02 & 0.82 & 0.09 & 0.00 & 0.00 & 0.00 & 0.02 \\
\hline 2,2-dimethylpentane & $\mathrm{I}$ & 7 & 100.21 & 0.67 & 79.20 & 92.8 & 95.6 & 0.36 & 0.00 & 0.05 & 0.00 & 0.02 & 0.00 & 0.12 & 0.00 & 0.00 & 0.37 & 0.03 \\
\hline 2,4-dimethylpentane & $\mathrm{I}$ & 7 & 100.21 & 0.67 & 80.50 & 83.1 & 83.8 & 0.11 & 0.00 & 0.04 & 0.00 & 0.00 & 0.01 & 0.11 & 0.00 & 0.00 & 4.12 & 0.03 \\
\hline 2,2,3-trimethylbutane & I & 7 & 100.21 & 0.69 & 80.90 & 112.1 & 101.3 & 29.58 & 0.00 & 0.11 & 0.00 & 0.03 & 0.00 & 0.12 & 0.00 & 0.00 & 0.38 & 0.03 \\
\hline 2-pentene, 2,4-dimethyl- & $\mathrm{O}$ & 7 & 98.19 & 0.70 & 85.30 & 86.4 & 74.0 & 0.00 & 0.02 & 0.08 & 0.00 & 0.00 & 0.52 & 0.09 & 0.00 & 0.00 & 0.31 & 0.02 \\
\hline 2,3-dimethylpentane & $\mathrm{I}$ & 7 & 100.21 & 0.69 & 86.10 & 80.8 & 86.6 & 1.24 & 0.01 & 0.07 & 0.00 & 0.00 & 0.22 & 0.09 & 0.00 & 0.00 & 0.35 & 0.01 \\
\hline $\begin{array}{c}1,1- \\
\text { dimethylcyclopentane }\end{array}$ & $\mathrm{N}$ & 7 & 98.19 & 0.75 & 87.50 & 92.3 & 89.3 & 0.02 & 0.19 & 0.21 & 0.00 & 0.21 & 1.79 & 0.09 & 0.00 & 0.00 & 0.22 & 0.00 \\
\hline 2,3-dimethylpentane & $\mathrm{I}$ & 7 & 100.21 & 0.70 & 89.80 & 91.1 & 88.5 & 1.89 & 0.01 & 0.09 & 0.00 & 0.00 & 0.23 & 0.10 & 0.00 & 0.00 & 0.36 & 0.02 \\
\hline 2-methylhexane & $\mathrm{I}$ & 7 & 100.21 & 0.68 & 90.10 & 42.4 & 46.4 & 0.00 & 0.03 & 0.03 & 11.86 & 0.65 & 2.52 & 0.10 & 0.18 & 0.00 & 0.32 & 0.00 \\
\hline $\begin{array}{c}1 \mathrm{c}, 3- \\
\text { dimethylcyclopentane }\end{array}$ & $\mathrm{N}$ & 7 & 98.19 & 0.74 & 90.80 & 79.2 & 73.1 & 0.00 & 0.94 & 0.14 & 0.00 & 0.60 & 1.68 & 0.08 & 0.00 & 0.00 & 0.23 & 0.00 \\
\hline $\begin{array}{c}1 \mathrm{t}, 3- \\
\text { dimethylcyclopentane }\end{array}$ & $\mathrm{N}$ & 7 & 98.19 & 0.75 & 91.70 & 80.6 & 72.6 & 0.01 & 1.12 & 0.15 & 0.00 & 0.61 & 1.72 & 0.08 & 0.00 & 0.00 & 0.00 & 0.00 \\
\hline 3-methylhexane & $\mathrm{I}$ & 7 & 100.21 & 0.69 & 91.90 & 52.0 & 55.8 & 0.00 & 0.02 & 0.04 & 6.55 & 0.54 & 2.08 & 0.03 & 0.00 & 0.00 & 0.00 & 0.00 \\
\hline $\begin{array}{c}11,2- \\
\text { dimethylcyclopentane }\end{array}$ & $\mathrm{N}$ & 7 & 98.19 & 0.75 & 91.90 & 86.1 & 81.1 & 0.00 & 0.57 & 0.18 & 0.00 & 0.48 & 1.65 & 0.08 & 0.00 & 0.00 & 0.00 & 0.00 \\
\hline 3-ethypentane & $\mathrm{I}$ & 7 & 100.21 & 0.70 & 93.50 & 65.0 & 69.3 & 0.01 & 0.01 & 0.06 & 0.92 & 0.15 & 0.00 & 0.00 & 0.00 & 0.00 & 0.00 & 0.00 \\
\hline 3-methyl-c-hexene-2 & $\mathrm{O}$ & 7 & 98.19 & 0.71 & 95.40 & 91.5 & 79.6 & 0.00 & 0.01 & 0.12 & 0.00 & 0.00 & 0.00 & 0.00 & 0.00 & 0.00 & 0.00 & 0.01 \\
\hline n-heptane & $P$ & 7 & 100.21 & 0.68 & 98.40 & 0.0 & 0.0 & 1.55 & 27.31 & 61.72 & 32.37 & 0.56 & 0.00 & 0.00 & 0.00 & 0.00 & 0.00 & 0.00 \\
\hline methylcyclohexane & $\mathrm{N}$ & 7 & 98.19 & 0.77 & 100.90 & 74.8 & 71.1 & 0.00 & 4.91 & 0.16 & 0.78 & 0.62 & 0.00 & 0.00 & 0.00 & 0.00 & 0.00 & 0.00 \\
\hline ethylcyclopentane & $\mathrm{N}$ & 7 & 88.19 & 0.77 & 103.50 & 67.2 & 61.2 & 0.00 & 4.20 & 0.14 & 25.47 & 0.61 & 0.00 & 0.00 & 0.00 & 0.00 & 0.00 & 0.00 \\
\hline toluene & A & 7 & 92.14 & 0.87 & 110.60 & 115.1 & 101.0 & 0.08 & 0.00 & 0.76 & 0.00 & 10.01 & 0.00 & 0.00 & 0.01 & 0.00 & 0.00 & 0.42 \\
\hline $\begin{array}{c}1,1,3- \\
\text { trimethylcyclopentane }\end{array}$ & $\mathrm{N}$ & 8 & 112.22 & 0.75 & 104.90 & 87.7 & 83.5 & 0.02 & 0.59 & 0.15 & 0.00 & 0.33 & 0.00 & 0.00 & 0.00 & 0.00 & 0.00 & 0.00 \\
\hline 2,5-dimethylhexane & $\mathrm{I}$ & 8 & 114.23 & 0.69 & 109.10 & 55.2 & 55.7 & 0.06 & 0.00 & 0.07 & 4.33 & 0.37 & 0.00 & 0.00 & 0.00 & 0.00 & 0.00 & 0.00 \\
\hline 2,4-dimethylhexane & $\mathrm{I}$ & 8 & 114.23 & 0.70 & 109.40 & 65.2 & 69.9 & 0.23 & 0.00 & 0.09 & 0.29 & 0.02 & 0.00 & 0.00 & 0.00 & 3.10 & 0.00 & 0.43 \\
\hline 2,2,3-trimethylpentane & $\mathrm{I}$ & 8 & 114.23 & 0.72 & 109.90 & 109.6 & 99.9 & 0.19 & 0.01 & 0.25 & 0.00 & 0.00 & 0.00 & 0.00 & 0.00 & 0.00 & 0.00 & 0.44 \\
\hline 3,3-dimethylhexane & $\mathrm{I}$ & 8 & 114.23 & 0.71 & 112.00 & 75.5 & 83.4 & 0.21 & 0.00 & 0.13 & 0.00 & 0.00 & 0.00 & 0.00 & 0.00 & 0.00 & 0.00 & 0.43 \\
\hline 2,3-dimethylhexane & $\mathrm{I}$ & 8 & 114.23 & 0.71 & 115.60 & 71.3 & 78.9 & 0.21 & 0.00 & 0.12 & 0.11 & 0.10 & 0.00 & 0.00 & 0.00 & 0.00 & 0.00 & 0.43 \\
\hline 2-methyl-3-ethylpentane & $\mathrm{I}$ & 8 & 114.23 & 0.71 & 115.60 & 87.3 & 88.1 & 0.20 & 0.00 & 0.17 & 0.00 & 0.00 & 0.00 & 0.00 & 0.00 & 0.00 & 0.00 & 0.43 \\
\hline $\begin{array}{c}1 \mathrm{c}, 2 \mathrm{t}, 4- \\
\text { trimethylcyclopentane }\end{array}$ & $\mathrm{N}$ & 8 & 112.22 & 0.76 & 116.70 & 89.2 & 79.5 & 0.16 & 0.00 & 0.25 & 0.00 & 1.28 & 0.00 & 0.00 & 0.00 & 0.00 & 0.00 & 0.43 \\
\hline 2-methylheptane & $\mathrm{I}$ & 8 & 114.23 & 0.70 & 117.70 & 20.7 & 23.1 & 0.26 & 0.00 & 0.01 & 0.21 & 18.93 & 0.00 & 0.00 & 0.00 & 2.82 & 0.00 & 0.43 \\
\hline 4-methylheptane & $\mathrm{I}$ & 8 & 114.23 & 0.70 & 117.70 & 26.7 & 39.0 & 0.24 & 0.00 & 0.01 & 0.23 & 6.77 & 0.00 & 0.00 & 0.01 & 0.69 & 0.00 & 0.43 \\
\hline 3,4-dimethylhexane & $\mathrm{I}$ & 8 & 114.23 & 0.72 & 117.70 & 76.3 & 81.7 & 0.20 & 0.00 & 0.14 & 0.00 & 0.03 & 0.00 & 0.00 & 0.00 & 0.96 & 0.00 & 0.43 \\
\hline 3-ethylhexane & $\mathrm{I}$ & 8 & 114.23 & 0.71 & 118.50 & 33.5 & 52.4 & 0.23 & 0.00 & 0.01 & 0.15 & 6.33 & 0.00 & 0.00 & 0.00 & 0.00 & 0.00 & 0.43 \\
\hline 3-methylheptane & $\mathrm{I}$ & 8 & 114.23 & 0.71 & 118.90 & 26.8 & 35.0 & 0.24 & 0.00 & 0.01 & 0.23 & 6.84 & 0.00 & 0.00 & 0.00 & 0.46 & 0.00 & 0.43 \\
\hline $\begin{array}{l}\text { 1,3-dimethyl-c- } \\
\text { cyclohexane }\end{array}$ & $\mathrm{N}$ & 8 & 112.22 & 0.76 & 119.40 & 71.7 & 71.0 & 0.16 & 0.00 & 0.15 & 0.55 & 3.99 & 0.00 & 0.00 & 0.00 & 0.00 & 0.00 & 0.43 \\
\hline $\begin{array}{c}1 \mathrm{1}, 4- \\
\text { dimethylcyclohexane }\end{array}$ & $\mathrm{N}$ & 8 & 112.22 & 0.76 & 119.40 & 68.3 & 62.2 & 0.17 & 0.00 & 0.13 & 0.69 & 4.44 & 0.00 & 0.00 & 0.00 & 0.00 & 0.00 & 0.43 \\
\hline $\begin{array}{c}1,1- \\
\text { dimethylcyclohexane }\end{array}$ & $\mathrm{N}$ & 8 & 112.22 & 0.78 & 119.60 & 87.3 & 85.9 & 0.14 & 0.00 & 0.27 & 0.00 & 2.87 & 0.00 & 0.00 & 0.00 & 0.00 & 0.00 & 0.43 \\
\hline 3c-ethylcyclopentane & $\mathrm{N}$ & 8 & 112.22 & 0.77 & 121.10 & 57.6 & 59.8 & 0.17 & 0.00 & 0.08 & 0.90 & 5.15 & 0.00 & 0.00 & 0.00 & 0.00 & 0.00 & 0.43 \\
\hline $\begin{array}{l}3 \mathrm{t} \text {,ethylmethylcyclopent } \\
\text { ane }\end{array}$ & $\mathrm{N}$ & 8 & 112.22 & 0.77 & 121.10 & 57.6 & 59.8 & 0.17 & 0.00 & 0.08 & 0.90 & 5.15 & 0.00 & 0.00 & 0.00 & 0.00 & 0.00 & 0.43 \\
\hline $\begin{array}{l}\text { cyclopentane, 1-ethyl-2- } \\
\text { methyl- }\end{array}$ & $\mathrm{N}$ & 8 & 112.22 & 0.77 & 121.10 & 57.6 & 59.8 & 0.17 & 0.00 & 0.08 & 0.90 & 5.15 & 0.00 & 0.00 & 0.01 & 0.00 & 0.00 & 0.43 \\
\hline $\begin{array}{c}\mathrm{2t}- \\
\mathrm{ethylmethylcyclopentan} \\
\mathrm{e}\end{array}$ & $\mathrm{N}$ & 8 & 112.22 & 0.77 & 121.20 & 57.6 & 59.8 & 0.16 & 0.00 & 0.08 & 0.92 & 5.08 & 0.00 & 0.00 & 0.01 & 0.00 & 0.00 & 0.43 \\
\hline $\begin{array}{c}1 \mathrm{1}, 3- \\
\text { dimethylcyclohexane }\end{array}$ & $\mathrm{N}$ & 8 & 112.22 & 0.78 & 123.40 & 67.2 & 68.2 & 0.16 & 0.00 & 0.14 & 0.86 & 4.79 & 0.00 & 0.00 & 0.01 & 0.00 & 0.00 & 0.43 \\
\hline $\begin{array}{c}1 \mathrm{c}, 4- \\
\text { dimethylcyclohexane }\end{array}$ & $\mathrm{N}$ & 8 & 112.22 & 0.78 & 124.30 & 67.2 & 68.2 & 0.15 & 0.00 & 0.14 & 0.92 & 4.63 & 0.00 & 0.00 & 0.02 & 0.00 & 0.00 & 0.43 \\
\hline n-octane & $\mathrm{P}$ & 8 & 114.23 & 0.70 & 125.70 & -18.3 & -14.3 & 0.28 & 0.00 & 0.01 & 0.14 & 0.00 & 0.00 & 0.00 & 0.36 & 0.00 & 0.00 & 0.43 \\
\hline
\end{tabular}

Page 15 of 27 


\begin{tabular}{|c|c|c|c|c|c|c|c|c|c|c|c|c|c|c|c|c|c|c|}
\hline ethylcyclohexane & $\mathrm{N}$ & 8 & 112.22 & 0.78 & 131.80 & 45.6 & 40.8 & 0.16 & 0.00 & 0.01 & 0.93 & 0.00 & 0.00 & 0.00 & 0.01 & 0.00 & 0.00 & 0.43 \\
\hline ethylbenzene & $\mathrm{A}$ & 8 & 106.17 & 0.87 & 136.20 & 107.4 & 97.9 & 0.05 & 0.00 & 0.47 & 0.00 & 0.00 & 0.00 & 0.00 & 0.00 & 0.00 & 0.00 & 0.42 \\
\hline p-xylene & $\mathrm{A}$ & 8 & 106.17 & 0.86 & 138.40 & 116.4 & 109.6 & 0.05 & 0.00 & 0.57 & 0.00 & 0.00 & 0.00 & 0.00 & 0.01 & 0.00 & 0.00 & 0.42 \\
\hline m-xylene & A & 8 & 106.17 & 0.86 & 139.10 & 117.5 & 115.1 & 0.05 & 0.00 & 0.60 & 0.00 & 0.00 & 0.00 & 0.00 & 0.00 & 0.00 & 0.00 & 0.42 \\
\hline o-xylene & $\mathrm{A}$ & 8 & 106.17 & 0.88 & 144.40 & 95.2 & 92.7 & 0.05 & 0.00 & 3.17 & 0.00 & 0.00 & 0.00 & 0.00 & 0.00 & 0.00 & 0.00 & 0.42 \\
\hline 2,4-dimethylheptane & $\mathrm{I}$ & 9 & 128.26 & 0.71 & 132.70 & 50.3 & 60.5 & 0.22 & 0.00 & 0.05 & 0.00 & 0.00 & 0.00 & 0.00 & 0.01 & 0.00 & 0.00 & 0.43 \\
\hline 2,2,3-trimethylhexane & $\mathrm{I}$ & 9 & 128.26 & 0.72 & 132.90 & 90.5 & 87.1 & 0.20 & 0.00 & 0.16 & 0.00 & 0.00 & 0.00 & 0.00 & 0.00 & 0.60 & 0.00 & 0.43 \\
\hline 2,5-dimethylheptane & $\mathrm{I}$ & 9 & 128.26 & 0.72 & 132.90 & 37.3 & 46.0 & 0.22 & 0.00 & 0.01 & 0.00 & 0.00 & 0.00 & 0.00 & 0.00 & 0.00 & 0.00 & 0.43 \\
\hline $\begin{array}{c}\text { trans-1,2- } \\
\text { diethylcyclopentane }\end{array}$ & $\mathrm{N}$ & 9 & 126.24 & 0.77 & 135.00 & 72.9 & 74.3 & 0.16 & 0.00 & 0.14 & 0.00 & 0.00 & 0.00 & 0.00 & 0.00 & 0.07 & 0.00 & 0.43 \\
\hline 2,6-dimethylheptane & I & 9 & 128.26 & 0.71 & 135.20 & 47.3 & 56.0 & 0.23 & 0.00 & 0.04 & 0.00 & 0.00 & 0.00 & 0.00 & 0.00 & 0.00 & 0.00 & 0.43 \\
\hline $\begin{array}{l}\text { cyclopentane, } 1,1,3,4- \\
\text { tetramethyl- }\end{array}$ & $\mathrm{N}$ & 9 & 126.24 & 0.77 & 138.40 & 87.7 & 83.5 & 0.15 & 0.00 & 0.21 & 0.00 & 0.00 & 0.00 & 0.00 & 0.00 & 0.57 & 0.00 & 0.43 \\
\hline 3,4-dimethylheptane & I & 9 & 128.26 & 0.73 & 140.60 & 61.5 & 74.9 & 0.20 & 0.00 & 0.08 & 0.00 & 0.00 & 0.00 & 0.00 & 0.00 & 0.00 & 0.00 & 0.43 \\
\hline 4-ethylheptane & $\mathrm{I}$ & 9 & 128.26 & 0.72 & 142.40 & 2.0 & 35.5 & 0.23 & 0.00 & 0.01 & 0.00 & 0.00 & 0.00 & 0.00 & 0.00 & 0.22 & 0.00 & 0.43 \\
\hline 4-methyloctane & $\mathrm{I}$ & 9 & 128.53 & 0.72 & 142.40 & 1.5 & 18.2 & 0.23 & 0.00 & 0.01 & 0.00 & 0.00 & 0.00 & 0.00 & 0.00 & 0.00 & 0.00 & 0.43 \\
\hline $\begin{array}{c}1 \mathrm{c}, 2 \mathrm{t}, 4 \mathrm{t}- \\
\text { trimethylcyclohexane }\end{array}$ & $\mathrm{N}$ & 9 & 126.24 & 0.78 & 143.00 & 72.9 & 74.3 & 0.15 & 0.00 & 0.15 & 0.00 & 0.00 & 0.00 & 0.00 & 0.00 & 0.00 & 0.00 & 0.43 \\
\hline 2-methyloctane & $\mathrm{I}$ & 9 & 128.26 & 0.71 & 143.30 & -1.0 & -0.2 & 0.24 & 0.00 & 0.01 & 0.00 & 0.00 & 0.00 & 0.00 & 0.00 & 0.00 & 0.00 & 0.43 \\
\hline 3-heptene, 4-ethyl- & $\mathrm{O}$ & 9 & 126.24 & 0.78 & 146.60 & 94.4 & 80.4 & 0.14 & 0.00 & 0.03 & 0.00 & 0.00 & 0.00 & 0.00 & 0.00 & 0.00 & 0.00 & 0.43 \\
\hline propylcyclohexane & $\mathrm{N}$ & 9 & 126.24 & 0.80 & 154.80 & 17.8 & 14.0 & 0.15 & 0.00 & 0.03 & 0.00 & 0.00 & 0.00 & 0.00 & 0.00 & 0.00 & 0.00 & 0.42 \\
\hline $\begin{array}{c}\text { 1-methyl-2- } \\
\text { propylcyclopentane }\end{array}$ & $\mathrm{N}$ & 9 & 126.24 & 0.80 & 154.80 & 62.8 & 61.1 & 0.14 & 0.00 & 0.10 & 0.00 & 0.00 & 0.00 & 0.00 & 0.01 & 0.00 & 0.00 & 0.43 \\
\hline n-propylbenzene & $\mathrm{A}$ & 9 & 120.20 & 0.86 & 159.20 & 111.0 & 98.7 & 0.05 & 0.00 & 0.37 & 0.00 & 0.00 & 0.00 & 0.00 & 0.00 & 0.00 & 0.00 & 0.42 \\
\hline $\begin{array}{l}\text { 1-methyl-3- } \\
\text { ethylbenzene }\end{array}$ & A & 9 & 120.20 & 0.86 & 161.30 & 112.1 & 100.0 & 0.05 & 0.00 & 0.39 & 0.00 & 0.00 & 0.00 & 0.00 & 0.00 & 0.00 & 0.00 & 0.42 \\
\hline $\begin{array}{l}\text { 1-methyl-4- } \\
\text { ethylbenzene }\end{array}$ & A & 9 & 120.20 & 0.86 & 162.00 & 111.1 & 97.0 & 14.13 & 0.00 & 0.37 & 0.00 & 0.00 & 0.00 & 0.00 & 0.00 & 0.00 & 0.00 & 0.42 \\
\hline 1,3,5-trimethylbenzene & $\mathrm{A}$ & 9 & 120.20 & 0.87 & 164.70 & 121.0 & 120.3 & 0.53 & 0.78 & 0.47 & 0.00 & 0.00 & 0.00 & 0.00 & 0.01 & 0.30 & 0.00 & 0.00 \\
\hline $\begin{array}{c}\text { 1-methyl-2- } \\
\text { ethylbenzene }\end{array}$ & A & 9 & 120.20 & 0.88 & 165.20 & 102.5 & 92.1 & 0.48 & 0.69 & 0.29 & 0.00 & 0.00 & 0.00 & 0.00 & 0.01 & 0.30 & 0.00 & 0.00 \\
\hline 1,2,4-trimethylbenzene & $\mathrm{A}$ & 9 & 120.20 & 0.88 & 169.40 & 110.5 & 106.0 & 0.50 & 0.73 & 0.38 & 0.00 & 0.00 & 0.00 & 0.00 & 0.01 & 0.00 & 0.00 & 0.00 \\
\hline 1,2,3-trimethylbenzene & A & 9 & 120.20 & 0.89 & 176.10 & 105.3 & 100.8 & 0.47 & 0.67 & 0.37 & 0.00 & 0.00 & 0.00 & 0.00 & 0.01 & 0.24 & 0.00 & 0.00 \\
\hline Indan & A & 9 & 118.18 & 0.96 & 177.90 & 113.7 & 106.8 & 0.39 & 0.56 & 6.80 & 0.00 & 0.00 & 0.00 & 0.00 & 0.31 & 0.00 & 0.00 & 0.00 \\
\hline heptane, 2,4,6-trimethyl- & I & 10 & 142.29 & 1.00 & 156.90 & 77.2 & 77.5 & 0.04 & 0.17 & 0.81 & 0.00 & 0.00 & 0.00 & 0.00 & 0.00 & 0.00 & 0.00 & 0.41 \\
\hline 2,3,6-trimethylheptane & I & 10 & 142.29 & 1.00 & 156.90 & 77.2 & 77.5 & 0.04 & 1.20 & 3.71 & 0.00 & 0.00 & 0.00 & 0.00 & 0.00 & 0.00 & 0.00 & 0.38 \\
\hline 2,7-dimethyloctane & I & 10 & 142.29 & 0.73 & 158.50 & 14.0 & 33.0 & 0.21 & 0.00 & 0.01 & 0.00 & 0.00 & 0.00 & 0.00 & 0.00 & 0.00 & 0.00 & 0.43 \\
\hline heptane, 2,5,5-trimethyl- & I & 10 & 142.29 & 0.73 & 160.40 & 14.0 & 33.0 & 0.22 & 0.00 & 0.01 & 0.00 & 0.00 & 0.00 & 0.00 & 0.00 & 0.00 & 0.00 & 0.43 \\
\hline 2,3-dimethyloctane(1) & $\mathrm{I}$ & 10 & 142.29 & 0.74 & 164.30 & 31.7 & 59.7 & 4.53 & 1.30 & 0.00 & 0.00 & 0.00 & 0.00 & 0.00 & 0.05 & 0.42 & 0.00 & 0.00 \\
\hline 4-methylnonane & I & 10 & 142.29 & 0.73 & 165.10 & -23.7 & -2.6 & 4.28 & 3.41 & 0.00 & 0.00 & 0.00 & 0.00 & 0.00 & 0.06 & 1.62 & 0.00 & 0.00 \\
\hline $\begin{array}{c}\text { 1-methyl-3-i- } \\
\text { propylbenzene }\end{array}$ & A & 10 & 134.22 & 0.86 & 175.10 & 110.5 & 97.7 & 0.52 & 0.74 & 0.24 & 0.00 & 0.00 & 0.00 & 0.00 & 0.02 & 0.00 & 0.00 & 0.00 \\
\hline $\begin{array}{l}\text { 1-methyl-4-i- } \\
\text { propylbenzene }\end{array}$ & A & 10 & 134.22 & 0.86 & 177.10 & 110.5 & 97.7 & 0.52 & 0.75 & 0.24 & 0.00 & 0.00 & 0.00 & 0.00 & 0.02 & 0.00 & 0.00 & 0.00 \\
\hline 2-methylindan & A & 10 & 132.10 & 0.96 & 177.90 & 113.7 & 106.8 & 0.39 & 0.54 & 0.89 & 0.00 & 0.00 & 0.00 & 0.00 & 0.38 & 0.05 & 0.00 & 0.00 \\
\hline 1,3-diethylbenzene & $\mathrm{A}$ & 10 & 134.22 & 0.86 & 181.10 & 115.5 & 97.0 & 0.52 & 0.75 & 0.30 & 0.00 & 0.00 & 0.00 & 0.00 & 0.00 & 0.00 & 0.00 & 0.00 \\
\hline $\begin{array}{l}\text { 1-methyl-3-n- } \\
\text { propylbenzene }\end{array}$ & A & 10 & 134.22 & 0.86 & 182.00 & 111.9 & 100.6 & 0.52 & 0.75 & 0.26 & 0.00 & 0.00 & 0.00 & 0.00 & 0.00 & 0.00 & 0.00 & 0.00 \\
\hline n-butylbenzene & $\mathrm{A}$ & 10 & 134.22 & 0.86 & 183.30 & 104.4 & 94.5 & 0.51 & 0.73 & 0.18 & 0.00 & 0.00 & 0.00 & 0.00 & 0.02 & 0.44 & 0.00 & 0.00 \\
\hline $\begin{array}{l}\text { 1-methyl-4-n- } \\
\text { propylbenzene }\end{array}$ & A & 10 & 134.22 & 0.86 & 183.40 & 110.9 & 97.6 & 0.52 & 0.75 & 0.24 & 0.00 & 0.00 & 0.00 & 0.00 & 0.02 & 0.00 & 0.00 & 0.00 \\
\hline 1,2-diethylbenzene & $\mathrm{A}$ & 10 & 134.22 & 0.88 & 183.50 & 104.2 & 89.3 & 0.48 & 0.69 & 0.21 & 0.00 & 0.00 & 0.00 & 0.00 & 0.00 & 0.30 & 0.00 & 0.00 \\
\hline $\begin{array}{c}\text { 1,3-didmethyl-5- } \\
\text { ethylbenzene }\end{array}$ & A & 10 & 134.22 & 0.88 & 183.60 & 114.8 & 102.5 & 0.49 & 0.71 & 0.34 & 0.00 & 0.00 & 0.00 & 0.00 & 0.01 & 0.00 & 0.00 & 0.00 \\
\hline 1,4-diethylbenzene & $\mathrm{A}$ & 10 & 134.22 & 0.86 & 183.80 & 115.5 & 97.0 & 0.52 & 0.75 & 0.30 & 0.00 & 0.00 & 0.00 & 0.00 & 0.00 & 0.00 & 0.00 & 0.00 \\
\hline $\begin{array}{c}\text { 1-methyl-2-n- } \\
\text { propylbenzene }\end{array}$ & A & 10 & 134.22 & 0.87 & 185.00 & 103.5 & 92.2 & 0.49 & 0.70 & 0.19 & 0.00 & 0.00 & 0.00 & 0.00 & 0.00 & 0.33 & 0.00 & 0.00 \\
\hline $\begin{array}{l}\text { 1,4,dimethyl-2- } \\
\text { ethylbenzene }\end{array}$ & $\mathrm{A}$ & 10 & 134.22 & 0.88 & 186.90 & 106.0 & 96.0 & 0.49 & 0.70 & 0.23 & 0.00 & 0.00 & 0.00 & 0.00 & 0.00 & 0.31 & 0.00 & 0.00 \\
\hline $\begin{array}{l}\text { 1,3-dimethyl-4- } \\
\text { ethylbenzene }\end{array}$ & $\mathrm{A}$ & 10 & 134.22 & 0.88 & 186.90 & 106.0 & 95.9 & 0.49 & 0.70 & 0.23 & 0.00 & 0.00 & 0.00 & 0.00 & 0.01 & 0.31 & 0.00 & 0.00 \\
\hline $\begin{array}{l}\text { 1,2-dimethyl-4- } \\
\text { ethylbenzene }\end{array}$ & $\mathrm{A}$ & 10 & 134.22 & 0.87 & 189.50 & 109.6 & 97.1 & 0.50 & 0.71 & 0.26 & 0.00 & 0.00 & 0.00 & 0.00 & 0.01 & 0.32 & 0.00 & 0.00 \\
\hline $\begin{array}{l}\text { 1,3-dimethyl-2- } \\
\text { ethylbenzene }\end{array}$ & $\mathrm{A}$ & 10 & 134.22 & 0.89 & 190.10 & 104.4 & 91.9 & 0.47 & 0.66 & 0.23 & 0.00 & 0.00 & 0.00 & 0.00 & 0.01 & 0.18 & 0.00 & 0.00 \\
\hline $\begin{array}{l}\text { 1,2-dimethyl-3- } \\
\text { ethylbenzene }\end{array}$ & $\mathrm{A}$ & 10 & 134.22 & 0.89 & 194.00 & 104.4 & 91.9 & 0.47 & 0.66 & 0.23 & 0.00 & 0.00 & 0.00 & 0.00 & 0.01 & 0.00 & 0.00 & 0.00 \\
\hline 2-methylindan(1) & $\mathrm{A}$ & 10 & 132.22 & 0.89 & 207.00 & 128.5 & 114.8 & 0.49 & 0.73 & 0.58 & 0.00 & 0.00 & 0.00 & 0.00 & 0.01 & 0.24 & 0.00 & 0.00 \\
\hline Napthalene & $\mathrm{A}$ & 10 & 128.17 & 1.03 & 218.00 & 74.4 & 65.7 & 0.30 & 0.37 & 0.82 & 0.00 & 0.00 & 0.00 & 0.00 & 0.38 & 0.00 & 0.00 & 0.00 \\
\hline $\begin{array}{c}\text { 1,4-diethyl-2- } \\
\text { methylbenzene }\end{array}$ & A & 11 & 148.24 & 0.89 & 190.00 & 104.5 & 92.3 & 0.47 & 0.65 & 0.14 & 0.00 & 0.00 & 0.00 & 0.00 & 0.01 & 0.00 & 0.00 & 0.00 \\
\hline $\begin{array}{c}\text { benzene, }(1,1- \\
\text { dimethylpropyl)- }\end{array}$ & A & 11 & 148.24 & 0.89 & 190.00 & 104.5 & 92.3 & 0.47 & 0.65 & 0.14 & 0.00 & 0.00 & 0.00 & 0.00 & 0.01 & 0.00 & 0.00 & 0.00 \\
\hline $\begin{array}{c}\text { 1-ethyl-2-i- } \\
\text { propylbenzene }\end{array}$ & A & 11 & 148.24 & 0.89 & 194.00 & 107.9 & 96.1 & 0.47 & 0.66 & 0.19 & 0.00 & 0.00 & 0.00 & 0.00 & 0.01 & 0.26 & 0.00 & 0.00 \\
\hline $\begin{array}{c}\text { 1-ethyl-4-i- } \\
\text { propylbenzene }\end{array}$ & A & 11 & 148.24 & 0.89 & 197.00 & 107.9 & 96.1 & 0.47 & 0.66 & 0.19 & 0.00 & 0.00 & 0.00 & 0.00 & 0.01 & 0.26 & 0.00 & 0.00 \\
\hline $\begin{array}{l}\text { 1-methyl-1-n- } \\
\text { butylbenzene }\end{array}$ & A & 11 & 148.24 & 0.89 & 199.00 & 103.5 & 92.1 & 0.46 & 0.65 & 0.13 & 0.00 & 0.00 & 0.00 & 0.00 & 0.01 & 0.00 & 0.00 & 0.00 \\
\hline 2-methylnapthalene & $\mathrm{A}$ & 11 & 143.17 & 1.02 & 241.10 & 74.4 & 85.7 & 0.00 & 0.00 & 0.00 & 0.00 & 0.00 & 0.00 & 0.00 & 0.00 & 0.00 & 0.00 & 0.00 \\
\hline
\end{tabular}

Page 16 of 27 


\begin{tabular}{|c|c|c|c|c|c|c|c|}
\hline $\mathrm{T}(\mathrm{K})$ & Vis. $\left(\mathrm{N} . \mathrm{s} / \mathrm{m}^{2}\right)$ & Sur. Tens. (N/m) & Heat of Vap. $(\mathrm{J} / \mathrm{kg})$ & Vap. Pres. (pa) & Therm. Cond. (W/m.K) & Density $\left(\mathrm{kg} / \mathrm{m}^{3}\right)$ & Heat Capacity (J/kg.K) \\
\hline & \multicolumn{7}{|c|}{ G1 } \\
\hline 270 & $9.43 \mathrm{E}-04$ & $2.46 \mathrm{E}-02$ & $5.01 \mathrm{E}+05$ & 11126.26234 & $1.31 \mathrm{E}-01$ & 774.9068727 & 1806.533439 \\
\hline 280 & $8.08 \mathrm{E}-04$ & $2.36 \mathrm{E}-02$ & $4.99 \mathrm{E}+05$ & 16015.26006 & $1.29 \mathrm{E}-01$ & 766.6030175 & 1851.241825 \\
\hline 290 & 7.00E-04 & $2.26 \mathrm{E}-02$ & $4.95 \mathrm{E}+05$ & 22486.67503 & $1.26 \mathrm{E}-01$ & 758.2112052 & 1896.102399 \\
\hline 300 & $6.12 \mathrm{E}-04$ & $2.16 \mathrm{E}-02$ & $4.92 \mathrm{E}+05$ & 30883.29071 & $1.23 \mathrm{E}-01$ & 749.7250641 & 1941.123582 \\
\hline 310 & $5.40 \mathrm{E}-04$ & $2.06 \mathrm{E}-02$ & $4.88 \mathrm{E}+05$ & 41589.92627 & $1.21 \mathrm{E}-01$ & 741.1375411 & 1986.323684 \\
\hline 320 & $4.79 \mathrm{E}-04$ & $1.97 \mathrm{E}-02$ & $4.84 \mathrm{E}+05$ & 55027.86692 & $1.18 \mathrm{E}-01$ & 732.4415031 & 2031.726036 \\
\hline 330 & $4.28 \mathrm{E}-04$ & $1.87 \mathrm{E}-02$ & $4.80 \mathrm{E}+05$ & 71667.69541 & $1.16 \mathrm{E}-01$ & 723.6283651 & 2077.368505 \\
\hline 340 & $3.85 \mathrm{E}-04$ & $1.78 \mathrm{E}-02$ & $4.75 \mathrm{E}+05$ & 92020.71423 & $1.13 \mathrm{E}-01$ & 714.6885298 & 2123.29708 \\
\hline 350 & $3.47 \mathrm{E}-04$ & $1.68 \mathrm{E}-02$ & $4.70 \mathrm{E}+05$ & 116635.4507 & $1.10 \mathrm{E}-01$ & 705.6114554 & 2169.567267 \\
\hline 360 & $3.14 \mathrm{E}-04$ & $1.59 \mathrm{E}-02$ & $4.64 \mathrm{E}+05$ & 146100.4287 & $1.08 \mathrm{E}-01$ & 696.385321 & 2216.248369 \\
\hline 370 & $2.86 \mathrm{E}-04$ & $1.50 \mathrm{E}-02$ & $4.58 \mathrm{E}+05$ & 181035.9202 & $1.05 \mathrm{E}-01$ & 686.9968106 & 2263.423763 \\
\hline 380 & $2.61 \mathrm{E}-04$ & $1.41 \mathrm{E}-02$ & $4.51 \mathrm{E}+05$ & 222106.692 & $1.02 \mathrm{E}-01$ & 677.4308462 & 2311.198973 \\
\hline 390 & $2.38 \mathrm{E}-04$ & $1.32 \mathrm{E}-02$ & $4.44 \mathrm{E}+05$ & 269985.1064 & $9.86 \mathrm{E}-02$ & 667.6702588 & 2359.695977 \\
\hline 400 & $2.18 \mathrm{E}-04$ & $1.24 \mathrm{E}-02$ & $4.37 \mathrm{E}+05$ & 325389.2106 & $9.48 \mathrm{E}-02$ & 657.695375 & 2409.070822 \\
\hline 410 & $1.98 \mathrm{E}-04$ & $1.15 \mathrm{E}-02$ & $4.29 \mathrm{E}+05$ & 389041.3144 & $8.49 \mathrm{E}-02$ & 647.4834938 & 2459.510764 \\
\hline 420 & $1.83 \mathrm{E}-04$ & $1.07 \mathrm{E}-02$ & $4.20 \mathrm{E}+05$ & 461677.485 & $8.25 \mathrm{E}-02$ & 637.0082147 & 2511.248201 \\
\hline 430 & $1.70 \mathrm{E}-04$ & $9.94 \mathrm{E}-03$ & $4.11 \mathrm{E}+05$ & 544032.7235 & $8.00 \mathrm{E}-02$ & 626.2385627 & 2564.571826 \\
\hline 440 & $1.58 \mathrm{E}-04$ & $9.17 \mathrm{E}-03$ & $4.01 \mathrm{E}+05$ & 636837.7944 & $7.73 \mathrm{E}-02$ & 615.1378302 & 2619.84567 \\
\hline 450 & $1.47 \mathrm{E}-04$ & $8.41 \mathrm{E}-03$ & $3.90 \mathrm{E}+05$ & 740804.7033 & $7.45 \mathrm{E}-02$ & 603.6620144 & 2677.533103 \\
\hline 460 & $1.36 \mathrm{E}-04$ & $7.67 \mathrm{E}-03$ & $3.79 \mathrm{E}+05$ & 856616.9652 & $7.12 \mathrm{E}-02$ & 591.7576669 & 2738.233151 \\
\hline 470 & $1.26 \mathrm{E}-04$ & $6.94 \mathrm{E}-03$ & $3.66 \mathrm{E}+05$ & 984906.2472 & $6.78 \mathrm{E}-02$ & 579.3588579 & 2802.73108 \\
\hline 480 & $1.16 \mathrm{E}-04$ & $6.24 \mathrm{E}-03$ & $3.52 \mathrm{E}+05$ & 1126247.183 & $6.43 \mathrm{E}-02$ & 566.3827699 & 2872.08023 \\
\hline 490 & $1.07 \mathrm{E}-04$ & $5.57 \mathrm{E}-03$ & $3.37 \mathrm{E}+05$ & 1281114.317 & $5.75 \mathrm{E}-02$ & 552.7230827 & 2947.720072 \\
\hline \multirow[t]{2}{*}{500} & $9.90 \mathrm{E}-05$ & $4.94 \mathrm{E}-03$ & $3.21 \mathrm{E}+05$ & 1449868.681 & $5.38 \mathrm{E}-02$ & 538.2396341 & 3031.677041 \\
\hline & \multicolumn{7}{|c|}{ G2 } \\
\hline 270 & $7.76 \mathrm{E}-04$ & $2.50 \mathrm{E}-02$ & $4.50 \mathrm{E}+05$ & 2433.044318 & $1.33 \mathrm{E}-01$ & 767.5506748 & 1793.37718 \\
\hline 280 & $6.72 \mathrm{E}-04$ & $2.39 \mathrm{E}-02$ & $4.48 \mathrm{E}+05$ & 4111.491295 & $1.30 \mathrm{E}-01$ & 759.1640759 & 1841.857007 \\
\hline 290 & $5.88 \mathrm{E}-04$ & $2.29 \mathrm{E}-02$ & $4.45 \mathrm{E}+05$ & 6673.664059 & $1.28 \mathrm{E}-01$ & 750.684873 & 1890.441926 \\
\hline 300 & $5.19 \mathrm{E}-04$ & $2.19 \mathrm{E}-02$ & $4.43 \mathrm{E}+05$ & 10449.78163 & $1.25 \mathrm{E}-01$ & 742.1062622 & 1939.160142 \\
\hline 310 & $4.61 \mathrm{E}-04$ & $2.09 \mathrm{E}-02$ & $4.40 \mathrm{E}+05$ & 15841.7104 & $1.23 \mathrm{E}-01$ & 733.4207211 & 1988.036822 \\
\hline 320 & $4.12 \mathrm{E}-04$ & $1.99 \mathrm{E}-02$ & $4.36 \mathrm{E}+05$ & 23326.51662 & $1.20 \mathrm{E}-01$ & 724.6199044 & 2037.111332 \\
\hline 330 & 3.70E-04 & $1.89 \mathrm{E}-02$ & $4.33 \mathrm{E}+05$ & 33456.9376 & $1.18 \mathrm{E}-01$ & 715.6945198 & 2086.434247 \\
\hline 340 & $3.35 \mathrm{E}-04$ & $1.79 \mathrm{E}-02$ & $4.29 \mathrm{E}+05$ & 46860.11201 & $1.15 \mathrm{E}-01$ & 706.6341787 & 2136.068719 \\
\hline 350 & $3.04 \mathrm{E}-04$ & $1.70 \mathrm{E}-02$ & $4.25 \mathrm{E}+05$ & 64234.69484 & $1.13 \mathrm{E}-01$ & 697.4272182 & 2186.092558 \\
\hline 360 & $2.76 \mathrm{E}-04$ & $1.60 \mathrm{E}-02$ & $4.20 \mathrm{E}+05$ & 86346.63764 & $1.10 \mathrm{E}-01$ & 688.0604842 & 2236.600916 \\
\hline 370 & $2.53 \mathrm{E}-04$ & $1.51 \mathrm{E}-02$ & $4.15 \mathrm{E}+05$ & 114023.9675 & $1.07 \mathrm{E}-01$ & 678.5190649 & 2287.709849 \\
\hline 380 & $2.31 \mathrm{E}-04$ & $1.41 \mathrm{E}-02$ & $4.10 \mathrm{E}+05$ & 148154.3828 & $1.05 \mathrm{E}-01$ & 668.7875765 & 2339.565888 \\
\hline 390 & $2.13 \mathrm{E}-04$ & $1.32 \mathrm{E}-02$ & $4.04 \mathrm{E}+05$ & 189665.7021 & $1.02 \mathrm{E}-01$ & 658.8461054 & 2392.333309 \\
\hline 400 & $1.96 \mathrm{E}-04$ & $1.23 \mathrm{E}-02$ & $3.98 \mathrm{E}+05$ & 239540.3782 & $9.89 \mathrm{E}-02$ & 648.6724707 & 2446.233309 \\
\hline 410 & $1.80 \mathrm{E}-04$ & $1.14 \mathrm{E}-02$ & $3.91 \mathrm{E}+05$ & 298786.2394 & $9.60 \mathrm{E}-02$ & 638.2410291 & 2501.525832 \\
\hline 420 & $1.67 \mathrm{E}-04$ & $1.05 \mathrm{E}-02$ & $3.83 \mathrm{E}+05$ & 368447.0028 & $9.30 \mathrm{E}-02$ & 627.5217478 & 2558.546355 \\
\hline 430 & $1.54 \mathrm{E}-04$ & $9.66 \mathrm{E}-03$ & $3.75 \mathrm{E}+05$ & 449586.0138 & $8.99 \mathrm{E}-02$ & 616.4791093 & 2617.71776 \\
\hline 440 & $1.43 \mathrm{E}-04$ & $8.81 \mathrm{E}-03$ & $3.66 \mathrm{E}+05$ & 543275.879 & $8.67 \mathrm{E}-02$ & 605.0706386 & 2679.581188 \\
\hline 450 & $1.32 \mathrm{E}-04$ & $7.98 \mathrm{E}-03$ & $3.56 \mathrm{E}+05$ & 650594.256 & $8.32 \mathrm{E}-02$ & 593.2448849 & 2744.846028 \\
\hline 460 & $1.23 \mathrm{E}-04$ & $7.17 \mathrm{E}-03$ & $3.45 \mathrm{E}+05$ & 772608.7673 & $7.96 \mathrm{E}-02$ & 580.9385878 & 2814.455472 \\
\hline 470 & $1.14 \mathrm{E}-04$ & $6.37 \mathrm{E}-03$ & $3.33 \mathrm{E}+05$ & 910364.3933 & $7.57 \mathrm{E}-02$ & 568.0725879 & 2889.693086 \\
\hline 480 & $1.06 \mathrm{E}-04$ & $5.60 \mathrm{E}-03$ & $3.20 \mathrm{E}+05$ & 1064857.788 & $7.14 \mathrm{E}-02$ & 554.5457324 & 2972.346328 \\
\hline 490 & $9.88 \mathrm{E}-05$ & $4.86 \mathrm{E}-03$ & $3.05 \mathrm{E}+05$ & 1237011.05 & $6.64 \mathrm{E}-02$ & 540.2254296 & 3064.98407 \\
\hline \multirow[t]{2}{*}{500} & $9.04 \mathrm{E}-05$ & $4.15 \mathrm{E}-03$ & $2.89 \mathrm{E}+05$ & 1427639.607 & $6.05 \mathrm{E}-02$ & 524.932302 & 3171.441666 \\
\hline & \multicolumn{7}{|c|}{ G3 } \\
\hline 270 & 7.37E-04 & $2.52 \mathrm{E}-02$ & $4.89 \mathrm{E}+05$ & 8184.740335 & $1.34 \mathrm{E}-01$ & 754.4964431 & 1843.456899 \\
\hline 280 & $6.43 \mathrm{E}-04$ & $2.42 \mathrm{E}-02$ & $4.84 \mathrm{E}+05$ & 11589.66708 & $1.31 \mathrm{E}-01$ & 746.1871014 & 1891.022831 \\
\hline 290 & $5.66 \mathrm{E}-04$ & $2.32 \mathrm{E}-02$ & $4.78 \mathrm{E}+05$ & 16114.58374 & $1.28 \mathrm{E}-01$ & 737.7858345 & 1938.675564 \\
\hline 300 & $5.02 \mathrm{E}-04$ & $2.21 \mathrm{E}-02$ & $4.72 \mathrm{E}+05$ & 22052.03375 & $1.26 \mathrm{E}-01$ & 729.2857984 & 1986.438167 \\
\hline 310 & $4.48 \mathrm{E}-04$ & $2.11 \mathrm{E}-02$ & $4.65 \mathrm{E}+05$ & 29746.18344 & $1.23 \mathrm{E}-01$ & 720.6796782 & 2034.340583 \\
\hline 320 & $4.02 \mathrm{E}-04$ & $2.01 \mathrm{E}-02$ & $4.59 \mathrm{E}+05$ & 39602.03575 & $1.21 \mathrm{E}-01$ & 711.9592739 & 2082.423899 \\
\hline 330 & 3.63E-04 & $1.91 \mathrm{E}-02$ & $4.52 \mathrm{E}+05$ & 52082.56597 & $1.18 \mathrm{E}-01$ & 703.1151917 & 2130.739045 \\
\hline 340 & $3.30 \mathrm{E}-04$ & $1.82 \mathrm{E}-02$ & $4.46 \mathrm{E}+05$ & 67724.9083 & $1.15 \mathrm{E}-01$ & 694.1371108 & 2179.353392 \\
\hline 350 & $3.00 \mathrm{E}-04$ & $1.72 \mathrm{E}-02$ & $4.39 \mathrm{E}+05$ & 87121.73197 & $1.13 \mathrm{E}-01$ & 685.0134583 & 2228.346282 \\
\hline 360 & $2.74 \mathrm{E}-04$ & $1.62 \mathrm{E}-02$ & $4.31 \mathrm{E}+05$ & 110934.3272 & $1.10 \mathrm{E}-01$ & 675.7311967 & 2277.816578 \\
\hline 370 & $2.51 \mathrm{E}-04$ & $1.53 \mathrm{E}-02$ & $4.24 \mathrm{E}+05$ & 139895.6625 & $1.07 \mathrm{E}-01$ & 666.2755638 & 2327.886922 \\
\hline 380 & $2.31 \mathrm{E}-04$ & $1.44 \mathrm{E}-02$ & $4.16 \mathrm{E}+05$ & 174772.3589 & $1.04 \mathrm{E}-01$ & 656.629751 & 2378.700881 \\
\hline 390 & $2.13 \mathrm{E}-04$ & $1.34 \mathrm{E}-02$ & $4.08 \mathrm{E}+05$ & 216408.0296 & $1.02 \mathrm{E}-01$ & 646.7744994 & 2430.440388 \\
\hline 400 & $1.97 \mathrm{E}-04$ & $1.25 \mathrm{E}-02$ & $3.99 \mathrm{E}+05$ & 265695.8897 & $9.87 \mathrm{E}-02$ & 636.6875892 & 2483.32908 \\
\hline 410 & $1.82 \mathrm{E}-04$ & $1.17 \mathrm{E}-02$ & $3.90 \mathrm{E}+05$ & 323561.1434 & $9.54 \mathrm{E}-02$ & 626.3431839 & 2537.642443 \\
\hline 420 & $1.68 \mathrm{E}-04$ & $1.08 \mathrm{E}-02$ & $3.81 \mathrm{E}+05$ & 390984.2874 & $9.18 \mathrm{E}-02$ & 615.7109768 & 2593.729276 \\
\hline 430 & $1.56 \mathrm{E}-04$ & $9.93 \mathrm{E}-03$ & $3.71 \mathrm{E}+05$ & 468975.5726 & $8.75 \mathrm{E}-02$ & 604.7550621 & 2652.033298 \\
\hline 440 & $1.45 \mathrm{E}-04$ & $9.10 \mathrm{E}-03$ & $3.60 \mathrm{E}+05$ & 558574.8597 & $8.45 \mathrm{E}-02$ & 593.4324134 & 2713.126633 \\
\hline 450 & $1.35 \mathrm{E}-04$ & $8.28 \mathrm{E}-03$ & $3.49 \mathrm{E}+05$ & 660843.6288 & $8.14 \mathrm{E}-02$ & 581.6907903 & 2777.760641 \\
\hline 460 & $1.25 \mathrm{E}-04$ & $7.48 \mathrm{E}-03$ & $3.37 \mathrm{E}+05$ & 776855.9524 & $7.79 \mathrm{E}-02$ & 569.4657863 & 2846.941321 \\
\hline 470 & $1.16 \mathrm{E}-04$ & $6.70 \mathrm{E}-03$ & $3.24 \mathrm{E}+05$ & 907686.867 & $7.32 \mathrm{E}-02$ & 556.67655 & 2922.046998 \\
\hline 480 & $1.08 \mathrm{E}-04$ & $5.95 \mathrm{E}-03$ & $3.10 \mathrm{E}+05$ & 1054397.606 & $6.95 \mathrm{E}-02$ & 543.219368 & 3005.018525 \\
\hline 490 & $9.99 \mathrm{E}-05$ & $5.22 \mathrm{E}-03$ & $2.94 \mathrm{E}+05$ & 1218008.321 & $6.56 \mathrm{E}-02$ & 528.9576519 & 3098.677961 \\
\hline
\end{tabular}

Page 17 of 27 


\begin{tabular}{|c|c|c|c|c|c|c|c|}
\hline 270 & 5.69E-04 & $2.36 \mathrm{E}-02$ & $4.27 \mathrm{E}+05$ & 9071.486823 & $1.26 \mathrm{E}-01$ & 743.7409236 & 1726.019282 \\
\hline 280 & $5.03 \mathrm{E}-04$ & $2.25 \mathrm{E}-02$ & $4.23 \mathrm{E}+05$ & 14519.74189 & $1.23 \mathrm{E}-01$ & 734.6038405 & 1779.816723 \\
\hline 290 & $4.48 \mathrm{E}-04$ & $2.13 \mathrm{E}-02$ & $4.19 \mathrm{E}+05$ & 22410.50946 & $1.21 \mathrm{E}-01$ & 725.3361018 & 1833.970164 \\
\hline 300 & 4.02E-04 & $2.02 \mathrm{E}-02$ & $4.14 \mathrm{E}+05$ & 33485.40557 & $1.18 \mathrm{E}-01$ & 715.92651 & 1888.546606 \\
\hline 310 & $3.62 \mathrm{E}-04$ & $1.91 \mathrm{E}-02$ & $4.09 \mathrm{E}+05$ & 48602.86601 & $1.15 \mathrm{E}-01$ & 706.3624711 & 1943.641246 \\
\hline 320 & $3.28 \mathrm{E}-04$ & $1.80 \mathrm{E}-02$ & $4.04 \mathrm{E}+05$ & 68733.58463 & $1.13 \mathrm{E}-01$ & 696.6297522 & 1999.368266 \\
\hline 330 & $2.99 \mathrm{E}-04$ & $1.69 \mathrm{E}-02$ & $3.99 \mathrm{E}+05$ & 94956.97627 & $1.10 \mathrm{E}-01$ & 686.7121892 & 2055.879036 \\
\hline 340 & $2.73 \mathrm{E}-04$ & $1.59 \mathrm{E}-02$ & $3.93 \mathrm{E}+05$ & 128447.6901 & $1.07 \mathrm{E}-01$ & 676.5913156 & 2113.342526 \\
\hline 350 & $2.50 \mathrm{E}-04$ & $1.48 \mathrm{E}-02$ & $3.87 \mathrm{E}+05$ & 170473.4672 & $1.04 \mathrm{E}-01$ & 666.2459151 & 2171.985006 \\
\hline 360 & $2.29 \mathrm{E}-04$ & $1.38 \mathrm{E}-02$ & $3.80 \mathrm{E}+05$ & 222381.9782 & $1.01 \mathrm{E}-01$ & 655.6514365 & 2232.084367 \\
\hline 370 & $2.11 \mathrm{E}-04$ & $1.27 \mathrm{E}-02$ & $3.72 \mathrm{E}+05$ & 285592.0181 & $9.84 \mathrm{E}-02$ & 644.7792429 & 2293.99089 \\
\hline 380 & $1.95 \mathrm{E}-04$ & $1.17 \mathrm{E}-02$ & $3.64 \mathrm{E}+05$ & 361583.884 & $9.54 \mathrm{E}-02$ & 633.5956181 & 2358.150839 \\
\hline 390 & $1.80 \mathrm{E}-04$ & $1.07 \mathrm{E}-02$ & $3.56 \mathrm{E}+05$ & 451890.8576 & $9.23 \mathrm{E}-02$ & 622.0604299 & 2425.141538 \\
\hline 400 & $1.66 \mathrm{E}-04$ & $9.74 \mathrm{E}-03$ & $3.46 \mathrm{E}+05$ & 558085.4116 & $8.92 \mathrm{E}-02$ & 610.130483 & 2495.716055 \\
\hline 410 & $1.54 \mathrm{E}-04$ & $8.77 \mathrm{E}-03$ & $3.36 \mathrm{E}+05$ & 681774.643 & $8.59 \mathrm{E}-02$ & 597.7451163 & 2570.885055 \\
\hline 420 & $1.43 \mathrm{E}-04$ & $7.83 \mathrm{E}-03$ & $3.25 \mathrm{E}+05$ & 824585.0033 & $8.24 \mathrm{E}-02$ & 584.8319107 & 2652.027765 \\
\hline 430 & $1.32 \mathrm{E}-04$ & $6.91 \mathrm{E}-03$ & $3.13 \mathrm{E}+05$ & 988151.2568 & $7.88 \mathrm{E}-02$ & 571.3000062 & 2741.080845 \\
\hline 440 & $1.22 \mathrm{E}-04$ & $6.01 \mathrm{E}-03$ & $2.99 \mathrm{E}+05$ & 1174091.128 & 7.49E-02 & 557.0320934 & 2840.843986 \\
\hline & \multicolumn{7}{|c|}{ G5 } \\
\hline 270 & $8.22 \mathrm{E}-04$ & $2.51 \mathrm{E}-02$ & $3.85 \mathrm{E}+05$ & 2595.285416 & $1.33 \mathrm{E}-01$ & 776.57769 & 1747.253406 \\
\hline 280 & 7.09E-04 & $2.41 \mathrm{E}-02$ & $3.79 \mathrm{E}+05$ & 3921.279092 & $1.30 \mathrm{E}-01$ & 768.216599 & 1795.650594 \\
\hline 290 & $6.18 \mathrm{E}-04$ & $2.31 \mathrm{E}-02$ & $3.73 E+05$ & 5825.877141 & $1.28 \mathrm{E}-01$ & 759.7659333 & 1844.153519 \\
\hline 300 & 5.43E-04 & $2.21 \mathrm{E}-02$ & $3.67 \mathrm{E}+05$ & 8529.491433 & $1.26 \mathrm{E}-01$ & 751.2192374 & 1892.783509 \\
\hline 310 & $4.81 \mathrm{E}-04$ & $2.11 \mathrm{E}-02$ & $3.61 \mathrm{E}+05$ & 12301.17111 & $1.23 \mathrm{E}-01$ & 742.5693823 & 1941.5642 \\
\hline 320 & 4.29E-04 & $2.02 \mathrm{E}-02$ & $3.56 \mathrm{E}+05$ & 17474.44016 & $1.21 \mathrm{E}-01$ & 733.8084778 & 1990.529841 \\
\hline 330 & $3.85 \mathrm{E}-04$ & $1.92 \mathrm{E}-02$ & $3.50 \mathrm{E}+05$ & 24448.81019 & $1.18 \mathrm{E}-01$ & 724.9277556 & 2039.724423 \\
\hline 340 & $3.47 \mathrm{E}-04$ & $1.83 \mathrm{E}-02$ & $3.45 \mathrm{E}+05$ & 33696.52462 & $1.16 \mathrm{E}-01$ & 715.9174372 & 2089.204643 \\
\hline 350 & $3.14 \mathrm{E}-04$ & $1.73 \mathrm{E}-02$ & $3.39 \mathrm{E}+05$ & 45757.97166 & $1.13 \mathrm{E}-01$ & 706.7665634 & 2139.039302 \\
\hline 360 & $2.85 \mathrm{E}-04$ & $1.64 \mathrm{E}-02$ & $3.33 \mathrm{E}+05$ & 61248.30843 & $1.11 \mathrm{E}-01$ & 697.4628932 & 2189.314682 \\
\hline 370 & $2.60 \mathrm{E}-04$ & $1.54 \mathrm{E}-02$ & $3.28 \mathrm{E}+05$ & 80853.12869 & $1.08 \mathrm{E}-01$ & 687.9934642 & 2240.136224 \\
\hline 380 & $2.38 \mathrm{E}-04$ & $1.45 \mathrm{E}-02$ & $3.22 \mathrm{E}+05$ & 105327.1179 & $1.06 \mathrm{E}-01$ & 678.3421753 & 2291.633585 \\
\hline 390 & 2.19E-04 & $1.36 \mathrm{E}-02$ & $3.16 \mathrm{E}+05$ & 135491.3493 & $1.03 \mathrm{E}-01$ & 668.4912606 & 2343.966601 \\
\hline 400 & $2.01 \mathrm{E}-04$ & $1.27 \mathrm{E}-02$ & $3.09 \mathrm{E}+05$ & 172236.3688 & $1.00 \mathrm{E}-01$ & 658.4203334 & 2397.33454 \\
\hline 410 & $1.85 \mathrm{E}-04$ & $1.19 \mathrm{E}-02$ & $3.03 \mathrm{E}+05$ & 216497.4382 & $9.77 \mathrm{E}-02$ & 648.1058316 & 2451.983324 \\
\hline & \multicolumn{7}{|c|}{ G6 } \\
\hline 270 & $5.20 \mathrm{E}-04$ & $2.38 \mathrm{E}-02$ & $3.90 \mathrm{E}+05$ & 5477.016174 & $1.26 \mathrm{E}-01$ & 736.8676376 & 1833.559196 \\
\hline 280 & $4.60 \mathrm{E}-04$ & $2.27 \mathrm{E}-02$ & $3.85 \mathrm{E}+05$ & 9038.08198 & $1.24 \mathrm{E}-01$ & 727.6414551 & 1885.35319 \\
\hline 290 & $4.09 \mathrm{E}-04$ & $2.15 \mathrm{E}-02$ & $3.80 \mathrm{E}+05$ & 14362.95691 & $1.21 \mathrm{E}-01$ & 718.2883792 & 1937.549303 \\
\hline 300 & $3.66 \mathrm{E}-04$ & $2.04 \mathrm{E}-02$ & $3.75 \mathrm{E}+05$ & 22062.45396 & $1.18 \mathrm{E}-01$ & 708.7975426 & 1990.220994 \\
\hline 310 & $3.30 \mathrm{E}-04$ & $1.93 \mathrm{E}-02$ & $3.69 \mathrm{E}+05$ & 32867.92711 & $1.16 \mathrm{E}-01$ & 699.1567287 & 2043.46369 \\
\hline 320 & $2.99 \mathrm{E}-04$ & $1.82 \mathrm{E}-02$ & $3.63 \mathrm{E}+05$ & 47629.73004 & $1.13 \mathrm{E}-01$ & 689.3521361 & 2097.395733 \\
\hline 330 & $2.71 \mathrm{E}-04$ & $1.72 \mathrm{E}-02$ & $3.57 \mathrm{E}+05$ & 67319.34416 & $1.10 \mathrm{E}-01$ & 679.3680999 & 2152.166371 \\
\hline 340 & $2.47 \mathrm{E}-04$ & $1.61 \mathrm{E}-02$ & $3.51 \mathrm{E}+05$ & 93024.55438 & $1.07 \mathrm{E}-01$ & 669.1867422 & 2207.961477 \\
\hline 350 & $2.26 \mathrm{E}-04$ & $1.51 \mathrm{E}-02$ & $3.45 \mathrm{E}+05$ & 125945.0485 & $1.05 \mathrm{E}-01$ & 658.787541 & 2265.013518 \\
\hline 360 & $2.08 \mathrm{E}-04$ & $1.40 \mathrm{E}-02$ & $3.38 \mathrm{E}+05$ & 167386.7567 & $1.02 \mathrm{E}-01$ & 648.1467847 & 2323.614941 \\
\hline 370 & $1.91 \mathrm{E}-04$ & $1.30 \mathrm{E}-02$ & $3.31 \mathrm{E}+05$ & 218755.4906 & $9.89 \mathrm{E}-02$ & 637.2368741 & 2384.136697 \\
\hline & \multicolumn{7}{|c|}{ G7 } \\
\hline 270 & 3.39E-04 & $1.99 \mathrm{E}-02$ & $4.01 \mathrm{E}+05$ & 16904.88156 & $1.18 \mathrm{E}-01$ & 673.2241843 & 2030.043588 \\
\hline 280 & $3.05 \mathrm{E}-04$ & $1.88 \mathrm{E}-02$ & $3.95 \mathrm{E}+05$ & 26035.9394 & $1.15 \mathrm{E}-01$ & 663.8314355 & 2084.165688 \\
\hline 290 & $2.77 \mathrm{E}-04$ & $1.77 \mathrm{E}-02$ & $3.89 \mathrm{E}+05$ & 38873.77836 & $1.12 \mathrm{E}-01$ & 654.2746125 & 2139.151119 \\
\hline 300 & $2.52 \mathrm{E}-04$ & $1.66 \mathrm{E}-02$ & $3.83 \mathrm{E}+05$ & 56440.81511 & $1.09 \mathrm{E}-01$ & 644.5373844 & 2195.156628 \\
\hline 310 & $2.30 \mathrm{E}-04$ & $1.55 \mathrm{E}-02$ & $3.76 \mathrm{E}+05$ & 79886.61864 & $1.06 \mathrm{E}-01$ & 634.6009993 & 2252.36903 \\
\hline 320 & $2.11 \mathrm{E}-04$ & $1.44 \mathrm{E}-02$ & $3.70 \mathrm{E}+05$ & 110505.5653 & $1.03 \mathrm{E}-01$ & 624.4450143 & 2311.037038 \\
\hline 330 & $1.94 \mathrm{E}-04$ & $1.34 \mathrm{E}-02$ & $3.62 \mathrm{E}+05$ & 149702.3099 & $1.00 \mathrm{E}-01$ & 614.0440394 & 2371.464737 \\
\hline 340 & $1.79 \mathrm{E}-04$ & $1.24 \mathrm{E}-02$ & $3.55 \mathrm{E}+05$ & 199008.098 & $9.74 \mathrm{E}-02$ & 603.368903 & 2434.05043 \\
\hline 350 & $1.65 \mathrm{E}-04$ & $1.14 \mathrm{E}-02$ & $3.46 \mathrm{E}+05$ & 260051.4712 & 9.43E-02 & 592.3851562 & 2499.302153 \\
\hline 360 & $1.52 \mathrm{E}-04$ & $1.04 \mathrm{E}-02$ & $3.38 \mathrm{E}+05$ & 334580.5007 & $9.12 \mathrm{E}-02$ & 581.0516108 & 2567.896697 \\
\hline & \multicolumn{7}{|c|}{ G8 } \\
\hline 270 & 3.84E-04 & $1.93 \mathrm{E}-02$ & $4.89 \mathrm{E}+05$ & 25273.96813 & $1.16 \mathrm{E}-01$ & 676.1991594 & 2008.600188 \\
\hline 280 & $3.43 \mathrm{E}-04$ & $1.82 \mathrm{E}-02$ & $4.84 \mathrm{E}+05$ & 37238.93435 & $1.14 \mathrm{E}-01$ & 666.8934367 & 2063.68956 \\
\hline 290 & $3.08 \mathrm{E}-04$ & $1.72 \mathrm{E}-02$ & $4.79 \mathrm{E}+05$ & 53449.86057 & $1.11 \mathrm{E}-01$ & 657.4299908 & 2119.449159 \\
\hline 300 & $2.79 \mathrm{E}-04$ & $1.61 \mathrm{E}-02$ & $4.73 \mathrm{E}+05$ & 74910.43577 & $1.08 \mathrm{E}-01$ & 647.7937538 & 2176.002886 \\
\hline 310 & $2.53 \mathrm{E}-04$ & $1.51 \mathrm{E}-02$ & $4.67 \mathrm{E}+05$ & 102732.6839 & $1.05 \mathrm{E}-01$ & 637.966986 & 2233.506792 \\
\hline 320 & $2.30 \mathrm{E}-04$ & $1.41 \mathrm{E}-02$ & $4.60 \mathrm{E}+05$ & 138128.0189 & $1.02 \mathrm{E}-01$ & 627.9295719 & 2292.157025 \\
\hline 330 & $2.11 \mathrm{E}-04$ & $1.30 \mathrm{E}-02$ & $4.52 \mathrm{E}+05$ & 182396.8028 & $9.91 \mathrm{E}-02$ & 617.6582227 & 2352.199893 \\
\hline 340 & $1.93 \mathrm{E}-04$ & $1.21 \mathrm{E}-02$ & $4.43 \mathrm{E}+05$ & 236916.9447 & $9.61 \mathrm{E}-02$ & 607.1257586 & 2413.945902 \\
\hline 350 & $1.77 \mathrm{E}-04$ & $1.11 \mathrm{E}-02$ & $4.34 \mathrm{E}+05$ & 303131.8202 & $9.30 \mathrm{E}-02$ & 596.3001683 & 2477.78933 \\
\hline 360 & 1.63E-04 & $1.01 \mathrm{E}-02$ & $4.24 \mathrm{E}+05$ & 382537.5199 & $8.97 \mathrm{E}-02$ & 585.1433587 & 2544.235938 \\
\hline 370 & $1.50 \mathrm{E}-04$ & $9.18 \mathrm{E}-03$ & $4.13 \mathrm{E}+05$ & 476669.3077 & $8.64 \mathrm{E}-02$ & 573.6094572 & 2613.942992 \\
\hline 380 & $1.39 \mathrm{E}-04$ & $8.28 \mathrm{E}-03$ & $4.01 \mathrm{E}+05$ & 587086.3849 & $8.31 \mathrm{E}-02$ & 561.6424569 & 2687.7782 \\
\hline 390 & $1.28 \mathrm{E}-04$ & $7.39 \mathrm{E}-03$ & $3.88 \mathrm{E}+05$ & 715354.1882 & $7.96 \mathrm{E}-02$ & 549.1728663 & 2766.909005 \\
\hline 400 & 1.19E-04 & $6.52 \mathrm{E}-03$ & $3.74 \mathrm{E}+05$ & 863022.1594 & $7.58 \mathrm{E}-02$ & 536.1127963 & 2852.941841 \\
\hline 410 & $1.10 \mathrm{E}-04$ & $5.68 \mathrm{E}-03$ & $3.58 \mathrm{E}+05$ & 1031594.056 & $7.18 \mathrm{E}-02$ & 522.3484976 & 2948.147129 \\
\hline 420 & $1.01 \mathrm{E}-04$ & $4.87 \mathrm{E}-03$ & $3.40 \mathrm{E}+05$ & 1222485.696 & $6.74 \mathrm{E}-02$ & 507.7285261 & 3055.838188 \\
\hline 430 & $9.31 \mathrm{E}-05$ & $4.08 \mathrm{E}-03$ & $3.20 \mathrm{E}+05$ & 1436957.46 & $6.24 \mathrm{E}-02$ & 492.0439518 & 3181.039119 \\
\hline 440 & $8.55 \mathrm{E}-05$ & $3.34 \mathrm{E}-03$ & $2.98 \mathrm{E}+05$ & 1676028.362 & $5.65 \mathrm{E}-02$ & 474.9929536 & 3331.753475 \\
\hline 450 & $7.80 \mathrm{E}-05$ & $2.64 \mathrm{E}-03$ & $2.74 \mathrm{E}+05$ & 1940280.622 & $4.87 \mathrm{E}-02$ & 456.1115986 & 3521.494414 \\
\hline 460 & $6.96 \mathrm{E}-05$ & $2.03 \mathrm{E}-03$ & $2.46 \mathrm{E}+05$ & 2229567.771 & $2.84 \mathrm{E}-02$ & 434.6207766 & 3774.940771 \\
\hline
\end{tabular}

Page 18 of 27 


\begin{tabular}{|c|c|c|c|c|c|c|c|}
\hline 470 & $6.30 \mathrm{E}-05$ & $1.68 \mathrm{E}-03$ & $2.13 \mathrm{E}+05$ & 2542368.958 & $1.62 \mathrm{E}-02$ & 406.0249823 & 4142.013227 \\
\hline 480 & $5.60 \mathrm{E}-05$ & $1.35 \mathrm{E}-03$ & $1.74 \mathrm{E}+05$ & 2874341.293 & $1.51 \mathrm{E}-02$ & 360.0020649 & 4739.008727 \\
\hline & \multicolumn{7}{|c|}{$\begin{array}{rr} & \text { G9 } \\
\end{array}$} \\
\hline 270 & $3.99 \mathrm{E}-04$ & $1.87 \mathrm{E}-02$ & $5.08 \mathrm{E}+05$ & 27849.92891 & $1.14 \mathrm{E}-01$ & 679.014613 & 1964.315053 \\
\hline 280 & $3.55 \mathrm{E}-04$ & $1.76 \mathrm{E}-02$ & $5.05 \mathrm{E}+05$ & 41759.02369 & $1.11 \mathrm{E}-01$ & 669.5707515 & 2018.084112 \\
\hline 290 & $3.17 \mathrm{E}-04$ & $1.65 \mathrm{E}-02$ & $5.02 \mathrm{E}+05$ & 60724.89918 & $1.08 \mathrm{E}-01$ & 659.962052 & 2072.51523 \\
\hline 300 & $2.85 \mathrm{E}-04$ & $1.55 \mathrm{E}-02$ & $4.97 \mathrm{E}+05$ & 85920.1272 & $1.05 \mathrm{E}-01$ & 650.1722175 & 2127.736577 \\
\hline 310 & $2.57 \mathrm{E}-04$ & $1.45 \mathrm{E}-02$ & $4.92 \mathrm{E}+05$ & 118625.2049 & $1.02 \mathrm{E}-01$ & 640.1836173 & 2183.90921 \\
\hline 320 & 2.33E-04 & $1.35 \mathrm{E}-02$ & $4.87 \mathrm{E}+05$ & 160213.8831 & 9.93E-02 & 629.9742284 & 2241.234556 \\
\hline 330 & $2.12 \mathrm{E}-04$ & $1.25 \mathrm{E}-02$ & $4.80 \mathrm{E}+05$ & 212137.1916 & $9.63 \mathrm{E}-02$ & 619.519194 & 2299.964626 \\
\hline 340 & $1.93 \mathrm{E}-04$ & $1.15 \mathrm{E}-02$ & $4.72 \mathrm{E}+05$ & 275906.7311 & 9.32E-02 & 608.7894141 & 2360.416236 \\
\hline 350 & $1.77 \mathrm{E}-04$ & $1.05 \mathrm{E}-02$ & $4.64 \mathrm{E}+05$ & 353071.8398 & $9.00 \mathrm{E}-02$ & 597.7504965 & 2422.984672 \\
\hline 360 & $1.62 \mathrm{E}-04$ & $9.57 \mathrm{E}-03$ & $4.55 \mathrm{E}+05$ & 445218.9636 & $8.67 \mathrm{E}-02$ & 586.3613497 & 2488.191854 \\
\hline 370 & $1.48 \mathrm{E}-04$ & $8.64 \mathrm{E}-03$ & $4.44 \mathrm{E}+05$ & 553923.4768 & $8.33 \mathrm{E}-02$ & 574.5722605 & 2556.693697 \\
\hline 380 & $1.36 \mathrm{E}-04$ & $7.74 \mathrm{E}-03$ & $4.32 \mathrm{E}+05$ & 680745.3657 & $7.96 \mathrm{E}-02$ & 562.3222037 & 2629.36001 \\
\hline 390 & $1.25 \mathrm{E}-04$ & $6.85 \mathrm{E}-03$ & $4.18 \mathrm{E}+05$ & 827192.9197 & $7.57 \mathrm{E}-02$ & 549.5349756 & 2707.351344 \\
\hline 400 & $1.15 \mathrm{E}-04$ & $5.99 \mathrm{E}-03$ & $4.04 \mathrm{E}+05$ & 994688.0295 & $7.13 \mathrm{E}-02$ & 536.1134566 & 2792.251857 \\
\hline 410 & $1.05 \mathrm{E}-04$ & 5.17E-03 & $3.87 \mathrm{E}+05$ & 1184508.562 & $6.39 \mathrm{E}-02$ & 521.9307715 & 2886.269317 \\
\hline 420 & $9.63 \mathrm{E}-05$ & $4.39 \mathrm{E}-03$ & $3.68 \mathrm{E}+05$ & 1397717.808 & $5.95 \mathrm{E}-02$ & 506.8160218 & 2992.572946 \\
\hline 430 & $8.81 \mathrm{E}-05$ & $3.65 \mathrm{E}-03$ & $3.47 \mathrm{E}+05$ & 1635068.339 & $5.45 \mathrm{E}-02$ & 490.5298964 & 3115.875803 \\
\hline 440 & $8.03 \mathrm{E}-05$ & $2.95 \mathrm{E}-03$ & $3.23 \mathrm{E}+05$ & 1896813.134 & $4.84 \mathrm{E}-02$ & 472.7197733 & 3263.435645 \\
\hline 450 & $7.28 \mathrm{E}-05$ & $2.31 \mathrm{E}-03$ & $2.97 \mathrm{E}+05$ & 2182465.837 & $4.01 \mathrm{E}-02$ & 452.828462 & 3447.004264 \\
\hline 460 & $6.39 \mathrm{E}-05$ & $1.77 \mathrm{E}-03$ & $2.66 \mathrm{E}+05$ & 2490316.675 & $1.84 \mathrm{E}-02$ & 429.8807038 & 3686.641049 \\
\hline 470 & $5.69 \mathrm{E}-05$ & $1.57 \mathrm{E}-03$ & $2.31 \mathrm{E}+05$ & 2816600.369 & $7.66 \mathrm{E}-03$ & 396.4679182 & 4018.852133 \\
\hline 480 & $5.02 \mathrm{E}-05$ & $1.39 \mathrm{E}-03$ & $1.89 \mathrm{E}+05$ & 3153731.948 & 7.35E-03 & 352.624925 & 4514.199525 \\
\hline 490 & $4.21 \mathrm{E}-05$ & $1.21 \mathrm{E}-03$ & $1.38 \mathrm{E}+05$ & 3485922.972 & $6.93 \mathrm{E}-03$ & 309.0452649 & 5307.464017 \\
\hline \multirow[t]{2}{*}{500} & 3.39E-05 & $1.05 \mathrm{E}-03$ & $7.09 \mathrm{E}+04$ & 3774308.797 & 4.97E-03 & 261.6465305 & 6491.753996 \\
\hline & \multicolumn{7}{|c|}{ G10 } \\
\hline 270 & $3.51 \mathrm{E}-04$ & $1.93 \mathrm{E}-02$ & $3.90 \mathrm{E}+05$ & 19802.22658 & $1.15 \mathrm{E}-01$ & 673.6792097 & 1981.912405 \\
\hline 280 & $3.14 \mathrm{E}-04$ & $1.82 \mathrm{E}-02$ & $3.85 \mathrm{E}+05$ & 30469.90749 & $1.12 \mathrm{E}-01$ & 664.1827419 & 2037.199134 \\
\hline 290 & $2.82 \mathrm{E}-04$ & $1.71 \mathrm{E}-02$ & $3.79 \mathrm{E}+05$ & 45371.7675 & $1.10 \mathrm{E}-01$ & 654.514024 & 2093.346643 \\
\hline 300 & $2.55 \mathrm{E}-04$ & $1.60 \mathrm{E}-02$ & $3.73 \mathrm{E}+05$ & 65611.38909 & $1.07 \mathrm{E}-01$ & 644.6555987 & 2150.514142 \\
\hline 310 & $2.31 \mathrm{E}-04$ & $1.50 \mathrm{E}-02$ & $3.67 \mathrm{E}+05$ & 92435.33448 & $1.04 \mathrm{E}-01$ & 634.5874038 & 2208.915869 \\
\hline 320 & $2.10 \mathrm{E}-04$ & 1.39E-02 & $3.60 \mathrm{E}+05$ & 127210.0129 & $1.01 \mathrm{E}-01$ & 624.2867413 & 2268.809977 \\
\hline 330 & $1.92 \mathrm{E}-04$ & $1.29 \mathrm{E}-02$ & $3.53 \mathrm{E}+05$ & 171422.0543 & $9.80 \mathrm{E}-02$ & 613.7274295 & 2330.529992 \\
\hline 340 & $1.76 \mathrm{E}-04$ & 1.19E-02 & $3.46 \mathrm{E}+05$ & 226666.1895 & $9.50 \mathrm{E}-02$ & 602.8773684 & 2394.503709 \\
\hline 350 & $1.61 \mathrm{E}-04$ & $1.09 \mathrm{E}-02$ & $3.37 \mathrm{E}+05$ & 294635.733 & $9.19 \mathrm{E}-02$ & 591.6991096 & 2461.286131 \\
\hline 360 & $1.48 \mathrm{E}-04$ & $9.89 \mathrm{E}-03$ & $3.29 \mathrm{E}+05$ & 377113.4987 & $8.87 \mathrm{E}-02$ & 580.1476573 & 2531.607832 \\
\hline \multirow[t]{2}{*}{370} & $1.36 \mathrm{E}-04$ & $8.93 \mathrm{E}-03$ & $3.19 \mathrm{E}+05$ & 475956.7849 & $8.54 \mathrm{E}-02$ & 568.1682164 & 2606.444009 \\
\hline & \multicolumn{7}{|c|}{ G11 } \\
\hline 270 & $6.04 \mathrm{E}-04$ & $2.35 \mathrm{E}-02$ & $3.82 \mathrm{E}+05$ & 2322.370281 & $1.29 \mathrm{E}-01$ & 732.9662523 & 1851.482942 \\
\hline 280 & $5.32 \mathrm{E}-04$ & $2.25 \mathrm{E}-02$ & $3.77 \mathrm{E}+05$ & 3935.113523 & $1.26 \mathrm{E}-01$ & 724.4873064 & 1903.920224 \\
\hline 290 & $4.73 \mathrm{E}-04$ & $2.14 \mathrm{E}-02$ & $3.73 \mathrm{E}+05$ & 6415.267931 & $1.24 \mathrm{E}-01$ & 715.9046848 & 1956.470494 \\
\hline 300 & $4.22 \mathrm{E}-04$ & $2.04 \mathrm{E}-02$ & $3.68 \mathrm{E}+05$ & 10101.55643 & $1.21 \mathrm{E}-01$ & 707.2102389 & 2009.176479 \\
\hline 310 & $3.80 \mathrm{E}-04$ & $1.94 \mathrm{E}-02$ & $3.63 \mathrm{E}+05$ & 15412.701 & $1.18 \mathrm{E}-01$ & 698.3948965 & 2062.088367 \\
\hline 320 & $3.43 \mathrm{E}-04$ & $1.84 \mathrm{E}-02$ & $3.58 \mathrm{E}+05$ & 22853.9045 & $1.16 \mathrm{E}-01$ & 689.4485177 & 2115.27219 \\
\hline 330 & $3.12 \mathrm{E}-04$ & $1.74 \mathrm{E}-02$ & $3.53 \mathrm{E}+05$ & 33019.63004 & $1.13 \mathrm{E}-01$ & 680.3597208 & 2168.810343 \\
\hline 340 & $2.84 \mathrm{E}-04$ & $1.65 \mathrm{E}-02$ & $3.48 \mathrm{E}+05$ & 46594.10802 & $1.11 \mathrm{E}-01$ & 671.115671 & 2222.804117 \\
\hline 350 & $2.60 \mathrm{E}-04$ & $1.55 \mathrm{E}-02$ & $3.43 \mathrm{E}+05$ & 64351.38812 & $1.08 \mathrm{E}-01$ & 661.7018257 & 2277.37902 \\
\hline 360 & 2.39E-04 & $1.46 \mathrm{E}-02$ & $3.37 \mathrm{E}+05$ & 87152.63101 & $1.05 \mathrm{E}-01$ & 652.1016184 & 2332.689461 \\
\hline 370 & 2.19E-04 & $1.36 \mathrm{E}-02$ & $3.31 \mathrm{E}+05$ & 115942.9449 & $1.03 \mathrm{E}-01$ & 642.2960664 & 2388.926324 \\
\hline 380 & $2.02 \mathrm{E}-04$ & $1.27 \mathrm{E}-02$ & $3.25 \mathrm{E}+05$ & 151747.455 & $1.00 \mathrm{E}-01$ & 632.264726 & 2446.327047 \\
\hline 390 & $1.87 \mathrm{E}-04$ & $1.18 \mathrm{E}-02$ & $3.18 \mathrm{E}+05$ & 195667.0723 & $9.72 \mathrm{E}-02$ & 621.9816311 & 2505.189546 \\
\hline 400 & $1.73 \mathrm{E}-04$ & $1.09 \mathrm{E}-02$ & $3.11 \mathrm{E}+05$ & 248874.2588 & $9.44 \mathrm{E}-02$ & 611.4171857 & 2565.891749 \\
\hline 410 & $1.60 \mathrm{E}-04$ & $9.97 \mathrm{E}-03$ & $3.03 \mathrm{E}+05$ & 312610.0549 & $9.14 \mathrm{E}-02$ & 600.5364345 & 2628.919966 \\
\hline
\end{tabular}

Page 19 of 27 
Dear Editor,

We are grateful for the thorough reviews which have led to a significantly improved version of the manuscript. Most of the comments were adopted here. Other comments are rebutted but clarifications were added to the revise manuscript. Each point made by the reviewers is now addressed:

\section{$\underline{\text { Reviewer \#1: }}$}

\begin{tabular}{|c|c|c|c|c|c|}
\hline \multicolumn{2}{|l|}{$11 / 02 / 2017$} & \multicolumn{4}{|c|}{ Reviewer \#: 208824} \\
\hline$\underline{\text { Conclusions }}$ & Archival & Integrity & Quality & Presentation & $\underline{\text { Innovative }}$ \\
\hline 1 & 1 & 2 & 1 & 3 & 5 \\
\hline & & & & & Revision History \\
\hline \multicolumn{6}{|l|}{ Comments } \\
\hline General & $\underline{\text { View }}$ & & & & \\
\hline
\end{tabular}

The changes made in the revised manuscript that are based on the comments of Reviewer\#1 are highlighted in "Yellow".

We first want to thank the reviewer or the comments which led to a significantly improved version of the manuscript. A decent amount of work has been done to improve the manuscript as per the reviewer's comments. We have also included new material especially in the CFD results section where we looked at the thermal efficiency and the volumetric fuel consumption. We therefore greatly appreciate if you can reevaluate the manuscript and consider changing the ratings if needed.

1. Many statements lack proper referencing. It is unacceptable to make unjustified sweeping statements like "many previous studies have ..." without any studies being cited. Even more grievous is that this whole study rests on the selection of density, RON and T90 as the orthogonal FACE fuel property variables, but the justification of these properties' selection is: "Previous GCI engines studies revealed that the density, T90 (or final boiling point (FBP)) and the RON of the GCI fuel are more influential than other physical and chemical properties when it comes to GCI engine operation." (without any literature referencing whatsoever!)

We apologize for not citing any references in those statements. We have now fixed this and included most of the relevant references in the revised version. This has been added to page 1:

"Certain fuel properties could affect the performance of the engine because since GCI combustion greatly depends is dependent on mixture stratification and as well as chemical kinetics [11, 12, 34, 39-42]."

This has also been added to page 2:

"Many previous studies have investigated the GCI combustion mode operating on fuels that are more reactive than commercial gasolines and have less reactivity compared to diesel fuels. These fuels are usually blended from various straight-run gasoline refinery streams. The research group at Saudi Aramco and its collaborators have extensively studied the combustion of many of these fuels in GCI engine operation at a wide range of operating conditions $[4,11,12,24,26,34,35,37,38,40,48-50]$."

References have also been added to justify choosing density, T90 and RON as the design parameters. The sentence on page 2 has been modified to read:

"Previous GCI engines studies revealed that the density [39], T90 (or final boiling point (FBP)) [34, 39, 41] and the RON [10, 13, $34,48-51]$ of the GCI fuel are more influential than other physical and chemical properties when it comes to in GCI engine operation."

Page 20 of 27

$10 / 19 / 2016$ 
2. My fundamental objection to the methodology of the study: while density, T90 and RON are certainly critical to GCI fuel performance, I would regard MON (or octane sensitivity) as too critical to be neglected in this analysis and possibly other key properties as well. I therefore regard this 3D property based approach as flawed and of negligible value. The logical flow of the literature review and introduction to the study also jars the reader in this regard, since the former highlights studies which showed a number of properties to be important to GCI, while the latter then suddenly selects density, T90 and RON, neglecting other key properties, without any referenced or logical justification.

We agree with the reviewer about the fact that other physical (such as heat of vaporization) and chemical (such as sensitivity) properties might also affect the combustion and emissions in GCI engine operation. However, design parameters needed to be determined because it was not possible to propose a standardized matrix considering all the possible influential properties. We have decided to go for the density, T90 and RON because the literature we have collected suggests that these are influential more than others as cited in the revised version. We have not found any published paper detailing the importance of sensitivity on GCI combustion and therefore $\mathrm{S}$ was not favored over the chosen ones to be one of the design variables. Also, we have not neglected the other physical and chemical properties of the proposed GCI fuels. We simply used density, T90 and RON as the design parameters, proposed and formulated the matrix. It is obvious that, after calculating the properties of the proposed fuels, the other physical and chemical properties are scattered over a realistic range. The sensitivity of the GCI fuels ranges from 0 to 9 and therefore, $\mathrm{S}$ can be looked at as a secondary design parameter when it comes to using one of the proposed fuels.

The same approach was used by the Cooperative Research Council when proposing the FACE fuels. They have picked RON (sensitivity), aromatics and n-paraffinic contents to be the design variable when proposing standardized fuels for spark ignition engine combustion. It is very well known that the heat of vaporization and the flame speeds significantly affect the combustion in SI mode. However, these were not included in the design variables. It cannot be that RON (S), aromatics and n-paraffinic contents are the only influential properties in SI combustion mode, however, the authors needed to design a standardized matrix and therefore had to use the most influential ones to design the matrix and the leave the other properties to be secondary design variables.

We have now added a more detailed description of how the design parameters were chosen. A new paragraph is now added to page 2:

\begin{abstract}
"The determination of the design parameters depends on the engine combustion mode and operating conditions. In spark ignition mode, it was previously shown that RON, sensitivity, aromatics and n-paraffinic contents were chosen to be the design parameters because of their primary importance to the performance of advanced gasoline-fueled spark ignited engines. This was used to propose and formulate the Fuels for Advanced Combustion Engines (FACE) gasolines [47]. In HCCI mode, T90 is not critical because of the very early injections where the fuel completely evaporates and premixes with air long before combustion occurs. However, the charge cooling due to the latent heat of vaporization is important because the in-cylinder temperature and equivalence ratio distribution is the main controlling parameter in compression ignition mode. In high-load diffusion combustion mode, T90 and latent heat of vaporization are not essential because of the late injections which occur at high in-cylinder pressures and temperatures. These high pressures and temperatures cause instantaneous vaporization and ignition of the fuel. Perhaps, the viscosity of the fuel is an important design parameter at these engine conditions because it affects the spray exit velocities and hence the breakup, mixing and combustion. In this work, the partially premixed compression ignition (PPCI) where injections occur between -50 to $-20 \mathrm{CAD}$ aTDC is the targeted combustion mode. Previous PPCI engines studies revealed that the density [39], T90 (or final boiling point (FBP)) [34, 39, 41] and the RON [10, 13, 34, 48-51] of the GCI fuel are more influential than other physical and chemical properties when it comes to in PPCI GCI engine operation. Other properties such as the heat of vaporization, lower heating value, hydrogen to carbon ratio, sensitivity, etc. might differently affect the PPCI combustion however, the density, T90 and RON were chosen to be the design parameters in this study. Therefore, the abovementioned properties are shown and discussed more than others in this work."
\end{abstract}

We have also added a sentence on page 4 regarding the possibility of choosing $\mathrm{S}$ as a secondary design parameter:

"Moreover, the GCI fuels have different sensitivities with G4, G5 and G7 are almost non-sensitive (S $\approx 0$ ), G11 is highly sensitive and the rest have moderate sensitivities. This variance in sensitivity can be used as a secondary design parameter in the presented GCI fuels because of the realistic range ( $\mathrm{S}=0$ to 9 )."

3. The methodology used to theoretically formulate the proposed GCI fuels is interesting, but while these fuels may be theoretically possible to formulate from their sub components, their real-life refinery production is unlikely to be economically viable. Indeed, the fuels often comprise of large volume fractions of a single obscure species (refer to the composition appendix A1) which results in rather discontinuous distillation curves seen in Figure 9. The RVP values of some of these fuels are in excess of $200 \mathrm{kPa}$ (not at all accurately described by the authors as "marginally higher than the regulated value"), making them

Page 21 of 27 
thoroughly impractical. One would therefore conclude that this study is aimed at generating theoretical insight, rather than a trajectory toward real-world GCI fuels?

We thank the reviewer to point this out. We have reformulated G7, G8, G9 and G10 to have reasonable RVP values. The new fuels have RVPs that are less than $120 \mathrm{kPa}$ which is very close to the specified values in many areas in the world including the US (110 kPa). The tables, figures and the text have been updated.

The economical viability of the proposed fuels was not a motive in the current work. As mentioned in the manuscript, the purpose of the work is to propose standardized GCI fuels that are scattered over a realistic range of values for different relevant properties. And yes, these fuels are only theoretically possible and we have not looked into the possibility of making these in a real refinery. The second phase of this work would be to try to blend some or all of these fuels using real refinery streams and make them available to the engine research community similar to FACE gasolines.

4. This study's methodology is further undermined by the use of PRF85 PRF60 and PRF40 as chemical surrogates for the GCI fuels in the numerical engine simulations. Not only does this approach smudge out minor differences in target and theoretical RON values of the fuels, but it also obliterates the effects of octane sensitivity, which is a critical property in auto-ignition modelling.

To use this sort of methodology and then present results on simulated engine fuel consumption and emissions is bogus and the conclusions made in the paper are unsurprisingly weak and erroneous.

We thank the reviewer for bringing this up. We have now rerun all the simulations with PRF surrogates that are equivalent to the RON values of the individual GCI fuels. For example, PRF85 was used as a chemical surrogate for G1 and G10. PRF83.6 was used to simulate the combustion of G9. Therefore, the minor differences in the RON values between the different fuels have been accounted for in the revised version. The text and Figures have been updated accordingly. The text on page 7 has been updated to read:

"PRF surrogates (mixtures of n-heptane and iso-octane) were used in this work. The PRF numbers were set to match RON of the GCI fuels presented in Table 4. PRF85 (85 vol.\% iso-octane and 15 vol.\% n-heptane) was used as a chemical surrogate for G1, G9 and G10. PRF 83.6 was utilized for G9. PRF60, PRF59.1 and PRF58.3 were used to mimic the autoignition characteristics of G2, G5, G6, G7 and G8 and PRF40 was used to simulate the chemistry G3 and G4."

Non-sensitive PRF surrogates were used for simplification purposes and to focus on the effects of the physical properties of the fuels on the GCI combustion and emissions. In addition, the only way of accounting for sensitivity is by using toluene primary reference fuels (TPRF), mixtures of toluene, iso-octane and n-heptane, to match the RON and MON of the targeted GCI fuel. Having only toluene to account for the sensitivity can be very misleading and concentrations as high as $50 \%$ toluene might be needed to match the sensitivity of 8 or 9 . Finally, the presented CFD simulations are just one example of how the properties of the fuels can affect the GCI combustion and surely there are ways of improving and extending the simulations. A paragraph is now added to page 9 clarifying this.

"The presented engine CFD simulations are just an illustrative example of how the physical and chemical properties of the fuels affect the combustion and emissions at GCI engine operation. Sensitivity was not accounted for in these simulations which were performed at only one engine condition (no-EGR low-load case). Accounting for sensitivity by using different surrogates such as toluene primary reference fuels (TPRF) can be a way to improve the predictions and highlight the effect of sensitivity on GCI combustion. Furthermore, simulating other engine conditions such as high-EGR and high-load can be very useful to examine the effect of engine operating range on the differences caused by the fuels' properties." 


\section{Reviewer \#2:}

\begin{tabular}{|c|c|c|c|c|c|}
\hline \multicolumn{2}{|l|}{ 11/18/2017 } & \multicolumn{4}{|c|}{ Reviewer \#: 210533} \\
\hline$\underline{\text { Conclusions }}$ & Archival & Integrity & $\underline{\text { Quality }}$ & Presentation & Innovative \\
\hline 5 & 4 & 7 & 5 & 5 & 5 \\
\hline & & & & & Revision History \\
\hline \multicolumn{6}{|l|}{ Comments } \\
\hline \multicolumn{6}{|l|}{ General } \\
\hline
\end{tabular}

The changes made in the revised manuscript that are based on the comments of Reviewer\#2 are highlighted in "Green"

We first want to thank the reviewer or the comments which led to a significantly improved version of the manuscript. A decent amount of work has been done to improve the manuscript as per the reviewer's comments. We have also included new material especially in the CFD results section where we looked at the thermal efficiency and the volumetric fuel consumption. We therefore greatly appreciate if you can reevaluate the manuscript and consider changing the ratings if needed.

1. Page 2: "Previous GCI engines studies revealed that the density, T90 (or final boiling point (FBP)) and the RON of the GCI fuel are more influential than other physical and chemical properties when it comes to GCI engine operation".

Provide references for "previous GCI engine studies".

References are now provided.

2. Page 2: "These GCI fuels were chosen in a systematic way where the effects of the individual targeted properties were isolated. This approach is similar to what was previously done with the Fuels for Advanced Combustion Engines (FACE) gasolines [44]".

As the focus of the paper is on generation of standardized GCI fuel matrix, a brief description of the approach should be provided. Merely providing a reference is not enough.

We have now added a more detailed description of how the design parameters were chosen. A new paragraph is now added to page 2:

\footnotetext{
"The determination of the design parameters depends on the engine combustion mode and operating conditions. In spark ignition mode, it was previously shown that RON, sensitivity, aromatics and n-paraffinic contents were chosen to be the design parameters because of their primary importance to the performance of advanced gasoline-fueled spark ignited engines. This was used to propose and formulate the Fuels for Advanced Combustion Engines (FACE) gasolines [47]. In HCCI mode, T90 is not critical because of the very early injections where the fuel completely evaporates and premixes with air long before combustion occurs. However, the charge cooling due to the latent heat of vaporization is important because the in-cylinder temperature and equivalence ratio distribution is the main controlling parameter in compression ignition mode. In high-load diffusion combustion mode, T90 and latent heat of vaporization are not essential because of the late injections which occur at high in-cylinder pressures and temperatures. These high pressures and temperatures cause instantaneous vaporization and ignition of the fuel. Perhaps, the viscosity of the fuel is an important design parameter at these engine conditions because it affects the spray exit velocities and hence the breakup, mixing and combustion. In this work, the partially premixed compression ignition (PPCI) where injections occur between -50 to $-20 \mathrm{CAD}$ aTDC is the targeted combustion mode. Previous PPCI engines studies revealed that the density [39], T90 (or final boiling point (FBP)) [34, 39, 41] and the RON [10, 13, 34, 48-51] of the GCI fuel are more influential than other physical and chemical properties when it comes to in PPCI GCI engine operation. Other properties such as the heat of vaporization, lower heating value, hydrogen to carbon ratio, sensitivity, etc. might differently affect the PPCI combustion however, the density, T90 and RON were chosen to be the design parameters in this study. Therefore, the abovementioned properties are shown and discussed more than others in this work."
}

3. Provide a clearer Figure 1...The $\mathrm{X}$ and $\mathrm{Y}$ axes are not properly visible.

Page 23 of 27

$10 / 19 / 2016$ 
Fixed.

4. Page 2: "Five proposed fuels have RON of 60 but different physical characteristics for the same purpose of isolating the effects of the individual properties". This statement is incorrect. Only four proposed fuels have RON = 60 in Table 1.

We apologize for this typo. The RON of G2 is meant to be 60 not 65 . This is now fixed in the revised version.

5. Is the reduced mechanism used in the simulation study already published? If yes, provide the specific reference. If not, provide mechanism validation results for 0D ignition delays against literature experimental data at engine relevant conditions.

The reduced mechanism has just been reviewed and accepted to be presented in the 2018 SAE world congress. The reference is now added in the revised version.

6. Where was the spray rate shape in Figure 12 obtained from? Was it based on experiments? Clarify.

The rate shape used in our simulations was derived from a common rail diesel injector. At the time of the simulations we performed, we did not have the rate shapes of the injector we have modeled. The rate shape won't change the comparisons and conclusions made in this work and hence the rate shape is provided here for results reproduction. The following text is added on page 8:

\section{"This rate shape was derived from a common rail diesel injector. The rate shape of the injector modeled here was not available at the time of the simulations we performed. The rate shape does not change the comparisons and conclusions made in this work and hence the rate shape is provided here for results reproduction."}

7. How were the boundary temperatures (Table 5) calculated? Were they prescribed arbitrarily or based on a 1D GT-Power model? Clarify. Also, what in-cylinder swirl was prescribed at IVC?

Couple of sentences and references have now been added to page 7 to describe the process of obtaining the boundary conditions.

8. The authors should provide "some" CFD validation results against experiments, at least for one operating point and fuel blend.

Unfortunately, no experimental data are yet available for the simulated combustion chamber geometry. This is an ongoing work and validation will be provided in future work. However, the spray models have been validated against reliable ECN spray data. This is a major step in obtaining good validation against engine data.

9. There are quite a few grammatical errors throughout the paper. The authors are suggested to proofread the manuscript rigorously.

The manuscript has been thoroughly checked for grammatical errors and typos. The changes are highlighted in "Grey".

Page 24 of 27 


\section{Reviewer \#3:}

\begin{tabular}{|c|c|c|c|c|c|}
\hline \multicolumn{2}{|l|}{$11 / 29 / 2017$} & \multicolumn{4}{|c|}{ Reviewer \#: 212805} \\
\hline Conclusions & Archival & Integrity & Quality & Presentation & Innovative \\
\hline 5 & 4 & 7 & 5 & 7 & 5 \\
\hline & & & & & Revision History \\
\hline \multicolumn{6}{|l|}{ Comments } \\
\hline General & View & & & & \\
\hline
\end{tabular}

The changes made in the revised manuscript that are based on the comments of Reviewer\#2 are highlighted in "Turquoise".

We first want to thank the reviewer or the comments which led to a significantly improved version of the manuscript. A decent amount of work has been done to improve the manuscript as per the reviewer's comments. We have also included new material especially in the CFD results section where we looked at the thermal efficiency and the volumetric fuel consumption. We therefore greatly appreciate if you can reevaluate the manuscript and consider changing the ratings if needed.

1. In the abstract on page 1 :

"The direct injection of fuel eliminates throttle losses yielding higher thermodynamic efficiencies..."

DI does not inherently eliminate throttling losses, it only enables stratified operation by which you can eliminate part-load throttling

This has been changed to read:

"The compression and lean combustion mode direct injection of fuel eliminates throttle losses yielding higher thermodynamic efficiencies and the better mixing of fuel/air due to the longer ignition delay times of the gasoline-like fuels allows better emission performance such as nitric oxides (NOx) and particulate matter (PM)."

2. In the introduction there is an ellipsis in the list (RON, MON, density, boiling range and ...), is this intentional? Did you mean to put etc.?

We apologize for the mistake. This is now fixed in the revised version.

3. It is very difficult to read the Density and T90 axis labels in Figures 1-3, this probably needs to be formatted a bit better

Fixed.

4. The authors MUST include a more detailed discussion regarding the selection of the parameters in the cube, as this is central to the paper. While I agree that T90, density and RON are all important, you have not convinced me that other parameters, such as chemical composition, are relatively less important. Why not latent heat of vaporization and its impact on charge cooling? T90 does indicate some idea of the vaporization rate, but if you are doing an early injection where there is plenty of time for mixing, is T90 really critical?

We have now added a more detailed description of how the design parameters were chosen. A new paragraph is now added to page 2:

"The determination of the design parameters depends on the engine combustion mode and operating conditions. In spark ignition mode, it was previously shown that RON, sensitivity, aromatics and n-paraffinic contents were chosen to be the design parameters because of their primary importance to the performance of advanced gasoline-fueled spark ignited engines. This was used to propose and formulate the Fuels for Advanced Combustion Engines (FACE) gasolines [47]. In HCCI mode, T90 is not

Page 25 of 27 
critical because of the very early injections where the fuel completely evaporates and premixes with air long before combustion occurs. However, the charge cooling due to the latent heat of vaporization is important because the in-cylinder temperature and equivalence ratio distribution is the main controlling parameter in compression ignition mode. In high-load diffusion combustion mode, T90 and latent heat of vaporization are not essential because of the late injections which occur at high in-cylinder pressures and temperatures. These high pressures and temperatures cause instantaneous vaporization and ignition of the fuel. Perhaps, the viscosity of the fuel is an important design parameter at these engine conditions because it affects the spray exit velocities and hence the breakup, mixing and combustion. In this work, the partially premixed compression ignition (PPCI) where injections occur between -50 to $-20 \mathrm{CAD}$ aTDC is the targeted combustion mode. Previous PPCI engines studies revealed that the density [39], T90 (or final boiling point (FBP)) [34, 39, 41] and the RON [10, 13, 34, 48-51] of the GCI fuel are more influential than other physical and chemical properties when it comes to in PPCI GCI engine operation. Other properties such as the heat of vaporization, lower heating value, hydrogen to carbon ratio, sensitivity, etc. might differently affect the PPCI combustion however, the density, T90 and RON were chosen to be the design parameters in this study. Therefore, the abovementioned properties are shown and discussed more than others in this work."

5. Does the reader really need to Figures 1,2 and 3 as well as Table 1? I think these items should be condensed to be more concise.

We believe that Figures 1 and 2 are needed to show how these fuels were originated. Table 1 is necessary to provide the numbers which might be difficult to extract from Figs. 1 and 2. The only Figure which might be redundant if Figure 3, however we introduced it because Fig. 2 is crowded. We therefore decided to keep all of them.

6. Is equation 2 even valid? While the RONs of paraffin blends are nearly linear functions of the concentration of the components, in general mixtures of more complex components such as olefins and aromatics tend to deviate from linear blending (Bradley and Morley, 1997).

The linear-by-mole blending rule is proven to be more accurate than linear-by-volume for multi-component mixtures. More accurate blending rules exist in literature, however due to the complexity level and the objective of this work, it was decided to go for the linear-by-mole model. A paragraph is now added to page 4 explaining this.

"The linear-by-mole blending rule was used here to calculate the RON of the formulated mixtures. The linear-by-mole is a better representative than linear-by-volume to predict the octane numbers of multi-component mixtures. This was proven for toluene primary reference fuels (TPRF) [52], TPRF with ethanol [53, 54] and multi-component with ethanol [55] mixtures. More complicated blending rules exist in literature. Ghosh et al. [56] developed a multi-variable detailed gasoline composition-base octane model. However, the linear-by-mole was chosen here because it was easier to be handled by the optimization solver. Also, the accuracy of the octane number prediction is not the main objective of this work."

7. The numbers in Figures 4 and 5 are barely legible, consider presenting this in a different manner.

The figures have been updated and the numbers have been removed.

8. Figures $6,7,8$ or perhaps an additional table should show the differences between the target GCI matrix properties and those determined by ASPEN.

Thank you for the suggestion. Figures 6 and 7 have been updated to show the targeted values on RON, T90 and density. Also, an additional table that contains all calculated properties has been added.

9. What equivalence ratio are your simulations run at (Table 5)?

The equivalence ratio details are now added to page 7.

10. The statement on page 7 "Any differences in the results are associated with the physical properties of the fuels", needs additional clarification. The fuels you are using have different LHVs, so have you injected the same amount of chemical energy into the cylinder in each simulation? Could these differences impact the combustion event? This also relates to my previous question about equivalence ratio, as it is will also differ across the range of fuels.

This sentence has been updated to include the lower heating value and RON differences effects. It now reads:

Page 26 of 27 
"Any differences in the results are associated with the physical properties, the minor differences in RON values and the lower heating values of the fuels."

Regarding the chemical energy, the injected mass was kept constant and not the chemical energy. Hence, fuels with different LHV will have different total chemical energy and therefore, the heating values do affect the combustion. The equivalence ratio is different because it is a function of the intake conditions and the surrogate used. When comparing fuels with the same RON, these are usually have very similar PRF surrogates and since the intake conditions are

11. Be careful what you say about fuel density in the conclusions. On a mass basis $(\mathrm{g} / \mathrm{kWh})$ they look favorable, but we pay for gasoline at the pump on a volume basis.

We have updated the discussion about the mass-based fuel consumption. We have also presented the volume-based fuel consumptions and the text on page 10 now reads:

"Compared to G2, G7 and G8 yielded around 8\% and 5.7\% improvements in mass-based ISFC and TE, respectively. An improvement of $8.8 \%$ in TE was observed with G5 compared to G2. However, NOx emissions are higher for G5, G7 and G8 compared to $\mathrm{G} 2$ because of the earlier combustion phasing. Calculating the volume-based ISFC would be useful because consumers pay for fuels on volume basis and hence fuels with higher densities are favorable. Comparing G2 and G8, the volume based ISFC are $254.46 \mathrm{~mL} / \mathrm{kWh}$ and $269.76 \mathrm{~mL} / \mathrm{kWh}$, respectively. It is clear that the trends have reversed where G2 result in lower volume based fuel consumption. The fuel consumption comparison between G2 and G5 does not change when converting it to volume-based because they have the same densities and hence G5 $(234.13 \mathrm{~mL} / \mathrm{kWh})$ is still more favorable than G2 and yield better fuel consumption." 